BULLETIN OF tHe AMERICAN MUSEUM OF NATURAL HISTORY

anthropological Papers of the American Museum of Natural History

Publications Committee

ROBERT S. VOSS, CHAIR

BOARD OF EDITORS

Jin Meng, Paleontology

Lorenzo Prendini, InVERTEBrate Zoology

ROBERT S. VosS, VerTEBRATE ZOOLOGY

Peter M. Whiteley, ANTHROPOLOGY

MANAGING EDITOR

MARY KNIGHT

Submission procedures can be found at http://research.amnh.org/scipubs

All issues of Novitates and Bulletin are available on the web from http://digitallibrary.amnh.org/dspace

Order printed copies from http://www.amnhshop.com or via standard mail from: American Museum of Natural History-Scientific Publications

Central Park West at 79th Street

New York, NY 10024

(2) This paper meets the requirements of ANSI/NISO Z39.48-1992 (permanence of paper).

On the cover: Reconstruction of the early Miocene INTERAtheriId Notoungulate Protypotherium, by Charles R. KNIGHT (CA. 1903), WITH THREE CRANIAL VIEWS BY BRUCE Horsfall (CA. 1909). RabBitlike appearance of ANIMALS IN KNIGHT'S DRAWING IS CONJECTURAL, BUT IN SOME TAXA CRANIAL feAtures IMPLy presence of large, mobile ears (e.G., PACHYRUKHINE HEGETOTHERIIDS).

THE SERRIALIS BONE, INTERPARIETALS, "X" ELEMENTS, ENTOTYMPANICS, AND THE COMPOSITION OF THE NOTOUNGULATE CAUDAL CRANIUM

\section{R.D.E. MACPHEE}

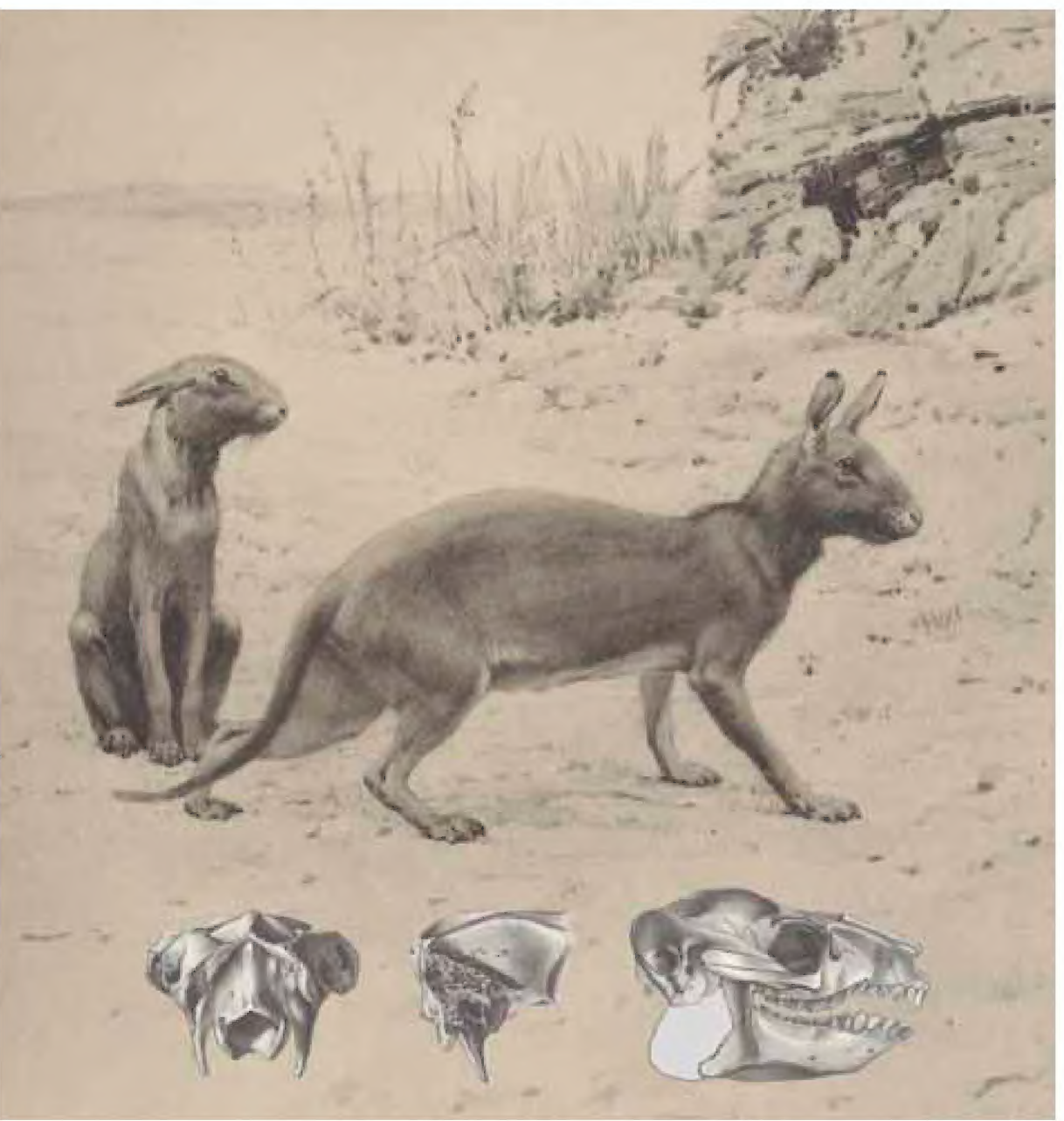

$\stackrel{\sim}{\stackrel{\circ}{+}}$

BULLETIN OF THE AMERICAN MUSEUM OF NATURAL HISTORY 


\title{
THE SERRIALIS BONE, INTERPARIETALS, “X” ELEMENTS, ENTOTYMPANICS, AND THE COMPOSITION OF THE NOTOUNGULATE CAUDAL CRANIUM
}

\author{
R.D.E. MACPHEE \\ Division of Vertebrate Zoology (Mammalogy) \\ American Museum of Natural History
}

BULLETIN OF THE AMERICAN MUSEUM OF NATURAL HISTORY

Number 384, 69 pp., 20 figures, 2 tables

Issued January 6, 2014 


\section{CONTENTS}

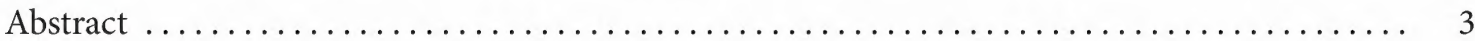

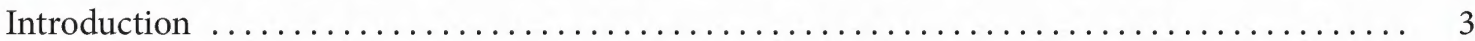

Methods, Specimens, Terminology, and Agenda $\ldots \ldots \ldots \ldots \ldots \ldots \ldots \ldots$

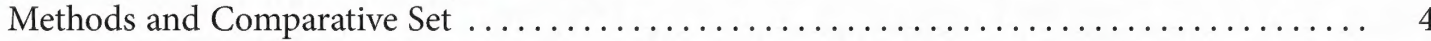

Oldfieldthomasia (Unnamed Basal Typothere Group, Oldfieldthomasiidae) .......... 5

Paedotherium (Hegetotherioidea, Hegetotheriidae, Pachyrukhinae) and Relatives ...... 8

Cochilius (Interatherioidea, Interatheriidae, Interatheriinae) and Relatives .......... 8

Other Placental Taxa .............................................. 9

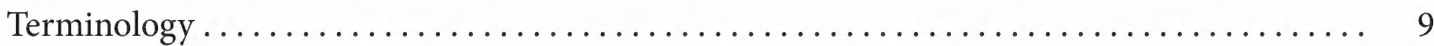

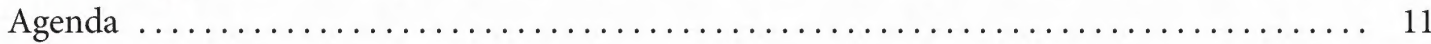

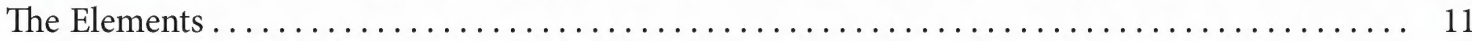

Simpson, Roth, and the Caudal Cranium of Oldfieldthomasia $\ldots \ldots \ldots \ldots \ldots \ldots \ldots \ldots \ldots$

The Serrialis and the Bony Covering of the Epitympanic Sinus . . . . . . . . . . . . . . 19

Epitympanic Theca: Definition and Development ...................... 19

Epitympanic Theca: The Question of Composition ...................... 21

Paedotherium ............................................. 24

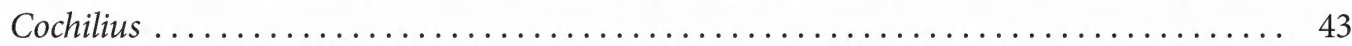

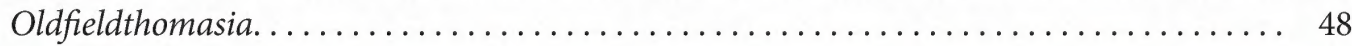

Interparietal Complex.......................................... 49

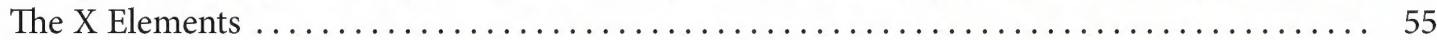

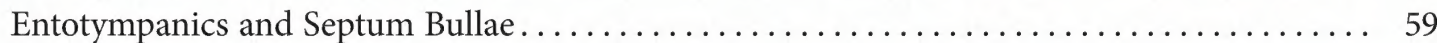

Entotympanic Presence in Cochilius volvens AMNH-VP $29651 \ldots \ldots \ldots \ldots \ldots \ldots \ldots \ldots$. . . . . 60

Entotympanic Presence in Other Notoungulates ....................... 61

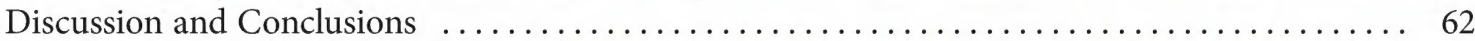

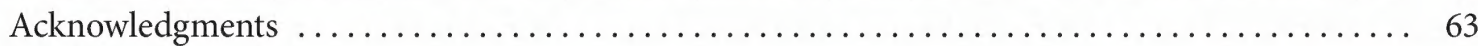

References .................................................. 64

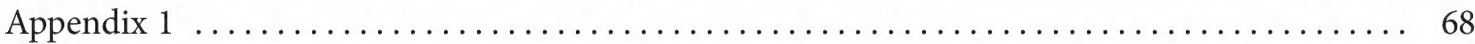




\begin{abstract}
The composition of the caudal cranium in Notoungulata, an extinct group of endemic South American "ungulates," has never been properly clarified. Some investigators have claimed that socalled "adventitious" elements, or elements not known to occur in other placentals, existed in the auditory regions of certain typotheres and toxodontians. Others have disputed this, arguing that sutures or other indicia that supposedly provide evidence of the developmentally independent origins of these alleged ossifications are either misinterpreted or inconstant. This study attempts to resolve the question of composition, as far as it is possible to do in the case of a wholly extinct clade, with detailed micro-CT investigations of several key taxa, including Oldfieldthomasia (Oldfieldthomasiidae), Paedotherium (Hegetotheriidae), and Cochilius (Interatheriidae). Results show that Santiago Roth was incorrect in asserting that certain notoungulates, such as pachyrukhine hegetotheres, possessed cranial elements (serrialis, posttympanicum, etc.) that are unrepresented in other placentals. George Gaylord Simpson also thought Roth was wrong, but erred in claiming to have discovered concrete evidence of two other ossifications, denoted by him as Xa and Xp, in the auditory region of Oldfieldthomasia. In adult notoungulates the interparietal complex is usually fused with the parietal, or supraoccipital, or both elements. As in certain other mammals, dorsal exposure of the supraoccipital is limited in notoungulates because it is often overplated by the interparietal complex, which thus provides a sort of "second" roof for the caudal cranium. However, there is no interparietal involvement in the middle ear cavity. Finally, for the first time plausible grounds can be offered for the existence of an entotympanic in a notoungulate (Cochilius). Evidence is increasing for the proposition that entotympanics are much more widespread than previously thought, and may in fact be present in most of the major groups of placentals. In summary, this study shows that in terms of participating elements there is nothing unique about the notoungulate caudal cranium, which was evidently as tightly constrained compositionally as it is in other placentals. Nevertheless, this portion of the skull, still notably underutilized in notoungulate studies, could be a crucial source of new characters for assessing higher-level relationships not only among notoungulates, but also among South American ungulates and their possible relatives.
\end{abstract}

\section{INTRODUCTION}

For most mammalian groups, total cranial composition-defined as the number, homology, and spatial organization of elements ${ }^{1}$ comprising the dermato-, chondro-, and splanchnocranium-

${ }^{1}$ A name-bearing cranial element may be characterized as any mineralized dense connective tissue that (1) primordially arises from mesoderm (including pharyngeal arch mesoderm) or neural crest, (2) terminally differentiates as a recognizably separate cartilage or bone, alone or in concert with enamel or enamellike tissues, (3) is consistently present during the development of individuals in the target taxon, and, significantly, (4) can be widely traced in other taxa within the same major grouping at the identical location on the skull (cf. Goodrich, 1931; De Beer, 1937; Presley, 1993; Moriss-Kay, 2001; Koyabu et al., 2012). Whether explicitly stated or not, the homological criterion (no. 4) is the one most frequently used observationally, and essentially assumes knowledge of nos. $1-3$, even if the only specimen-based evidence is adult. If the course of development (especially no. 2) is unknown, however, fusions may not be detected. was thought to have been largely settled by comparative morphologists working during the past century and a half (e.g., Parker, 1885; Flower, 1876; Gregory, 1910; Weber, 1927; van der Klaauw, 1931; Goodrich, 1931; De Beer, 1937; Starck, 1967; Romer and Parsons, 1977; Moore, 1981; Zeller, 1989; Presley, 1993; Mead and Fordyce, 2009; Koyabu et al., 2012; and many others). However, for some groups uncertainties still endure, usually because elements found in some taxa have eluded detection in others-due to small size, for example, or a rapid loss of separate identity because of early fusion with neighboring bones (for some instructive examples, see Broom, 1916; Hunt, 1974; MacPhee, 1981; Bronner et al., 1990; Novacek, 1993).

A case in point is Notoungulata, conventionally regarded as an order of endemic South 
American "ungulates" ("meridiungulates" of some authors) that radiated into a wide array of niches over the course of the Cenozoic before the last of them disappeared at the end of the Pleistocene (McKenna and Bell, 1997; Cifelli, 1993; Cassini et al., 2010; Vizcaino et al., 2012). As might be expected, one outcome of this extensive radiation was a substantial amount of morphological diversification, both cranially and postcranially (e.g., Billet, 2011; Shockey and Flynn, 2007). Of particular interest here is the unconfirmed claim, made on several occasions by different authors, that the skull of notoungulates included additional or so-called adventitious elements, as well as unexpected divisions within conventional bone territories. To date, despite a certain amount of commentary and speculation on this point, there has been no final resolution regarding the existence of such ossifications, let alone their frequency or homology (see Roth, 1903; van Kampen, 1905; Sinclair, 1909; Scott 1912a, 1912b; van der Klauuw, 1931; Simpson, 1936, 1967; Patterson, 1932, 1977; Prothero, 1993; Gabbert, 2004; Billet et al., 2009).

Given renewed interest in the wider relationships of meridiungulates (e.g., Agnolin and Chimento, 2011; O'Leary et al., 2013; but see Bond et al., 2011; Billet and Martin, 2011; Billet and de Muizon, 2013), this is an opportune time to critically review the evidence for novel or unexpected elements in notoungulates, as well as to provide new observations on the caudal cranium of this group that may help in framing future character analyses.

\section{METHODS, SPECIMENS, TERMINOLOGY, AND AGENDA}

\section{Methods and Comparative Set}

The caudal cranium for present purposes may be defined as that part of the skull lying caudal to a semicoronal plane passing through the sphenooccipital synchondrosis, including therewith both the basicranium and the overlying part of the cranial vault. Much of the anatomical discus- sion in this paper concerns the proper identification of indicia, or indicators, of true sutures vs. breaks, cracks, fractures, and other misleading signs of separate origin. Other features, particularly those concerned with the passage of blood vessels and nerves, are briefly noted where relevant; a fuller presentation of cranial vasculature and related structures in selected notoungulates will appear elsewhere (MacPhee, in prep.).

Several core taxa, detailed further below, constitute the comparative set for most of the observations made in this paper (see table 1). For grouping purposes, parent ("family") allocations within the major clades Typotheria and Toxodontia largely, but not exclusively, follow Billet (2011) or Reguero and Prevosti (2010). Within Typotheria, which is the focus of this paper, two major subclades can be defined and reasonably characterized cladistically (Billet, 2011): "Interatheriidae + relatives," and the "Archaeohyracidae + Mesotheriidae + Hegetotheriidae" complex. To simplify reference, however, these subclades would benefit from having non-sesquipedalian names; I use intheratherioids for the first group and hegetotherioids for the second, more diverse group of notoungulates.

My selection of taxa and specimens for study was determined by the nature of the morphological problems that needed to be solved. Many more might have been included, but it was necessary to keep the study within manageable limits. In addition to conventional macroscopic examination of intact and broken specimens, better preserved material was subjected to microCT scanning using a GE eXplore Locus (at Ohio University) or a GE Phoenix vtomex s240 (at AMNH); 2D sections and rendered volumes were visualized with Fiji (ImageJ) $1.47 \mathrm{u}$ software (Schindelin et al., 2012) or VGStudio Max 2.1. Thanks to digital reslicing options, one's choice of planes for visualization of specific features is essentially limitless. However, as an aid to comprehension, with some exceptions virtual sections in this paper are presented in one or another of the classical X-Y-Z axes (denoted as coronal, parasagittal, and horizontal in figure 
legends). Virtual sections of paleontological specimens rarely reproduce well as published figures unless they are first cleared of obfuscating noise. Legibility of discontinuities (sutures as well as fractures) was enhanced by carefully increasing contrast, sharpening edges, and emphasizing lines during processing. Otherwise, retouching has been kept to a minimum and matrix, if present, has been left in situ if it does not hamper identification of structures.

Although the convenience of micro-CT scanning technology has improved markedly in the last several years, the inherent limits of resolution with affordable, currently available instruments, combined with the problem of properly interpreting specimens inevitably compromised by damage, precludes fine histological-scale interpretation in most instances (although things ought to improve in the near future, especially for applications of interest to paleontologists; Metscher, 2009). In any case, every effort has been made to illustrate relevant morphological points and anatomical bases for analyses conducted in the text. For ease of reference, figures 1-20 are organized as far as possible in album format, meaning that illustrations relating to a single taxon are purposely grouped together wherever possible.

Looking for sutures on the walls of paratympanic spaces in adult skulls is often frustrating, because remodeling tends to obliterate external traces of any sutures that might have existed earlier in ontogeny. However, indicia may still exist within the substance of the bones involved, and these can sometimes be identified with CT visualization. Taphonomically induced fracturing in fossils is an added complication, although it is usually possible to tell the difference between breaks and real sutures from their appearance and position.

Fortunately, some particularly informative specimens were available for this study, especially the examples of Cochilius (representing interatherioids) and Paedotherium (hegetotherioids) given detailed treatment in following sections. Less well-preserved specimens of sev- eral other taxa (Notopithecus, Protypotherium, Archaeophylus, and Hegetotherium) were also examined and in some cases scanned, but because of their condition or other problems they necessarily play a smaller role in the analyses. All of the taxa mentioned so far are predominantly or exclusively Neogene. Older "primitive typotheres" (a nonphylogenetic grouping that includes several, doubtlessly distinct clades such as Colbertia and Campanorco, plus their relatives) are represented, albeit inadequately, in this study by Oldfieldthomasia. Sample sizes are admittedly small, but this is due mostly to the paucity of truly well-preserved fossils, even in collections that are otherwise outstanding. Except where recent revisions have required a change, species names are those encountered on museum labels. Many specimens used in this paper lacked age assignments; rather than attempt to certify each assignment made in table 1 , I have generally entered genus-level ages from the Paleontology Database (http://paleodb.org) or McKenna and Bell's (1997) compendium. SALMAs, if available, are copied under Remarks without comment as to their accuracy.

\section{Oldfieldthomasia \\ (Unnamed Basal Typothere Group, Oldfieldthomasiidae)}

Oldfieldthomasia has long been placed in its own family (Simpson, 1967; Billet, 2011), to which a handful of other Paleogene taxa of debated affiliations (e.g., Acropithecus rigidus) have gradually accreted, thus possibly rendering the family paraphyletic (see García López, 2011; Reguero and Prevosti, 2010; Billet, 2011). Available cranial material of this genus is decidedly poor, but retains historical importance because of Simpson's (1936) study of Oldfieldthomasia cf. debilitata AMNH-VP 26800, discussed here in some detail (see figs. 1, 5-7, 20; appendix 1). This specimen is (or was) a partial skull from the locality of Cerro Blanco, now known to be of Middle Eocene age (cf. Reguero and Prevosti, 2010). Virtual sections of the preserved left 


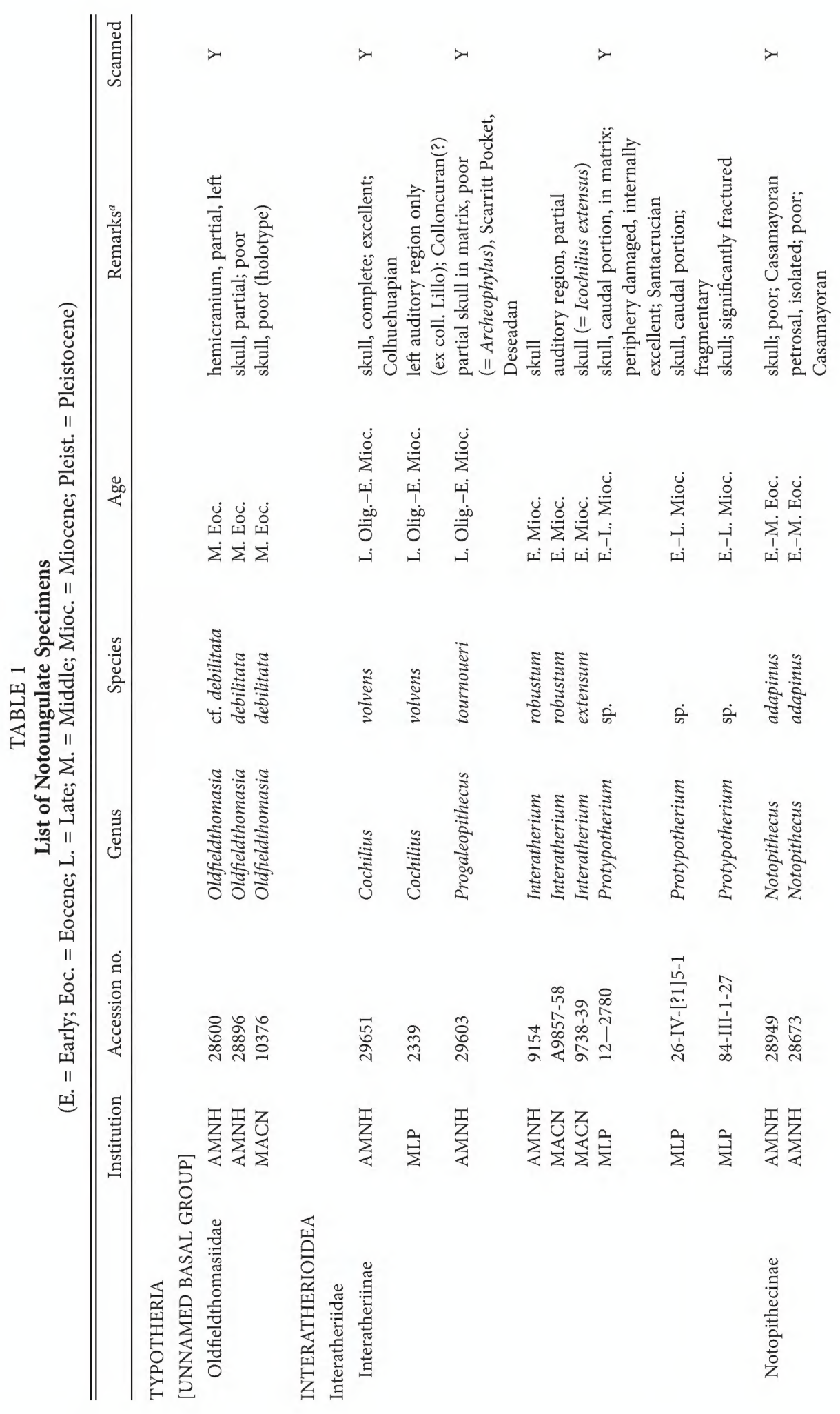




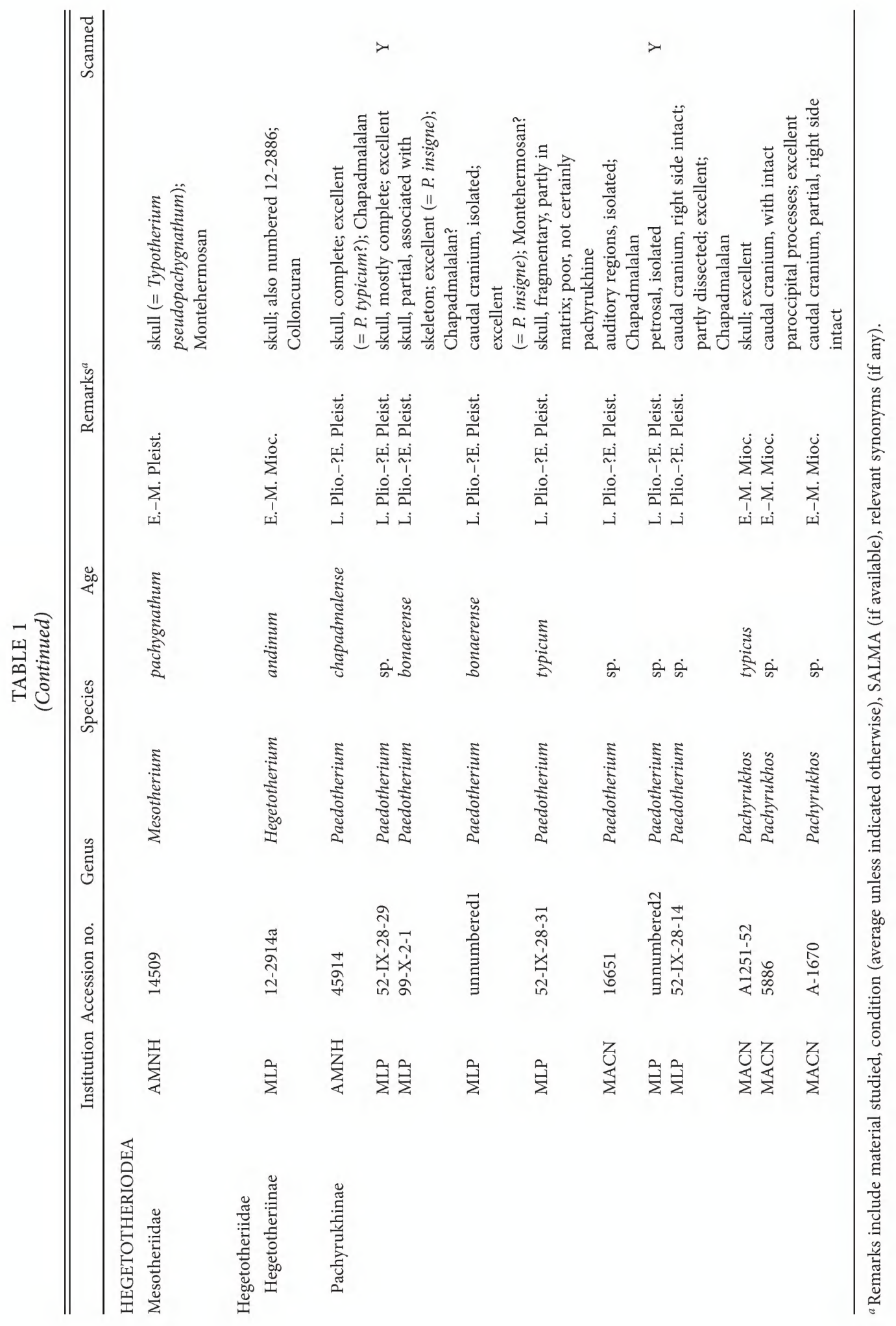


hemicranium are of limited use because so much of the fossil has been lost or damaged (figs. 1, 7). Indeed, Simpson may have chosen this particular specimen to work on because it was already much battered and destructive sampling could be justified. This may have been the wrong choice for experimentation, however, for his results were predictably poor and he never attempted to prepare another South American ungulate in this manner.

Other Specimens Studied. Also examined were the holotype skull of Oldfieldthomasia debilitata (MACN 10376) and another cranial specimen in the AMNH-VP collection (AMNH-VP 28896), but because of their condition (which Simpson [1932a: 7] unaccountably described as "well preserved") they supplied nothing of value to the interpretation effort.

\section{Paedotherium \\ (Hegetotherioidea, Hegetotheriidae, Pachyrukhinae) and Relatives}

The target genera Paedotherium and Pachyrukhos (nec Pachyruc[h]us, Pachyrucos [McKenna and Bell, 1997: 466]), which are morphologically extremely similar, contain many named species. As Cerdeño and Bond (1998) have shown, sorting out which nominal species belongs to which genus is not a straightforward matter, and in the past generic assignment often seems to have been based on age rather than morphology. In any case, apart from the teeth, discernible differences in the crania of these taxa are few and possibly largely size related, with definite Pachyrukhos being somewhat more robust than definite Paedotherium. For the purposes of this study, little of value is lost by frequently ganging them together as "pachyrukhines."

Pachyrukhinae is an indisputably monophyletic clade of hegetotheres whose known range extends from Deseadan or even Tinguirirican to ?Ensenadan time (Cerdeño and Bond, 1998; Reguero et al., 2007; Reguero and Prevosti, 2010; Billet, 2011). Pachyrukhinae is invariably paired with Hegetotheriinae to form Hegetotheriidae, the sister group of which is the grouping of "late" nominal archaeohyracids identified by Billet et al. (2009; Billet, 2011). No cranial material of earlier members of Pachyrukhinae (Deseadan Prosotherium and allies; see Reguero and Prevosti, 2010) has been described.

Specimens Studied. Available specimens of Paedotherium (figs. 8-12) were in much better condition than those of Pachyrukhos. The sample examined in this paper includes AMNH-VP 45914, an excellent skull of Paedotherium chapadmalense (probably a synonym of $P$. typicum) and some good material of $P$. bonaerense (as relimited by Cerdeño and Bond [1998], here including MLP unnumbered 1 and $P$. insigne MLP 99-X-2-1). A number of other Paedotherium specimens in table 1 (e.g., MLP unnumbered2), mostly lacking dentitions, cannot be validly referred to species and are thus listed as "sp." Other specimens: Pachyrukhos typicus MACN 1251-52; Pachyrukhos sp. MACN 5886. A representative of the related taxon Hegetotherium andinum (MLP 12-2914a) was examined but not scanned. (This genus needs revision, and this species name may not be valid; G. Billet, personal commun.)

Mesotherium pachygnathum AMNH-VP 14509 , representing a second family, Mesotheriidae, was only cursorily examined and was judged a poor candidate for scanning. However, the late survival of this genus suggests that good material should exist and should be sought for future work.

\section{Cochilius (Interatherioidea, Interatheriidae, Interatheriinae) and Relatives}

Cochilius volvens, a moderately early member of the Interatheriidae, is represented in the comparative set by AMNH-VP 29651 from a locality "south of Lago Colhué-Huapi" (Simpson, 1932b: 1), not otherwise identified. Structural details are well preserved at the microanatomical level, with few seriously fragmented areas (figs. 13-15). Other specimens examined: Cochilius volvens MLP 2339 (ex coll. Lillo). 
Protypotherium is common in Patagonian Santacrucian localities and thus well represented in museum collections. MLP $12-2780$ is waterworn and partly encased in matrix; although damaged on exposed surfaces, scanning revealed that matrix-covered areas were quite intact. A mineral sinter, investing all surfaces, is particularly noticeable on trabeculae filling the epitympanic sinus; digital removal did not provide acceptable results, so images are presented as they appear in the original scans (figs. 16-17).

Other specimens examined: Interatherium (= Icochilius) extensum MACN 9738-39; Interatherium rodens MACN 9857-58.

Progaleopithecus tournoueri, which has a complicated taxonomic history, is of interest because it is part of a group standing as sister to Cochilius, Protypotherium, and Interatherium (see Hitz et al., 2006). Unfortunately, the only available specimen with a caudal cranium (AMNH-VP 29603) turned out on scanning to be much battered and figures little in this account.

Notopithecus adapinus AMNH-VP 28949 and 28673, representing the earliest conventionally recognized interatheriid subfamily (Notopithcinae), are very poorly preserved, although virtual sections of the skull were of some use in connection with gathering data on the presence of an entotympanic and septum bullae in notoungulates.

\section{Other Placental Taxa}

Interpretation of the highly derived cranial organization of pachyrukhine notoungulates was aided to some degree by studying taxa to which they have been historically and are still occasionally compared, as examples of detailed convergences among placentals arising from vastly different phylogenetic progenitors (figs. 18, 19). The list of useful comparisons could be long, but as this is not a functional anatomical study, attention was focused on examining selected young and/or damaged specimens of a few informative taxa in the AMNH-M's extensive holdings of Glires.
Specimens studied (all AMNH-M): Leporidae: jackrabbit, Lepus californicus 177068, 5887. Dipodomyidae: Merriam's kangaroo rat, Dipodomys merriami 8598, 182081; Heermann's kangaroo rat, $D$. heermanni 124172; painted spiny pocket mouse, Liomys pictus annectens 190257; long-tailed pocket mouse, Chaetodipus formosus 248737; Merriam's pocket mouse, Perognathus merriami 188632.

\section{Terminology}

I have mostly used obvious English equivalents of morphological nomina endorsed by the fifth edition of Nomina Anatomica Veterinaria (NAV), despite the fact that the NAV does not adequately encompass conditions in groups lacking economic significance for humans. With regard to notoungulate anatomy, I did not hesitate to use alternatives when NAV terms were inapplicable for one reason or another, or to coin my own where the NAV was silent (for glossaries, imagery, and applications relating to anatomical terminology, see http://www.morphobank.org; among hardcopy resources, see MacPhee [1981], Evans and de Lahunta [2012], Wible [2007, 2009], and associated bibliographies). The following paragraph summarizes, in no particular order, various terminological decisions made in the course of this study.

Reference to the serrialis bone, Roth's name for one of his novel cranial ossifications, is needed for historical reasons; elementum serriale, also Roth's, refers to the same entity, with neuter noun and adjective in agreement. For historical reasons as well I retain epitympanic sinus, but replace the cumbersone sheath of the styloid process (i.e., vagina processus styloidei) with the now more widely used hyoid recess. The combination tympanostyloid is used to refer to the two, usually fused, ossifications (tympanohyoid and stylohyoid) that comprise the cranial end of the hyoid apparatus in mammals (Starck, 1967) and assumed to be present as two ontogenetically independent elements in notoungulates. In a similar vein, when needing to refer to bones that are 
compound in the adult due to fusion of ontogenetically separate elements, I use the convention "bone1 + bone2," e.g., "parietal + interparietal." An exception is the traditional and easily interpreted compound petrotympanic (petrosal + ectotympanic). Prior to fusion, or in cases in which their separate natures can still be identified, petrosal and ectotympanic are distinguished as such. However, this is often difficult to do, not only with regard to these two elements but also the squamosal, which often fuses with them in complex ways. The parietals and interparietals usually show complete fusion as well (and for this reason are simply named "parietal" in figures).

Compared to many other placentals, the endocranial petrosal crest is much enlarged in notoungulates, and forms an expansive tentorium osseum together with descending sheets from both the supraoccipital (tentorial process of the supraoccipital) and the parietal/interparietal (tentorial process of the parietal). These processes wall off a major dehiscence, part of which accommodates a sulcus for a vascular channel apparently identical to the transverse sinus of many other placentals (MacPhee and Cartmill, 1986), although in the notoungulate case the tributary system for this channel is exceedingly complex. This sinus is linked posteriorly to the large aperture on the caudal surface of the cranium that is traditionally named the mastoid foramen. Billet and de Muizon (2013) have produced several reasons for thinking that this aperture may be better regarded as the homolog of the external opening of the posttemporal canal of various mammals (Wible, 1984). Since foramina are normally named after the structures they transmit, this name change carries some implications. As conventionally understood, in most mammals possessing one the true mastoid foramen transmits only an emissary vein related to the sigmoid sinus, whereas the posttemporal canal houses the arteria diploetica magna and a coaxial system of veins linked to one or more major venous sinuses in the lateral wall of the skull (Wible, 1984, 2010;
Gaudin, 2011). The arteria diploetica magna is connected extracranially to the occipital artery (of which it is a derivative) and intracranially to the stapedial system (or remnants thereof). Its area of supply varies across taxa, but would have primitively included numerous structures in the rostral end of the head normally subserved by stapedial distributaries. At present, the published evidence for the claim that the arteria diploetica magna is present in notoungulates is based on interpretation of an isolated petrosal (of probable notoungulate affinity) from Itaboraí. Billet and de Muizon (2013; personal commun.) are currently investigating conditions in later, more complete material that should further elucidate vascular arrangements in this group.

As much of this paper is taken up with determining suture patterns, for clarity I have adopted the simple expedient of naming most sutures by reference to the bone territories involved (e.g., petroso-exoccipital suture). However, in the case of the squamosal I have taken a different course. This element is involved in sutural relationships, sometimes multiple, with almost every other bone comprising the caudal cranium. The sutures bounding the squamosal's contribution to the bony covering of the epitympanic sinus, the epitympanic theca (see The Elements), are the ones that have been in most contention. I discriminate these as thecal sutures (e.g., parieto-thecal suture), and show that most are indeed faced by squamosal material, although with contributions by the petrosal and ectotympanic in circumscribed areas.

Apart from primates, the so-called petrotympanic fissure almost never exhibits that particular construction in mammals, and is better named glaserian fissure despite use of an eponym. In most notoungulates the "fissure" is simply a site of sutural contact between the preotic ends of the squamosal (and often the alisphenoid) and the auditory bulla, hence the alternative squamoso-bullar or squamoso-ectotympanic suture.

Anatomical, institutional, and other abbreviations are defined in table 2. 


\section{AgendA}

This study is one part of a much larger program intended to place character analysis of the cranial morphology of South American ungulates on a firmer footing, for eventual integration with other systematic data sets (e.g., Reguero and Prevosti, 2010) to produce and test phylogenetic hypotheses. Whether Xenungulata, Astrapotheria, Notoungulata, Pyrotheria, and Litopterna can be holophyletically gathered into a single supertaxon (Meridiungulata) has long been argued. But whether or not Meridiungulata eventually proves to be a wastebasket, for present purposes the adjective "meridiungulate" remains useful for corporate reference to these traditional orders.

In principle, the best way to settle the cranial composition of any taxon is through a comparative approach in which neontological, paleontological, and ontogenetic, and comparative evidence, if available and relevant, may play mutually reinforcing roles (MacPhee, 1981; Koyabu et al., 2012). However, the situation in which these various approaches can be brought together for such a purpose is rarely encountered. Often, one has only adult material to work with, and to make developmental inferences therefrom one must make judicious use of inferences based on conditions in taxa that may be at various phylogenetic removes from the ones comprising the target. This is a legitimate approach if the point of doing so is to understand some relationship or ontogenetic occurrence for which direct data are otherwise unavailable (e.g., possible instances of early fusions among elements in the target taxon).

As already noted, this study is concerned with evaluating the evidence and interpretations marshaled by previous investigators to support their identification of what might be called "suspect elements" in the notoungulate caudal cranium. I have concentrated on typotherians because their (generally) smaller size simplified both study and scanning, and because they have been more central to the composition debate than toxodontians have been. Nevertheless, the findings presented here are believed to apply to all notoungulates. The most efficient way of presenting my observations and conclusions is to consider each element of interest separately, under the following headings: (1) serrialis and the bony covering of the epitympanic sinus; (2) interparietal complex; (3) the X elements; and (4) entotympanics and septum bullae.

Compositional questions of the sort presented here have played only a minor role in notoungulate systematics in the past several decades, and it might be asked why it is important to reevaluate morphological debates that have long since dwindled into insignificance. But this lack of attention mostly reflects the fact that some avenues of paleontological investigation are much harder to traverse than others, especially if they require destructive sampling methods-as microanatomical studies traditionally do. The advent of virtual sectioning has changed the landscape in this regard, as I hope this paper illustrates.

\section{THE ELEMENTS}

\section{Simpson, Roth, AND the \\ Caudal Cranium of Oldfieldthomasia}

My interest in reopening the question of notoungulate cranial composition was stimulated by examination of the original drawings relating to Simpson's (1936) description of cranial composition in Oldfieldthomasia cf. debilitata AMNH 26800 (appendix 1). Simpson thought that by studying the caudal cranium of an ostensibly primitive notoungulate in great detail he could determine once and for all whether there was any substance to Roth's (1903) observations regarding "extra" elements in the notoungulate caudal cranium. As he pointed out with some asperity, Roth's (1903) descriptions were difficult to follow because of his use of idiosyncratic, poorly defined morphological terms and meandering speculations regarding the homologies of the several novel elements that he thought he had detected. 
TABLE 2

Abbreviations

INSTITUTIONAL

AMNH-M

AMNH-VP
American Museum of Natural History,

Department of Mammalogy

American Museum of Natural History, Department of Vertebrate Paleontology
MACN

MLP ditus to epitympanic sinus

(= pneumatic foramen)

aperture of the auditory tube

anular bridge (of crista tympani, ectotympanic)

aperture of aqueductus vestibuli

aperture of tubal canal

alisphenoid bone

auditory bulla

auditory ossicle(s) (nonspecific)

auditory tube

basicapsular fenestra (= basisphenoid-

bulla suture)

BOC

br

BSP

can semic caud can semic rost caud car for

caud crus ect

caud pars canal

cerebl fos

coch

coch can

cran cav

cr lat

cr meat

cr pet

cr transv

cr tym

crph can

crus com

div

dors hiat ridge

dors midcr hiat

dors vestib area

ECT

ect/ent sut

ect/theca sut

ENT

EOC basioccipital bone

broken, fracture (d)

basisphenoid bone

caudal (= posterior) semicircular canal

rostral (= anterior) semicircular canal

caudal (= posterior) carotid foramen

posterior crus of ectotympanic

caudal portion of pars canalicularis

("mastoid")

cerebellar fossa

cochlea

cochlear canaliculus

cranial cavity (fossa)

crista lateralis (of retrotympanic

process)

crista meatus (of ectotympanic)

petrosal crest

crista transversa

crista tympani

craniopharyngeal canal

crus commune

diverticulum (nonspecific)

dorsal midcranial hiatus

dorsal vestibular foramen

(for vestibular n., vestibular area

of internal acoustic meatus)

ectotympanic bone

ectotympano-entotympanic suture

ectotympano-thecal suture

entotympanic

exoccipital bone dorsal hiatal ridge eoc/bulla sut

\begin{tabular}{|c|c|}
\hline \multirow{5}{*}{$\begin{array}{l}\text { eoc/bulla sut } \\
\text { epitym sin } \\
\text { epitym theca }\end{array}$} & $\begin{array}{l}\text { exoccipito-bullar suture } \\
\text { (between paroccipital process }\end{array}$ \\
\hline & and ectotympanic) \\
\hline & epitympanic sinus \\
\hline & epitympanic theca \\
\hline & $\begin{array}{l}\text { (bony covering of epitympanic } \\
\text { sinus, regardless of construction) }\end{array}$ \\
\hline ext acous can & external acoustic canal \\
\hline ext acous meat & external acoustic meatus \\
\hline fac can & facial canal \\
\hline fac for & $\begin{array}{l}\text { facial foramen (for facial } \mathrm{n}, \\
\text { internal acoustic meatus) }\end{array}$ \\
\hline fac sulc & facial sulcus \\
\hline fen vest & fenestra vestibule \\
\hline for & foramen (nonspecific) \\
\hline for magn & foramen magnum \\
\hline for ovale & foramen ovale \\
\hline for ram temp & foramen for ramus temporalis \\
\hline FRO & frontal bone \\
\hline hyd rec & hyoid recess \\
\hline hypogl for & hypoglossal foramen \\
\hline INC & incus bone \\
\hline inf petr sin & inferior petrosal sinus \\
\hline INP & interparietal \\
\hline inp/soc sut & interparieto-supraoccipital suture \\
\hline $\begin{array}{l}\text { inp/theca sut } \\
\text { jug for }\end{array}$ & interparieto-thecal suture \\
\hline lin temp & linea temporalis \\
\hline mast can & $\begin{array}{l}\text { mastoid canaliculus (for auricular ramus } \\
\text { of vagus n.) }\end{array}$ \\
\hline mand fos & mandibular fossa \\
\hline mast for & mastoid foramen \\
\hline MAX & maxillary bone \\
\hline med paratym cav & medial paratympanic cavity \\
\hline met sut & metopic suture \\
\hline midcr hiat & midcranial hiatus \\
\hline nuch $\mathrm{cr}$ & nuchal crest \\
\hline OCC & occipital bone (nonspecific) \\
\hline occ cond & occipital condyle \\
\hline PAL & palatine bone \\
\hline PAR & parietal bone \\
\hline PAR-INP & $\begin{array}{l}\text { parietal + interparietal bones } \\
\text { (when fused) }\end{array}$ \\
\hline par/inp sut & parieto-interparietal suture \\
\hline $\mathrm{par} / \mathrm{soc}$ sut & parieto-supraoccipital suture \\
\hline
\end{tabular}

Museo Argentino de Ciencias Naturales Bernardino Rivadavia, Sección Paleontología de Vertebrados Museo de La Plata, Departamento Scientifico de Paleontología de Vertebrados 
TABLE 2

(Continued)

\begin{tabular}{|c|c|c|c|}
\hline \multirow{3}{*}{ par/theca sut } & parieto-thecal suture (= squamoso- & squ pr & processus squamosus (of lagomorphs) \\
\hline & parietal suture; may also involve & squ/asp sut & squamoso-alisphenoid suture \\
\hline & interparietal) & squ/ect sut & squamoso-ectotympanic suture \\
\hline \multirow{2}{*}{$\begin{array}{l}\text { parocc pr } \\
\text { PET }\end{array}$} & paroccipital process & squ/par sut & squamoso-parietal suture (may also \\
\hline & $\begin{array}{l}\text { petrosal bone (when separable from } \\
\text { ectotympanic) }\end{array}$ & stylomast for & $\begin{array}{l}\text { involve interparietal) } \\
\text { stylomastoid foramen }\end{array}$ \\
\hline \multirow[t]{2}{*}{ pet/bulla sut } & petroso-bullar suture (petroso- & subarc fos & subarcuate fossa \\
\hline & $\begin{array}{l}\text { ectotympanic or petroso-entotympanic) } \\
\text { petroso-ectotympanic suture }\end{array}$ & suprmeat sp squ & $\begin{array}{l}\text { suprametal spine of the squamosal } \\
\text { (in Dipodomys) }\end{array}$ \\
\hline \multirow[t]{2}{*}{ pet/eoc sut } & petroso-exoccipital suture & teg tym & tegmen tympani \\
\hline & (on paroccipital process) & temp ridge & temporal ridge (for temporalis $\mathrm{m}$.) \\
\hline pet/theca sut & petroso-thecal suture & temp fos & temporal fossa (for temporalis $\mathrm{m}$.) \\
\hline petmast can & $\begin{array}{l}\text { petromastoid canaliculus } \\
\text { (= subarcuate canaliculus) }\end{array}$ & tent pr par & $\begin{array}{l}\text { tentorial process of parietal } \\
\text { (endocranial) }\end{array}$ \\
\hline \multirow{3}{*}{$\begin{array}{l}\text { pirif fen } \\
\text { posttemp can } \\
\text { preot fl }\end{array}$} & piriform fenestra & tent pr soc & tentorial process of supraoccipital \\
\hline & posttemporal canal (= mastoid foramen) & & (endocranial) \\
\hline & $\begin{array}{l}\text { preotic flange (of alisphenoid and } \\
\text { squamosal) }\end{array}$ & theca & $\begin{array}{l}\text { theca, thecal (in relation to bony } \\
\text { covering of epitympanic recess) }\end{array}$ \\
\hline prom & promontorium & theca ala eoc & thecal ala of exoccipital \\
\hline PTE & pterygoid bone & theca ala pet & thecal ala of petrosal \\
\hline $\mathrm{ptm} / \mathrm{eoc}$ sut & $\begin{array}{l}\text { petrotympano-exoccipital suture } \\
\text { (area of paroccipital process) }\end{array}$ & $\begin{array}{l}\text { theca ala soc } \\
\text { theca sp }\end{array}$ & $\begin{array}{l}\text { thecal ala of supraoccipital } \\
\text { thecal spine }\end{array}$ \\
\hline \multirow{6}{*}{$\begin{array}{l}\text { ram temp } \\
\text { retroart for } \\
\text { retroart pr } \\
\text { retroart sin } \\
\text { retrotym fis } \\
\text { retrotym pr }\end{array}$} & ramus temporalis (rami temporales) & to & to, toward (used with other \\
\hline & retroarticular (= postglenoid) foramen & & abbreviations) \\
\hline & retroarticular (= postglenoid) process & tract spir for & tractus spiralis foraminosus (for \\
\hline & $\begin{array}{l}\text { retroarticular sinus } \\
\text { retrotympanic fissure }\end{array}$ & & $\begin{array}{l}\text { cochlear n., cochlear area of internal } \\
\text { acoustic meatus) }\end{array}$ \\
\hline & retrotympanic (= posttympanic) & transv sin & transverse sinus \\
\hline & process & & transverse sulcus \\
\hline \multirow{9}{*}{$\begin{array}{l}\text { rost crus ect } \\
\text { sag cr } \\
\text { sep } \\
\text { sep bulla } \\
\text { sigm sulc } \\
\text { sin } \\
\text { SOC } \\
\text { soc/theca sut }\end{array}$} & rostral crus of ectotympanic & tub sulc & tubal sulcus \\
\hline & sagittal crest & tym cav & tympanic cavity \\
\hline & septum (nonspecific) & tymstyld & tympanostyloid (cranial end of hyoid) \\
\hline & septum bullae & vasc can & vascular canal (nonspecific) \\
\hline & sigmoid sulcus & vasc for & vascular foramen (-mina) (nonspecific) \\
\hline & vascular sinus (nonspecific) & vent vestib area & ventral vestibular foramen \\
\hline & supraoccipital bone & & (for vestibular $n$,, vestibular area of \\
\hline & supraoccipito-thecal suture & & internal acoustic meatus) \\
\hline & (in pachyrukhines) & verm fos & vermiform fossa \\
\hline \multirow{4}{*}{$\begin{array}{l}\text { sphenorb for } \\
\text { sphocc syn } \\
\text { SQU } \\
\text { squ bar }\end{array}$} & sphenorbital foramen & $\mathrm{Xa}$ & element Xa (of Simpson) \\
\hline & sphenooccipital synchondrosis & $\mathrm{Xp}$ & element Xp (of Simpson) \\
\hline & squamosal bone & ZYG & zygomatic bone \\
\hline & squamosal bar & zyg pr sqam & zygomatic process of squamosal \\
\hline \multicolumn{4}{|l|}{ OTHER } \\
\hline \multirow[t]{2}{*}{ CONICET } & Consejo Nacional de Investigaciones & rev. & sides reversed (on images of specimens) \\
\hline & Científicas y Técnicas (Argentina) & s. & section \\
\hline $\mathrm{CT}$ & computed tomography & SALMA & South American Land Mammal Age \\
\hline NAV & $\begin{array}{l}\text { Nomina Anatomica Veterinaria, 5th ed. } \\
\text { (2012) (http://www.wava-amav.org/ } \\
\text { nav_nev.htm) }\end{array}$ & & \\
\hline
\end{tabular}


A

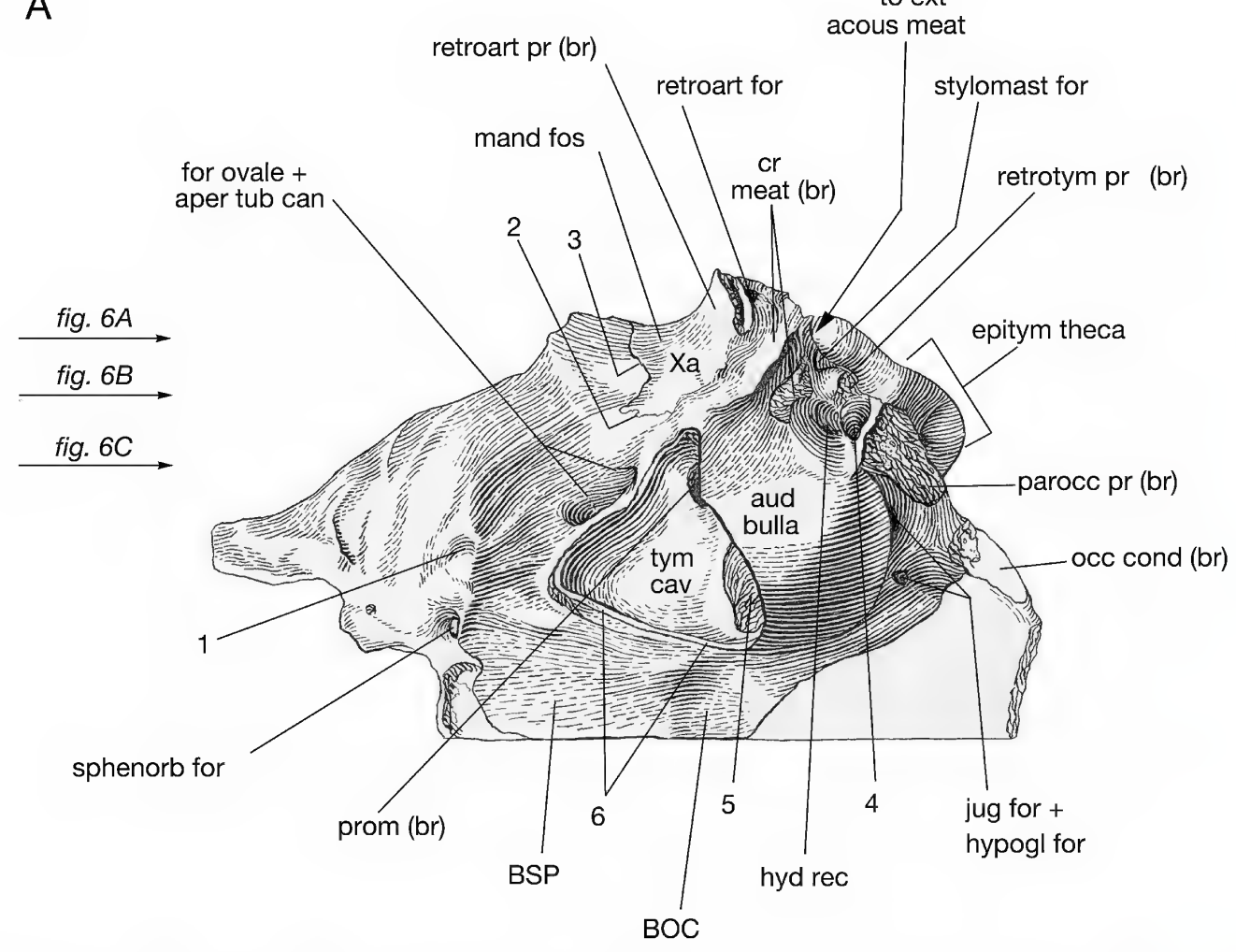

FIG. 1. Oldfieldthomasia cf. debilitata AMNH-VP 28600, left hemicranium in ventral (A; above), oblique ventrolateral (B; opposite), and caudal (C; opposite) aspects (after Simpson [1936], slightly modified and relabeled). Scale bar in $\mathrm{C}=0.5 \mathrm{~cm}$ (all to same scale). Most but not all of the features identified in Simpson's (1936) original illustrations are included in the following key (updated with modern nomina where necessary): 1, ?foramen; 2, part of (preotic) squamoso-alisphenoid suture; 3, apparent "suture" (in fact a fracture) delimiting element Xa according to Simpson (see text); 4, exposed cellule (not stylomastoid foramen, contra Simpson); $\mathbf{5}$, fractured area in tympanic roof; $\mathbf{6}$, broken edge of bulla; $\mathbf{7}$, retroarticular sinus, exposed by breakage; 8, floor of epitympanic sinus (not posttemporal canal/“mastoid foramen," contra Simpson). The specimen is obviously in poor condition, with many broken (br) structures. In the drawings as originally published, bone was not properly differentiated from matrix still adherent to inner walls of epitympanic sinus. In C, Simpson evidently assumed that the matrix-filled area (asterisk, ${ }^{*}$ ) incorporated the actual caudal wall of the theca, and that the declivity medial to it (8) was therefore the "mastoid foramen" (= posttemporal canal). Declivity is in fact curved floor of epitympanic sinus, not an aperture; true posttemporal canal lies, as indicated, more medially and dorsally within a groove appearing on original drawing but not called out as such. Stylomastoid and hypoglossal foramina originally drawn slightly out of place (now corrected); hyoid recess cannot be seen from this angle (thus omitted); and leader for Xp points to nothing interpretable as an independent element (as in original drawing). In A, small arrows with italicized figure numbers indicate approximate planes of virtual sections (figs. 6, 7). 
B

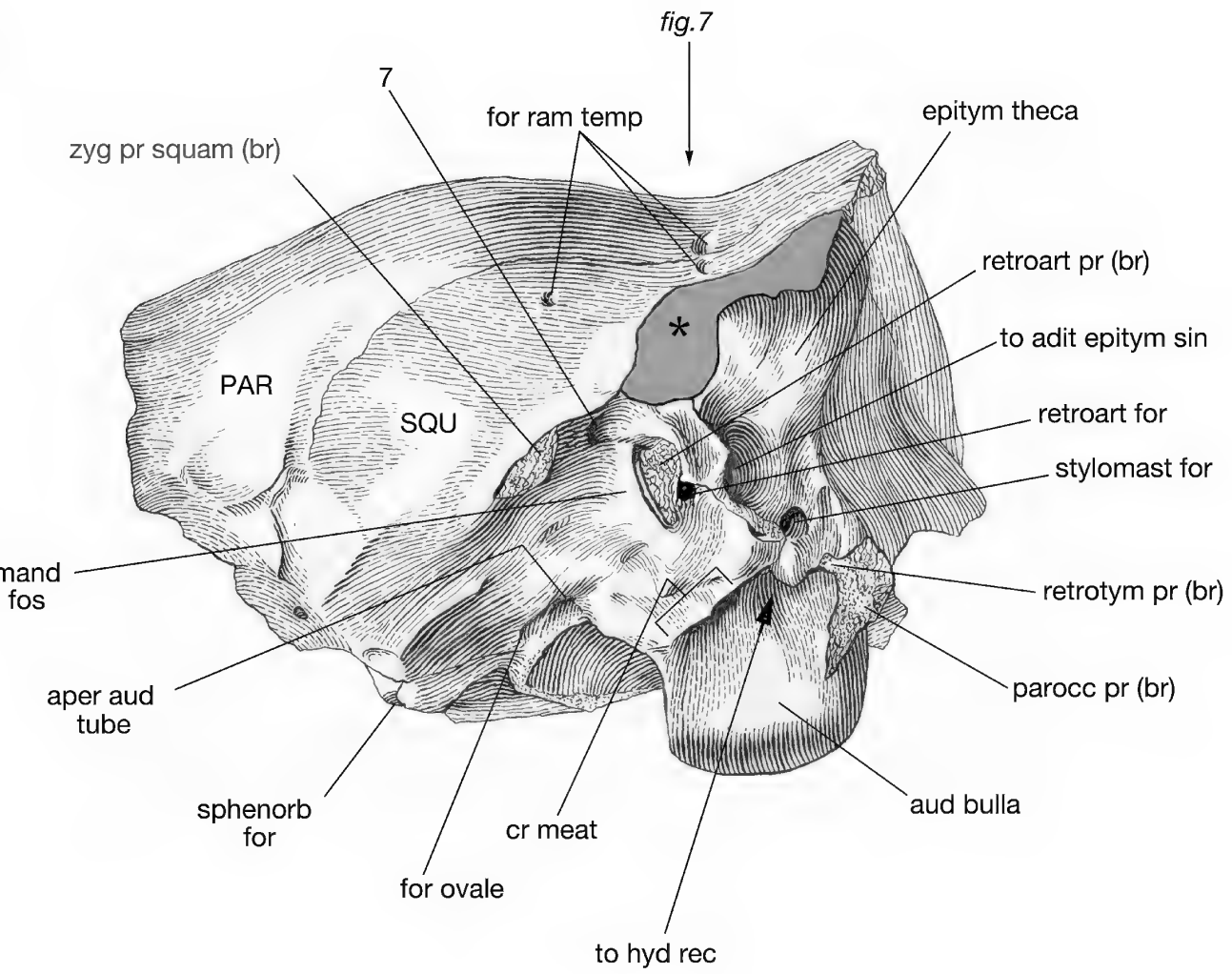

C

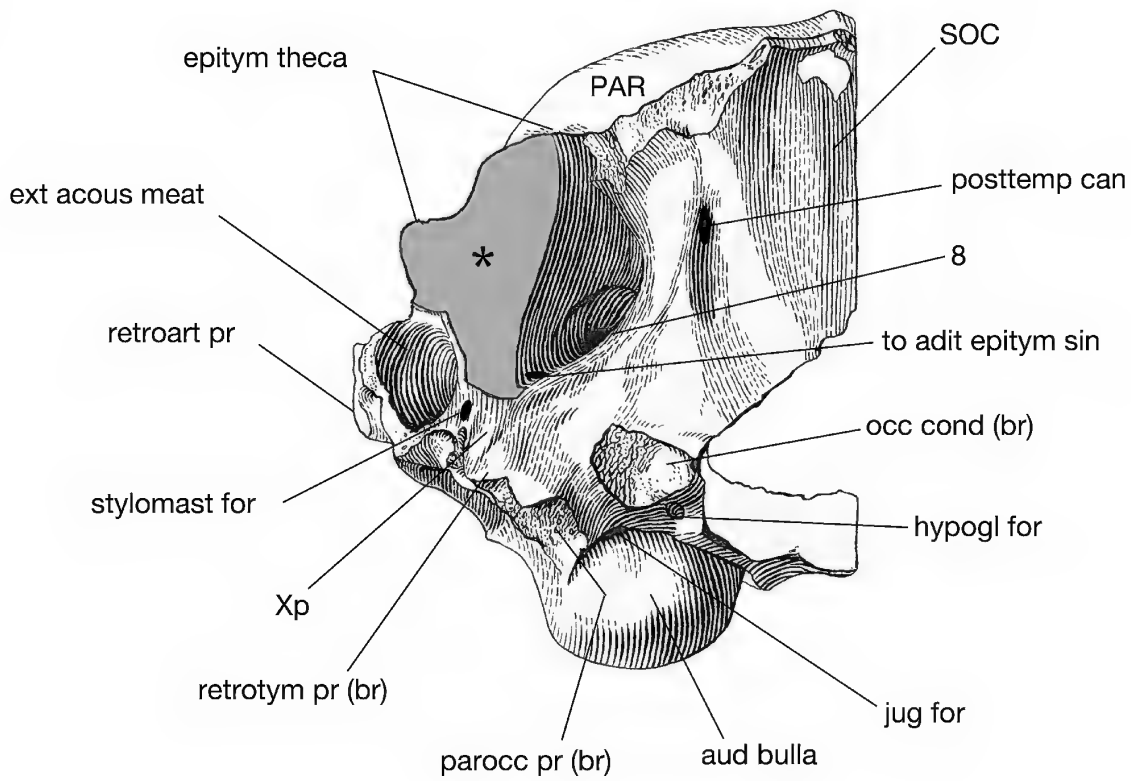




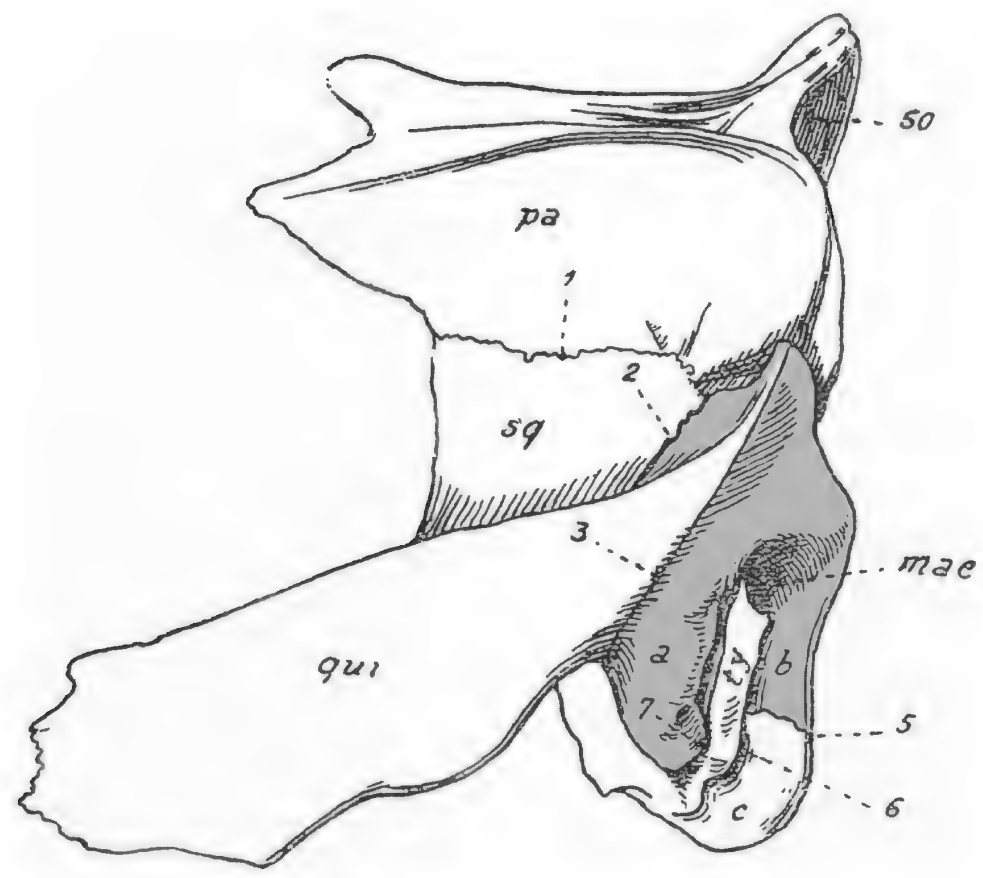

FIG. 2. Skull of a specimen of Toxodon, apparently juvenile (after Roth, 1903: text-fig. A; scale not provided), showing extent of supposed serrialis (gray shading) and other novel ossifications according to boundaries implied by Roth's determinations of supposed sutures. In fact, none of the elements so delimited qualifies as an independent ossification (see text). Abbreviations according to original caption: $\mathbf{a}, \mathbf{b}$, elementum serriale = prosquamosum; $\mathbf{c}$, elementum posttympanicum = quadratum; mae, external acoustic meatus; pa, parietale; qui, elementum zygoma = quatrojugale; so, supraocipitale; sq, squamosum; ty, tympanicum; 1, sutura squamoso-parietalis; 2, sutura squamoso-serrialis; 3, sutura zygoma-serrialis; 4, [not provided in original]; 5, sutura mastoideo-posttympanica; 6, incisura mastoidea; 7, fissura glaseri. Although this has yet to be demonstrated for Toxodon, some of these alleged sutures could be the result of Roth's misinterpreting borders related to thecal alae-thin sheets of bone formed by the exoccipital, supraoccipital, and petrosal which encroach onto the squamosal thecae and sometimes form self-sutures, to varying extents among notoungulate taxa (cf. Paedotherium, fig. 12B-F).

To undertake his study, Simpson first divided the Oldfieldthomasia skull midsagittally, reserving the left half for macroscopic study. He secured the right half in a lapidary jig of his own design (Simpson, 1933a) and "sectioned" it in 0.4 $\mathrm{mm}$ increments, recording surface details as the specimen was incrementally ground down (for additional information, see appendix 1). At some stage needle preparation was begun on the unsectioned left side but never completed, presumably because the specimen's poor overall condition made it pointless (fig. 1A-C). Simpson undertook this destructive-sampling approach for a specific reason: Although notoungulate skulls were then and even now are often found in reasonably complete condition, diagenetically induced fracturing makes it difficult to identify, let alone follow, fine sutural details. Simpson evidently hoped to solve this problem by avoiding altogether the ordinary preparation methods used in vertebrate paleontology. Clearly, his idea was to have the matrix adherent to the specimen (with an additional plaster coating) function in much the same way that paraffin embedding does in histology, i.e., by keeping structures intact and in their original relationship during cutting operations. 


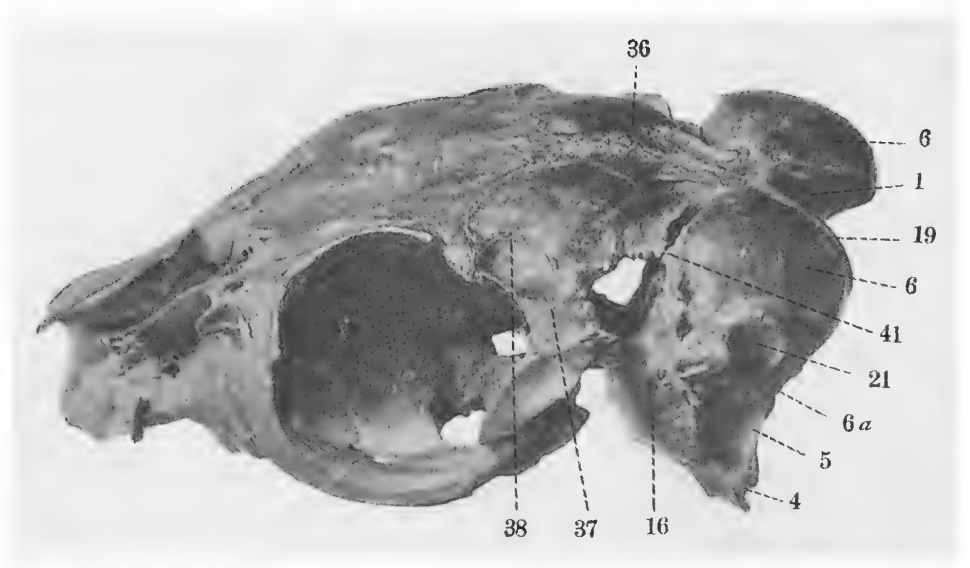

FIG. 3. Skull of an adult Pachyrukhos typicus, as illustrated and interpreted by Roth (1903: pl. I, fig. 6; original magnification, cited as approximately natural size); oblique dorsolateral aspect. Roth's key (translated), with controversial names in quotation marks, preferred name following in parentheses: 1, supraoccipital; 4, paroccipital process; 5 , retrotympanic process; $\mathbf{6}$, "pars mastoidea" (= epitympanic theca); $6 \boldsymbol{a}$, crista lateralis; 16, auditory bulla; 19, "sutura mastoideo-supraoccipitalis" (= supraoccipito-thecal suture); 21, external acoustic meatus; 36, parietal; 37, squamosal; 38, squamoso-parietal suture; 41, "sutura squamoso-mastoidea (escamo-serrial)" (= actually parieto-thecal suture in this specimen, as the squamosal bar has broken away; see text).

In his paper Simpson (1936) dismissed Roth's (1903) contentions concerning extra cranial bones in notoungulates as being either mistaken or unverifiable, but in fact his own study of Oldfieldthomasia AMNH 28600 cannot be regarded as definitive. The skull was not as well preserved as he had hoped, and he lacked similarly prepared specimens of other taxa to which AMNH 28600 might have been profitably compared. Because Simpson's artist, Mildred Clemans, did not (or could not) consistently distinguish between sutures and fractures seen on the surface of the specimen as it underwent incremental grinding, her pencil drawings are sometimes hard to interpret at the very places where certainty is critical. In particular, when a line (whether meant to represent a suture or a break) that should be present in several section drawings is absent in one or more, it is impossible to say whether this was due to a lapsus, or due to something else, such as fusion. This ambiguity could sometimes be overcome by close examination of consecutive drawings, but it is clear that small-scale features were often difficult for the artist to follow across the relatively large (400 $\mu \mathrm{m}$ ) gap between successive surfaces (see appendix 1).

In view of this, it is somewhat ironic to record that Simpson himself claimed to have detected at least one ("Xa") and possibly two ("Xp") suturedelimited elements not identified (at least as such) by any previous investigator (figs. 1, 5, 20), adding a further note of complexity to the problem of defining the composition of the notoungulate caudal cranium. Simpson described these $\mathrm{X}$ elements as "adventitious" - not the best choice for a covering term, although also used by Patterson (1932; Riggs and Patterson, 1935) in similar contexts. There are, of course, truly accidental or sporadic ossifications, such as wormian bones, that are presumably the result of idiopathic genetic or developmental error (Steele and Bramblett, 1988). But there are also ossifications for which this description does not apply, because they are constantly present within a given taxon and thus not at all "adventitious" in the sense of randomly occurring. When such bones are detected the usual question about them is whether 


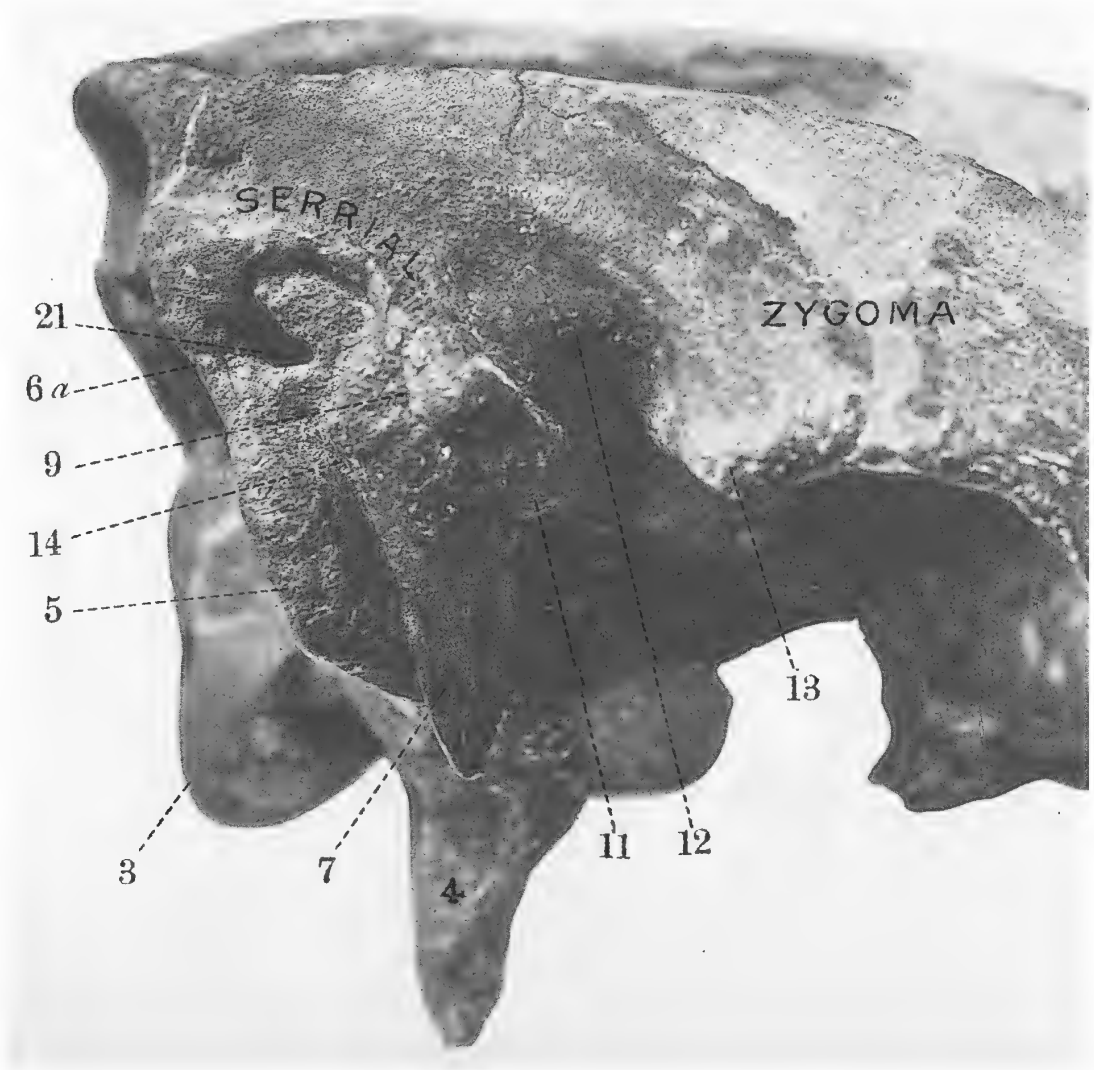

FIG. 4. Caudal cranium of adult Nesodon ovinus, as illustrated and interpreted by Roth (1903: pl. III, fig. 2; original magnification, cited as approximately one-third natural size); lateral aspect. The label "serrial" is simply floated over the external acoustic meatus, with no bounding sutures indicated, making it impossible to evaluate Roth's (1903) reason for discriminating it as such. Roth's key (terminology translated, updated, and annotated as in fig. 3 ): $\mathbf{3}$, occipital condyle; $\mathbf{4}$, paroccipital process; $\mathbf{5}$, retrotympanic process; $\mathbf{6 a}$, "pars mastoidea" (= caudal section of pars canalicularis, exposed on margin of posttemporal canal); 7, crista meatus; 9, glaserian fissure; 11, retroarticular process; 12, mandibular fossa; 13, articular tubercle; 14, "incisura mastoidea" (= cleft between crista meatus and retrotympanic process); 21, external acoustic meatus.

they represent either derepressed elements that were phenotypically present in more primitive relatives, or actual neomorphs (cf. De Beer, 1937; Presley, 1993; Wible et al., 2008). This is doubtless the inquiry that Simpson would have liked to have undertaken in connection with his $\mathrm{X}$ elements, but, unsure of what they were or what they meant, he quite properly avoided discussion of their possible occurrence in other mammals.

Simpson's study of Oldfieldthomasia is still cited in the specialist literature for its anatomical observations (e.g., Macrini et al., 2010; Billet, 2011), but his major arguments and inferences, like those of Roth, Patterson, and others considered in following sections, need to be reviewed in light of the new observations made here. Also, Simpson's (1936) paper is inadequately illustrated: he published only a small selection of the complete drawings made by Clemans (appendix 1 ), and even these are not sufficiently interpreted for one to make sense of three-dimensional structural relationships. To assist the reader in 
this regard I include some previously unpublished Oldfieldthomasia drawings from the AMNH-VP archives (fig. 20) as well as a few virtual sections through the preserved hemicranium (figs. 6, 7).

\section{The Serrialis and the Bony Covering of the Epitympanic SinUs}

Elementum serriale was Roth's (1903) term for the ostensibly independent ossification forming the bony walls of the epitympanic sinus and related areas in at least some meridiungulates (figs. 2-4). As presented in further detail below, his interpretation conflicted with the prevailing assumption that the sinus was contained within bone derived from the squamosal, as would be expected on the basis of conditions in most other mammals. Roth's (1903) fundamental assertion was that the established view could not be correct, for he believed that he had observed definite sutures in several taxa that clearly defined the true caudal limits of the squamosal and separated it from the what actually composed the bony covering of the epitympanic sinus-the serrialis.

Simpson (1936) stated that he was unable to identify any such suture or sutures in Oldfieldthomasia AMNH-VP 28600, or any other notoungulate for that matter, but ultimately left it open whether this was due to the absence of something at least occasionally present in this group, wholesale error on Roth's part, or the age and condition of the specimens examined. This state of affairs has persisted to the present, in part because the osteological correlates of cranial growth and pneumatization in Notoungulata have never been adequately evaluated. As much revolves around a proper understanding of the pneumatization of the epitympanic sinus, we shall first consider this middle ear space from developmental and comparative perspectives.

\section{Epitympanic Theca: Definition and Development}

As Roth (1903) was the first to adequately document, middle ear pneumatization is notably extensive in notoungulates, and a capacious, dorsally prominent paratympanic space on the caudal cranial sidewall has long been counted as a derived character shared by all but the most primitive members of this group (Roth, 1903; Patterson, 1936; Cifelli, 1993; Gabbert, 2004; Reguero and Prevosti, 2010; Billet, 2011). In comparative morphology this space is regarded as a derivative of the epitympanic recess, the excavation that typically lodges the heads of the malleus and incus as well as the dorsalmost part of the membranous sac that fills the adult middle ear, the cavum tympani (van der Klaauw, 1931; Fleischer, 1973; MacPhee, 1981; Macrini et al., 2010). The dorsal wall of the recess is normally, but not always, formed by the petrosal (tegmen tympani) and a shelf (or epitympanic wing) of the squamosal, or both projections in proportions that vary considerably among mammals (van der Klaauw, 1931; MacPhee, 1981; Maier, 2013).

In the assumed primitive therian condition (van Kampen, 1905; van der Klaauw, 1931; Starck, 1967; Novacek, 1977, 1993; MacPhee, 1981; MacPhee and Cartmill, 1986), the recess is merely a dimple in the tympanic roof, but in many mammals it becomes a major paratympanic space under the pervasive influence of middle ear pneumatization. Great expansion of the recess is generally regarded as part of an adaptation for low-frequency sensitivity (e.g., Fleischer, 1973, 1978; Webster, 1975; Webster and Webster, 1975). Although at the cellular level the remodeling process is fundamentally the same wherever it occurs in the skull (Fawcett, 1997), the "same" paratympanic space may be positioned in somewhat different locations in different taxa, which has led, perhaps inevitably, to the coining of a plethora of synonyms in the mammalogical literature (e.g., "mastoid bullae" in notoungulates [Sinclair, 1909]; "anterior mastoid sinus" in Dipodomys [Howell, 1932]; "dorsal bulla" in Cavia [Gacek, 1975]).

In notoungulate studies the traditional term for both the volume and its bony covering is epitympanic sinus, but its use applied to the latter 


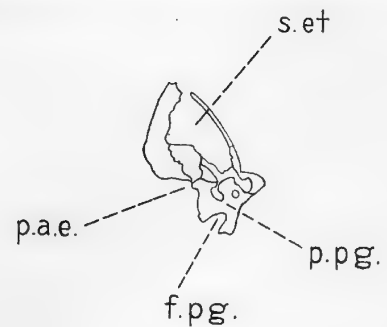

5

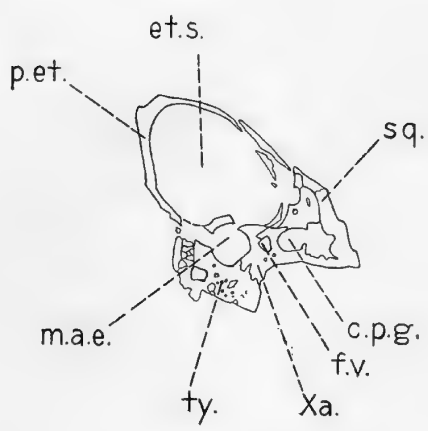

15
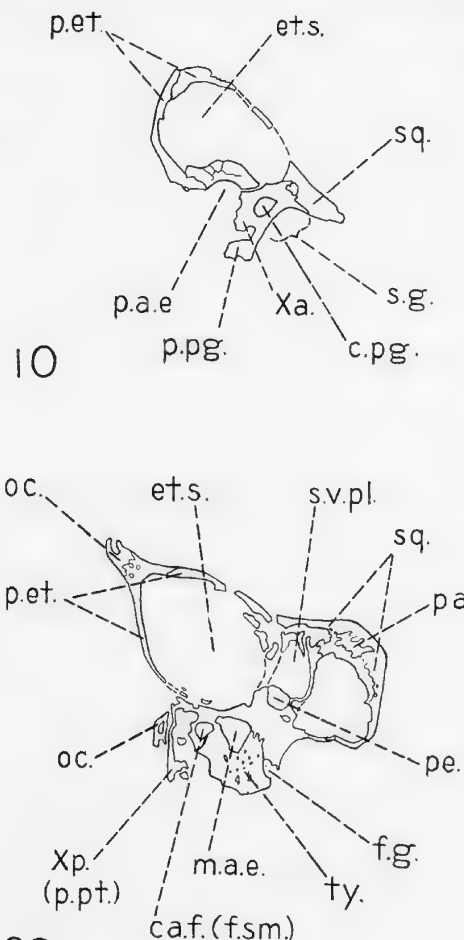

20

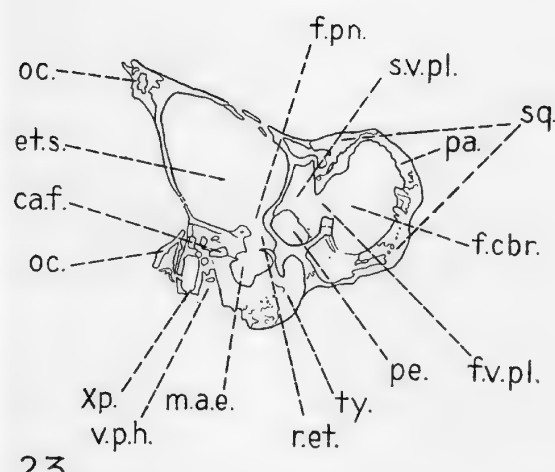

23

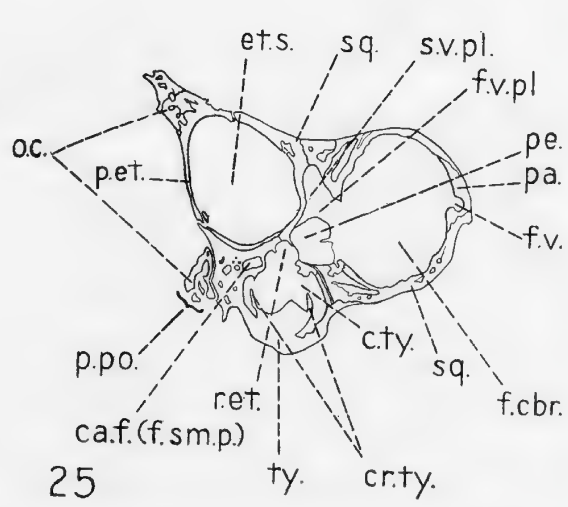

25

FIG. 5. Oldfieldthomasia cf. debilitata AMNH-VP 28600, right hemicranium, parasagittal sections (after Simpson, 1936: fig. 5; original magnification, cited as natural size); rostral to right. This plate includes the only section illustrations of elements Xa and Xp in Simpson's paper (ss. 10, 15, 20, and 23; cf. comparable virtual parasagittal sections in fig. 6). Neither of these putative elements passes tests for recognizing independent ossifications; see text and appendix 1. Key (Simpson's nomina in parentheses, if different from usages preferred here; periods in original omitted): caf, facial canal (canalis facialis); cpg, retroarticular canal/foramen (postglenoid canal); crty, crista tympanica; cty, tympanic cavity; ets, epitympanic sinus; fcbr, cerebral fossa; fsmp, stylomastoid foramen (foramen stylomastoideum primitivum); fg, glaserian fissure (fissura glaseri); fpg, retroarticular canal/foramen (postglenoid foramen); fpn, aditus of epitympanic sinus (foramen pneumaticum); fsm, stylomastoid foramen; fv, venous foramen; fvpl, posterolateral cerebral venous foramen; mae, external 
element is objectionable because a sinus is by definition a vacuity, not a solid structure. I therefore propose the alternative term "theca ${ }^{2}$ epitympanica" to refer to the bony shell, of whatever composition, that encloses the epitympanic sinus and communicates with the tympanic cavity proper by an aditus (= foramen pneumaticum). ${ }^{3}$ Billet and de Muizon (2013) identified a small excavation in the tympanic roof of an isolated notoungulate petrosal from Itaboraí as the epitympanic recess. There is no suggestion of an aditus, suggesting that the epitympanic sinus as a paratympanic space was primitively absent.

\section{Epitympanic Theca: The Question of Composition}

In Roth's (1903) opinion, the notoungulate epitympanic sinus lay within, and was thus covered by the "pars mastoidea," which he regarded as homologous with the mastoid area of humans. Although it had long since been accepted that the human mastoid is simply an integral part of the petrosal, and not a phylogenetically inde-

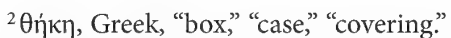

${ }^{3}$ Van Kampen (1905) maintained that an aditus to the epitympanic sinus (aditus ad sinus epitympanicus, preferred to nonspecific "pneumatic foramen") had to be present to warrant distinguishing an epitympanic sinus from a simple epitympanic recess. However, a neat funnel-shaped aperture is not always present in mammals even when paratympanic spaces are large. It should be noted that Simpson's (1933b) positioning of the entrance to the epitympanic sinus in the astrapothere Trigonostylops AMNH 26800 is external to any plausible location for the flaccid or dorsal part of the tympanic membrane. This is morphologically impossible; paratympanic spaces develop in relation to the membrane-lined cavum tympani and remain spatially and functionally continuous with it. The excavation he identified on the external margin of the external acoustic meatus is probably a channel related to the retroarticular system of veins.
}

pendent ossification, ${ }^{4}$ Roth (1903: 17) invited much later confusion by asserting that, at least in notoungulates, his pars mastoidea was part of (?or incorporated) a distinct ossification that was separated from the squamosal proper by features that he named "sutura zygoma-serrialis" and "sutura squamoso-mastoidea (escamo-serrial)." Additionally, because Roth also claimed that additional sutures (e.g., "sutura mastoideopetrosa") separated the serrialis-mastoid from the petrosal, it followed that much of the dorsal sidewall of the notoungulate skull--including the epitympanic theca, roof of the external acoustic meatus, and nearby processes-had to be formed by this unusual element, homologous in his view with the prosquamosal (= supratemporal) of anomodontian therapsids (fig. 2).

Roth's claim to have discovered an element heretofore undetected in the mammalian cranium was a major challenge to conventional morphological thinking, and it did not go unchallenged. To be sure, some investigators working on notoungulates in the early part of the last century, such as Sinclair (1909), Scott (1912a, 1912b), and Patterson (1932, 1936), accepted one or another of Roth's claims, albeit with reservations. Sinclair (1909: 71), for example, thought he had found one of Roth's "extra" sutures in a

${ }^{4}$ Roth (1903) obviously thought (incorrectly) that the mastoid ossification center for the petrosal, as found in humans, represented an element that was originally independent but later suppressed in the course of evolution. In a further terminological complication, Roth (1903) called the caudalmost portion of the notoungulate petrosal the "protuberancia petrosa" rather than "the mastoid," as would have been ordinarily done at this time in (for example) large-animal veterinary anatomy texts (e.g., Sisson, 1911). The unusual term "serrialis" is based on an eponym (see Simpson, 1936) and to my knowledge has never been discussed outside of notoungulate studies.

acoustic meatus; oc, occipital; pa, parietal; pae, porus acusticus externus; pe, petrosal (periotic); pet, squamosal theca (pars epitympanica of squamosal); ppg, retroarticular process (postglenoid process); ppo, paroccipital process; ppt, posttympanic process; ret, epitympanic recess; set, epitympanic sinus; sg, mandibular fossa (glenoid surface); sq, squamosal; svpl, posterolateral venous sinus; ty, ectotympanic (tympanic); vph, hyoid recess (vagina processus hyoidei); Xa, element Xa (anterior adventitious element); $\mathbf{X p}$, element Xp (posterior adventitious element). 


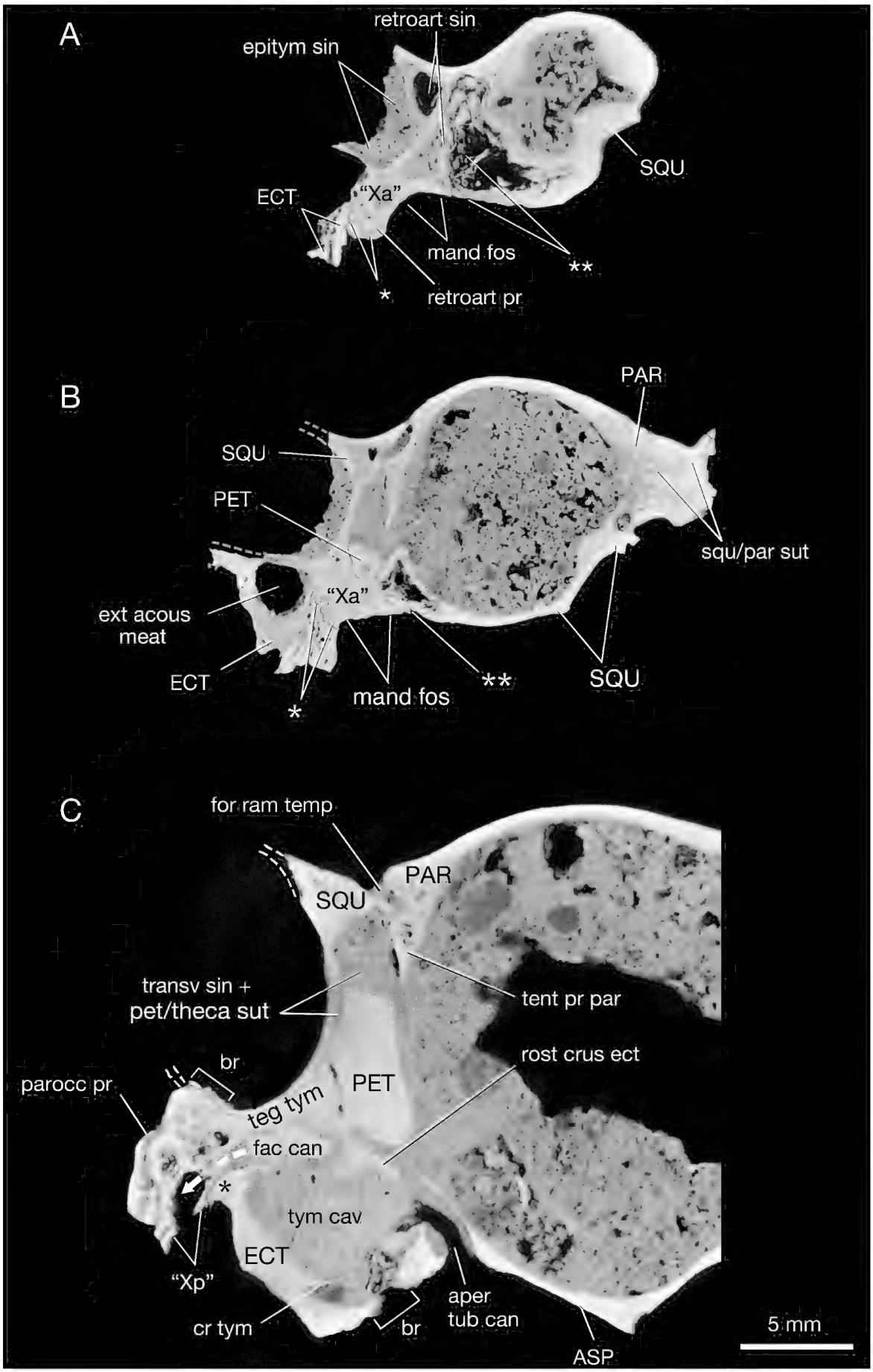

FIG. 6. Oldfieldthomasia cf. debilitata AMNH-VP 28600, left hemicranium, virtual parasagittal sections (for approximate locations see fig. 1A); rostral to right. All to scale in C. A and $\mathbf{B}$, sections through lateral cranial wall and external acoustic meatus: single white asterisk, definite suture between rostral crus of ectotympanic and alleged element Xa; double white asterisks, fracture zone (not a suture) passing through mandibular 
specimen of Hegetotherium, and also noted that in Pachyrukhos "the greatly distended mastoid bulla[e] .... show but slight contact with the squamosal," thereby implying that the epitympanic thecae were largely enclosed by petrotympanic material, if not the serrialis per se. Scott (1912b) was more dubious, although he utilized the term "pars serrialis" (but "of the squamosal," he insisted, not "of the mastoid," as Roth had asserted). Patterson (1932: 18-19) also spoke uncertainly of "the pars serrialis of the squamosal, that bone having retained the sutures [sic] between its three centers of ossification in some of his [i.e., Roth's] specimens. Between this pars serrialis and the mastoid Roth never made a clear distinction." Patterson kept looking for evidence, however (e.g., Riggs and Paterson, 1935: 190), concluding in the case of one aged specimen of the isotemnid toxodontian Pleurostylodon (E. Eoc.) that, despite the absence of any traces whatsoever, "[adventitious] elements may be present."

Simpson (1936: 9) was more definitive in his assessment:

Apparently he [Roth] only believed himself actually to have observed this suture in two cases, and these are open to question, since there is a strong possibility that the supposed suture is merely a crack. As far as I know, no subsequent student has recorded a suture in this region.... Without denying the possibility of sutural separation, it is fair to say that none is demonstrated and the epitympanic wall may at least provisionally be considered as a part of the squamosal, for which I propose the name pars epitympanica.

For Simpson (1936: 8)—and, given his influence, for virtually every subsequent student of the notoungulate cranium-the only plausible conclusion was that "the epitympanic sinus is not in the mastoid but in part of the squamosal."

The two specimens to which Simpson (1936) referred in this quotation were not further identified; however, the examples reproduced in figures 2-4 are ones for which Roth specifically identified bounding sutures (Toxodon, Pachyrukhos) or the position of the serrialis (Nesodon). With regard to Toxodon, Roth must have investigated material in which sutural markings were (for that genus) remarkably clear, because basicranial sutures on most toxodontian skulls tend to be obliterated, or at least difficult to trace, even in the rare event that the skull itself is well preserved (cf. van Kampen, 1905: 617; Patterson, 1932).

fossa, same as feature 3 in figure $1 \mathrm{~A}$. C, section through lateral portion of tympanic cavity, tegmen tympani: single black asterisk is adjacent to definite suture between caudal crus of ectotympanic and alleged element Xp; dashed white arrow extends from facial canal into aperture of stylomastoid foramen, to mimic route of cranial nerve VII; narrow dashed lines suggest trend of thecal walls, very little of which is left. All other discontinuities are interpretable as fractures. As is evident, this side of the skull of AMNH-VP 28600 is in worse condition than the side that Simpson (1936) prepared. Although Simpson stated that he could detect sutures that completely, or almost completely, delimited his elements Xa and Xp from surrounding bones, he failed to adequately label these sutures on section drawings. In this figure, the labels "Xa" and "Xp" are placed approximately where Simpson situated them in his published drawings. Ignoring fractures, the area of $\mathrm{Xa}$ is seen to be completely continuous with the preotic or retroarticular portion of the squamosal, of which it must be considered an inherent part. Because of breakage, the precise relationships of Xp and the petrosal tegmen tympani, caudal crus of the ectotympanic, and epitympanic theca are uncertain. The interpretation favored here is that Xp is indistinguishable from (the rest of) the retrotympanic process and is therefore mostly or entirely squamosal. Note that, as Simpson delimited it, $\mathrm{Xp}$ is not much more than a bony conduit for the transiting facial nerve. Perhaps differences in bone density in this area contributed to Simpson's belief that an independent element was present (see fig. 20). He was, however, correct in concluding that the epitympanic theca is mostly formed by the squamosal. The condition of the bulla in this specimen precludes identification of an entotympanic, if any, in Oldfieldthomasia. A few of the many broken (br) areas are specially noted. 
By contrast, Paedotherium and its close relative Pachyrukhos are excellent candidates for the present investigation. Key sutures on pachyrukhine caudal crania are easily discerned, as they evidently remained open over the entire life span, and both genera are well represented in major paleontological collections. Indeed, it is to conditions in pachyrukhines rather than Oldfieldthomasia that Simpson (1936) should have turned when undertaking his investigation of cranial composition in notoungulates, as they unquestionably possess the most derived squamosal seen in this group. If their thecal composition is nevertheless closely comparable to that of the other notoungulates examined here, as I maintain, then it is extremely unlikely that other, unstudied taxa will radically differ.

\section{Paedotherium}

Despite the derived nature of Pachyrukhinae, the three specimens (AMNH-VP 45914, MLP 52-IX-28-29, and MLP unnumbered2) on which this section is chiefly based provide excellent insights into the morphology of the hegetotherioid caudal cranium. As in the case of the other specimens reviewed in this paper, all are fully adult.

The existence of unexpected elements cannot be discounted merely because their distinctiveness is hard to establish in the adult stage. This is particularly important to emphasize in the case of pachyrukhines, because in these hegetotherioids conditions are complicated. At first glance the squamous portion of the squamosal appears to be reduced to an insignificant rod, the squamosal bar, and thus seems an unlikely source for the thecal covering. In fact, the rostral part of the squamosal is directly connected to the caudal cranium at only one place, the tiny area of continuity between the squamosal bar and the rostral thecal wall (fig. 8D). Sections support this impression (fig. 12A, C). Although frequently broken in specimens, this area of continuity is not the site of a detectable suture (fused or otherwise) and is no wider than the bar itself, i.e., $\sim 2 \mathrm{~mm}$. To explain how such remarkably derived conditions may nevertheless conform to those found in other notoungulates requires considerable morphological exploration and comparisons with other placentals with similarly modified squamosals, provided in the rest of this section.

Pachyrukhine notoungulates are chiefly famous for their remarkable morphological and presumed ecological convergence on certain members of Glires, particularly certain leporids and caviomorphs (Sinclair, 1909; Kraglievich, 1936; Scott, 1937; Cifelli, 1985; Dozo, 1996, 1997; Reguero et al., 2007). Leporid similarities are especially noteworthy and include such features as the long, narrow rostrum bearing lateral rarefactions, lengthy diastemata, markedly hypsodont/hypselodont cheek teeth, ever-growing incisors, voluminous orbits, basicranial kyphosis, persistent fontanelles or cranial hiatuses, deep mandibular ascending rami, highly reduced and barlike squamous portion of the squamosal, and possible leaping adaptations (Sinclair, 1909; Scott, 1937; Cerdeño and Bond, 1998; Cassini et al., 2010).

A previously unexplored example of leporid/ pachyrukhine convergence-the presence of a potential intracranial joint (ICJ)-has, on investigation, turned out to be basic to the proper interpretation of the pachyrukhine caudal cranium. The existence of an ICJ in certain lagomorphs (e.g., jackrabbit, Lepus californicus) was first hypothesized by Bramble (1989), who pointed out that, in the midcranial area, a complex of aligned sutural and synchondrosial dense connective tissues intervenes between bone territories in such a way that bone-on-bone contact within the joint is minimized. Providing a kind of syndesmotic "O-ring" of soft tissues, this arrangement divides the skull into two functional moieties: the rostral, comprising all the elements lying in advance of a semicoronal plane through the sphenooccipital synchondrosis, and the caudal, comprising the rear part of the cranium together with the auditory regions. In $L$. californicus there is probably very little actual movement at the ICJ; its actual purpose, as 


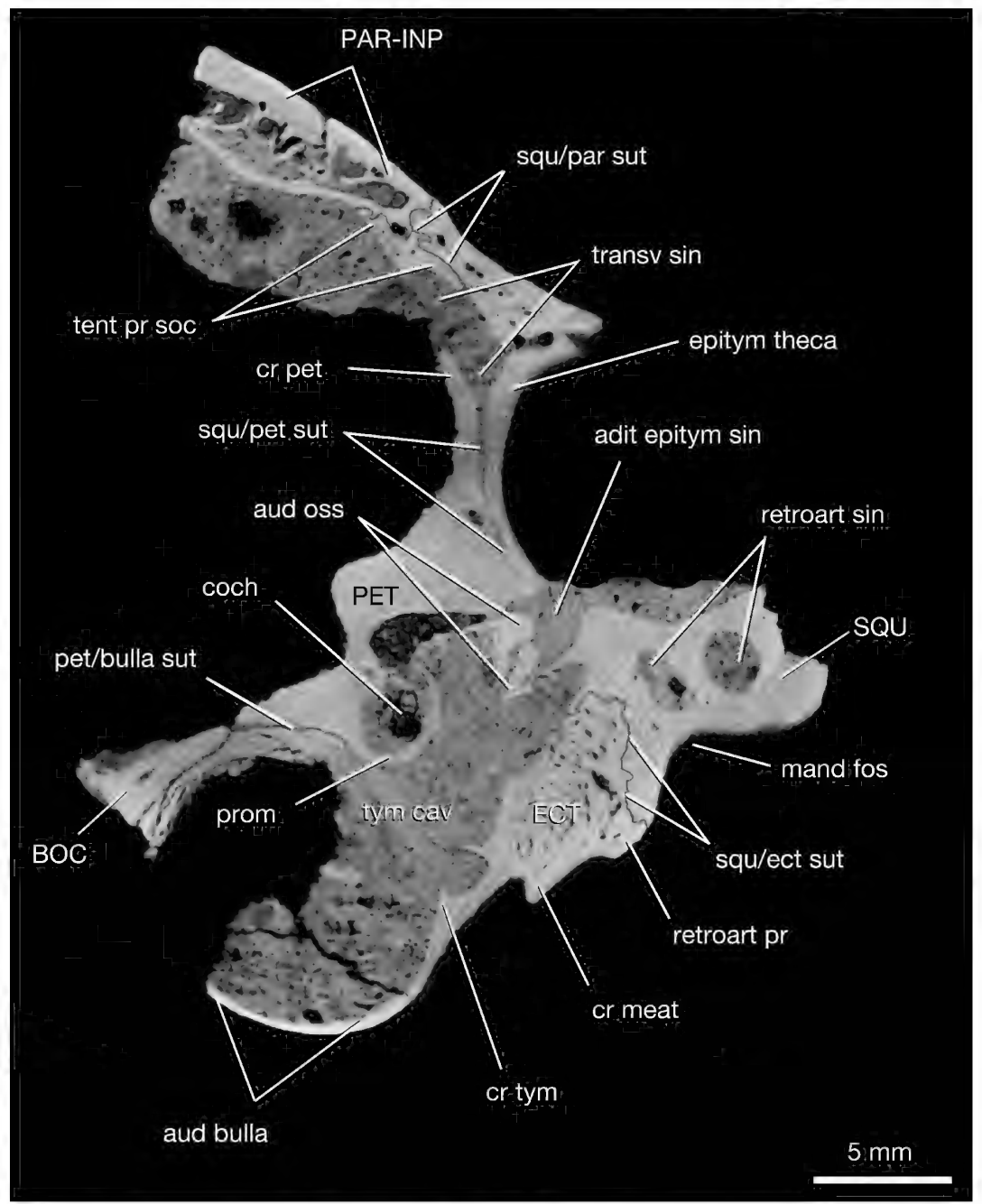

FIG. 7. Oldfieldthomasia cf. debilitata AMNH-VP 28600, left hemicranium, virtual coronal section; for approximate location see figure $1 \mathrm{~B}$; lateral to right. In this section, the only suture found on preserved part of lateral wall of auditory region is the squamoso-ectotympanic suture; retroarticular process formed jointly by squamosal and ectotympanic, with no evidence of additional element Xa. Petrosal material contributes modestly to medial margin of aditus to epitympanic sinus and therefore to thecal wall. Matrix (see fig. 1) filling epitympanic sinus has been partially removed to facilitate labeling. Auditory ossicles-fragments of malleus and incus-are out of position in aditus to epitympanic sinus.

inferred by Bramble (1989), is to act as part of a shock-absorbing apparatus to prevent deformation of the orbits (and therefore visual impairment) during the strike phase of ballistic leaping (see also Stott et al., 2010). On the other hand, short-limbed, nonleaping Ochotona has some of the osteological correlates noted above for Lepus in even more exaggerated form (see Wible, 2007), but with much larger paratympanic spaces, suggesting isolation of the auditory apparatus may also be significant for other reasons as well.

Regardless of putative ICJ function, the alignment of relevant sutures, synchondroses, and hiatuses in pachyrukhines is certainly similar 

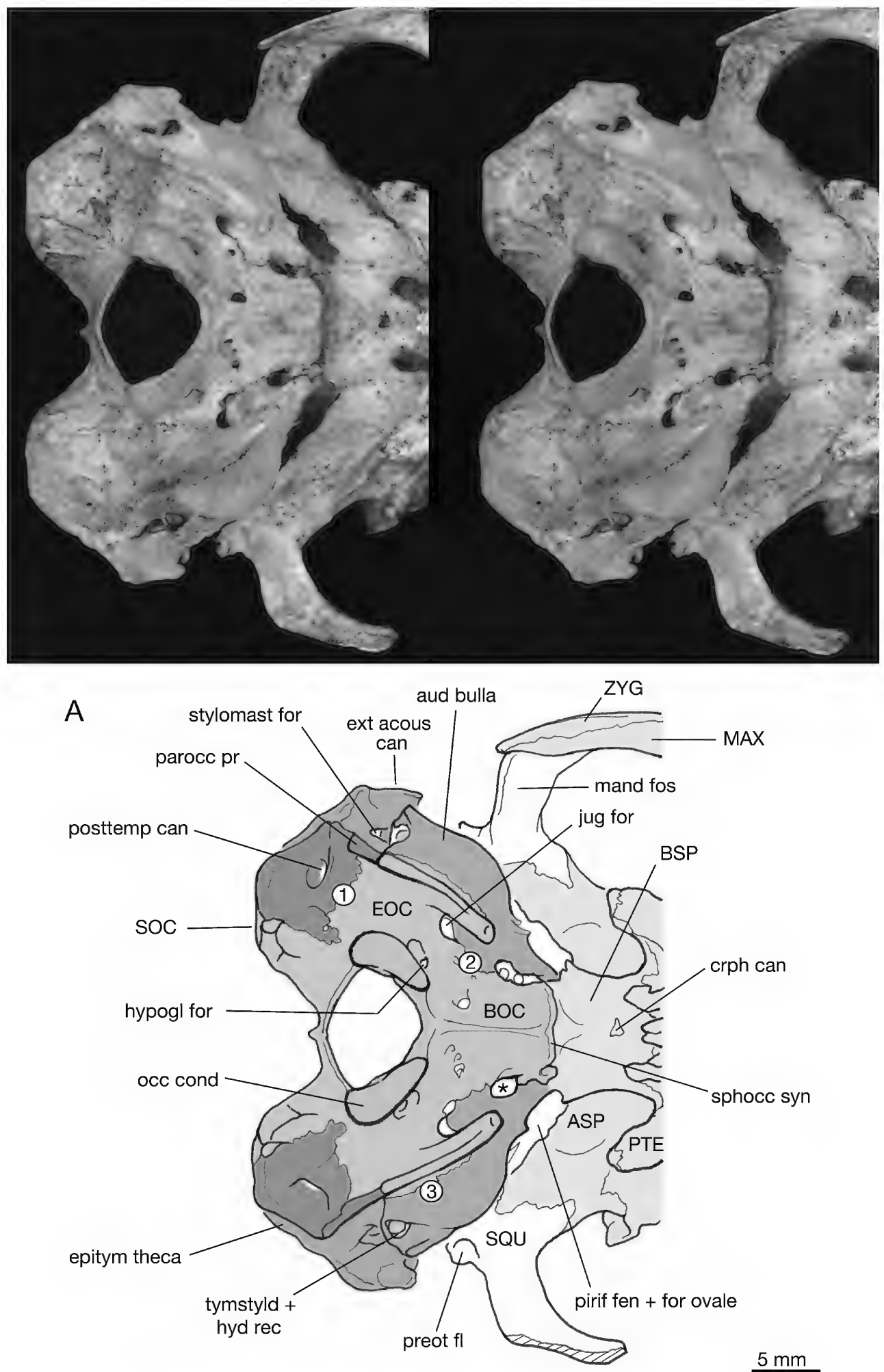


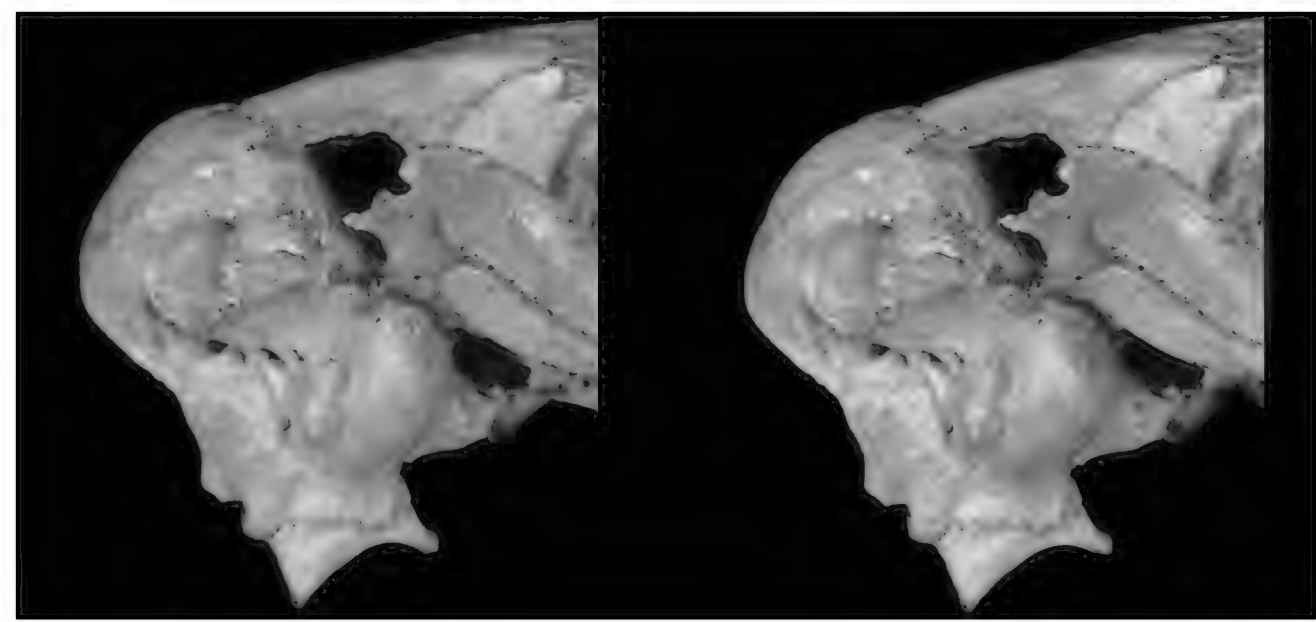

B

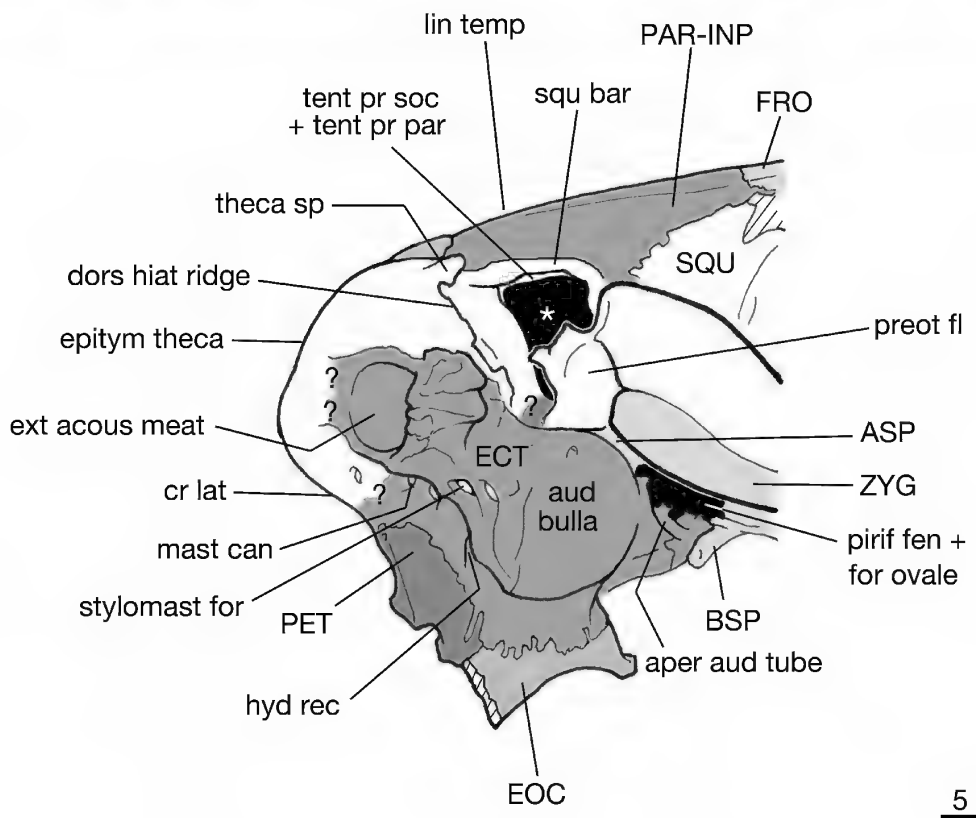

$5 \mathrm{~mm}$

FIG. 8. Paedotherium sp. AMNH-VP 45914, stereopair views of caudal cranium (with keys) in ventral (A), right lateral (B), right caudal (C), and dorsal (D) aspects, on this and subsequent pages. All to scale in A. In key diagrams, squamosal (including external aspect of epitympanic theca) is white; other elements colored differing shades of gray. Question marks indicate indistinct or inferred borders between squamosal theca and some other element; hachure indicates major breakage. Delicate ventrocaudal extremity of paroccipital process is usually broken off in pachyrukhine skulls (see Sinclair, 1909: pl. X, text-fig. 4). Key to A: 1, petroso-exoccipital suture; 2 , basioccipito-bullar suture; 3, exoccipito-bullar suture (on paroccipital process); asterisk lies in foramen sometimes identified as "foramen lacerum medium" or "carotid canal" in notoungulate studies (but see Gabbert, 2004). Note small, cylindrical tympanostyloids situated within hyoid recesses. Unidentified large basioccipital foramina (multiple on specimen's left side) lying close to the midline are likely venous ports. Key to B: asterisk in dorsal midcranial hiatus. Klinocrany is obvious in this aspect; compare less derived Cochilius (fig. 13B). Note within dorsal hiatus the slight exposure of petrosal (question mark) and tentorial processes of supraoccipital and parietal. Key to C: 1, supraoccipito-thecal suture; 2, petroso-exoccipital suture. 


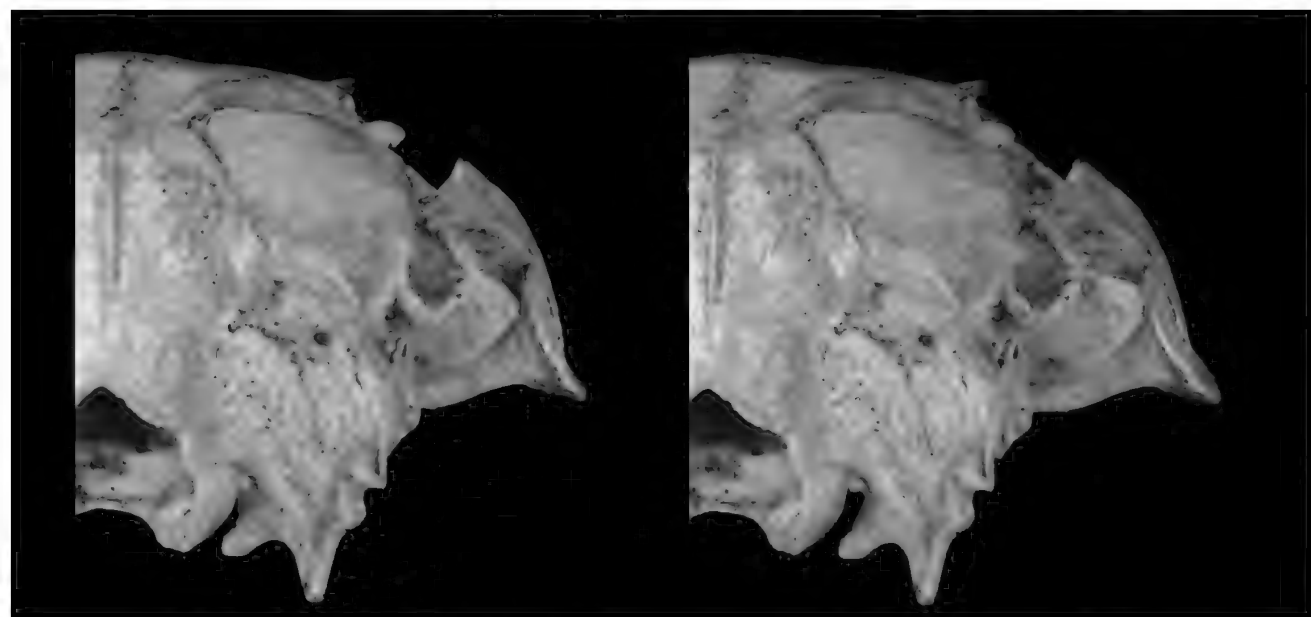

C

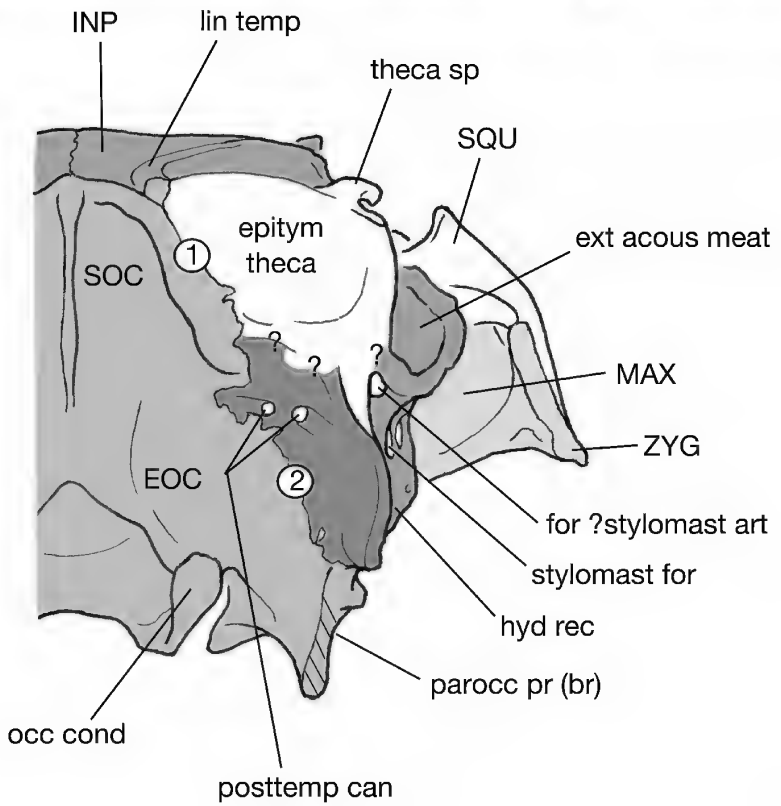

$5 \mathrm{~mm}$

FIG. 8. (Continued.) Precise positions of sutures on caudal aspect of skull notably vary among Paedotherium specimens because overgrowths (alae) from surrounding elements may develop in such a way that they produce internal or self-sutures, thereby falsely suggesting presence of separate elements (e.g., "mastoideo-posttympanic suture" between theca and petrosal in Hegetotherium mirabile AMNH-VP 9223; Sinclair [1909: 71, text-fig. 14]). In this specimen, probable position of lines of fusion among elements indicated by question marks. Externally, aperture of posttemporal canal actually lies at junction of three bone territories (petrosal, squamosal, and exoccipital), but how the aperture is framed in the adult varies. Petrosal also produces alae, which may overgrow the posttemporal dehiscence in such a way that in some specimens (as here) the aperture appears to be wholly encased by petrosal material. In pachyrukhines the paroccipital process is a broad flange that incorporates not only exoccipital material but also ectotympanic and petrosal. Size of individual contributions also varies (cf. figs. 9B, 12F, G). In AMNH-VP 45914, both ectotympanic and petrosal appear on lateral side. As usual there is no sutural or other identifiable boundary between supraoccipital and exoccipital. Key to D: 1, supraoccipito-thecal suture; 2, parieto-thecal suture (along squamosal bar); asterisk, ?lateral interparietal (see text). 

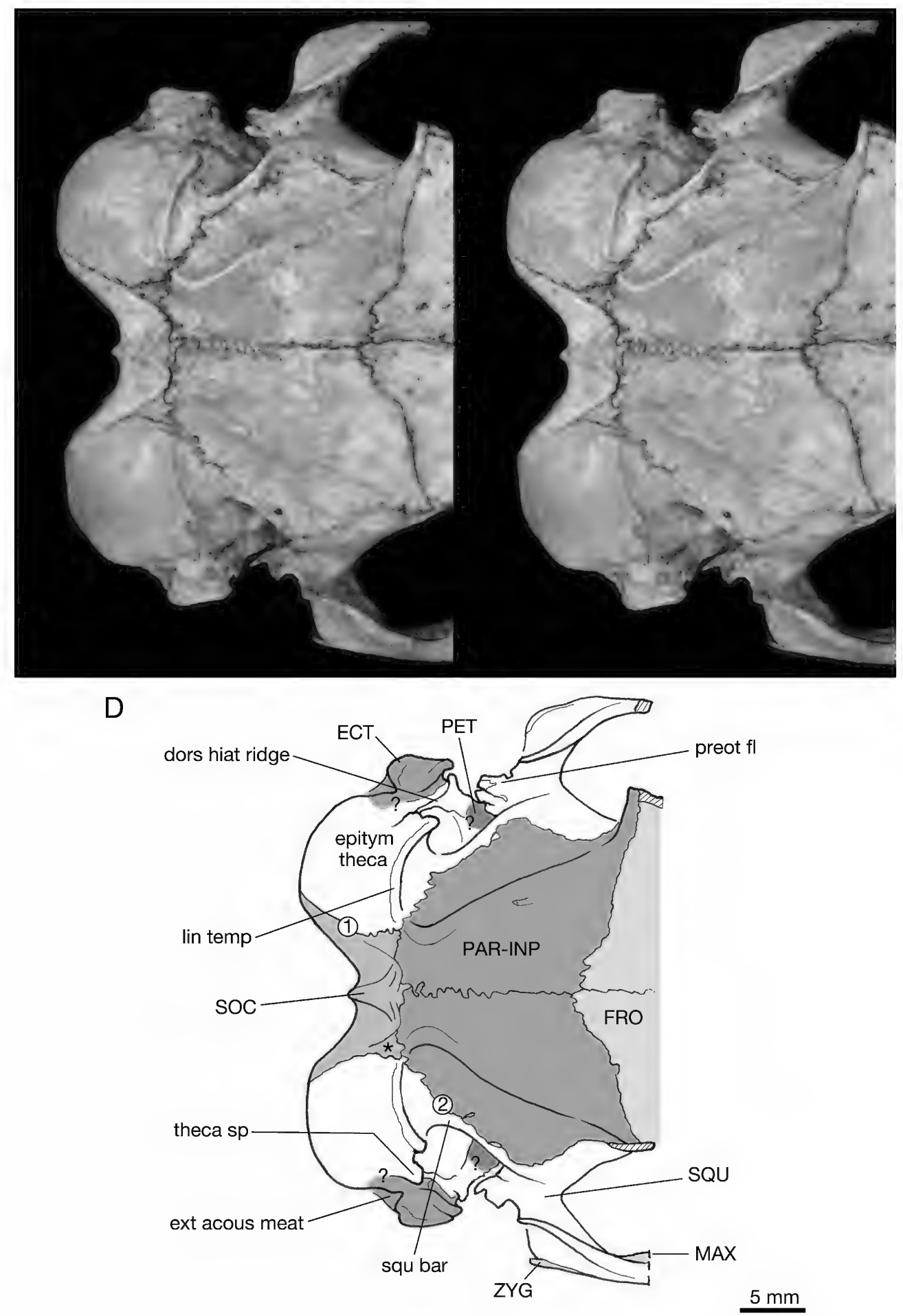


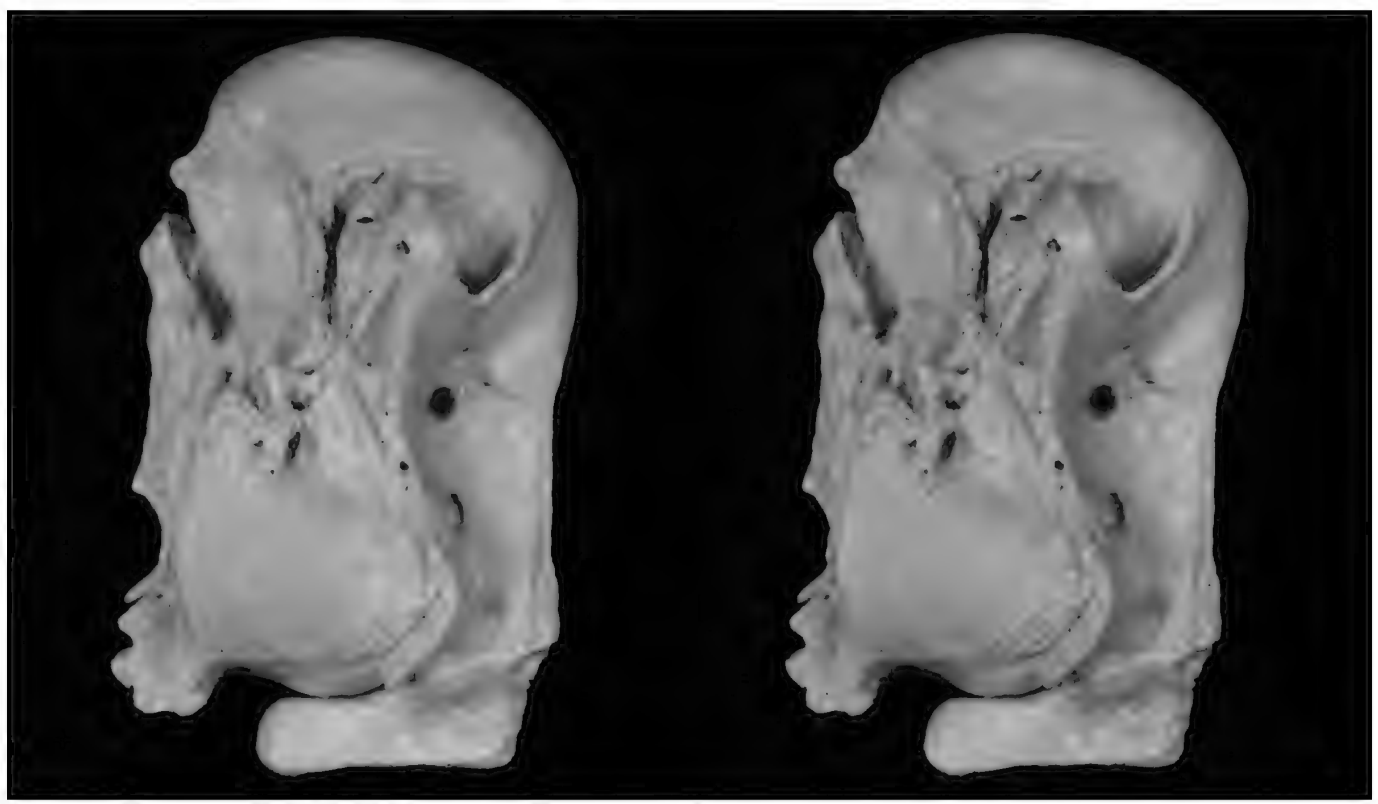

A

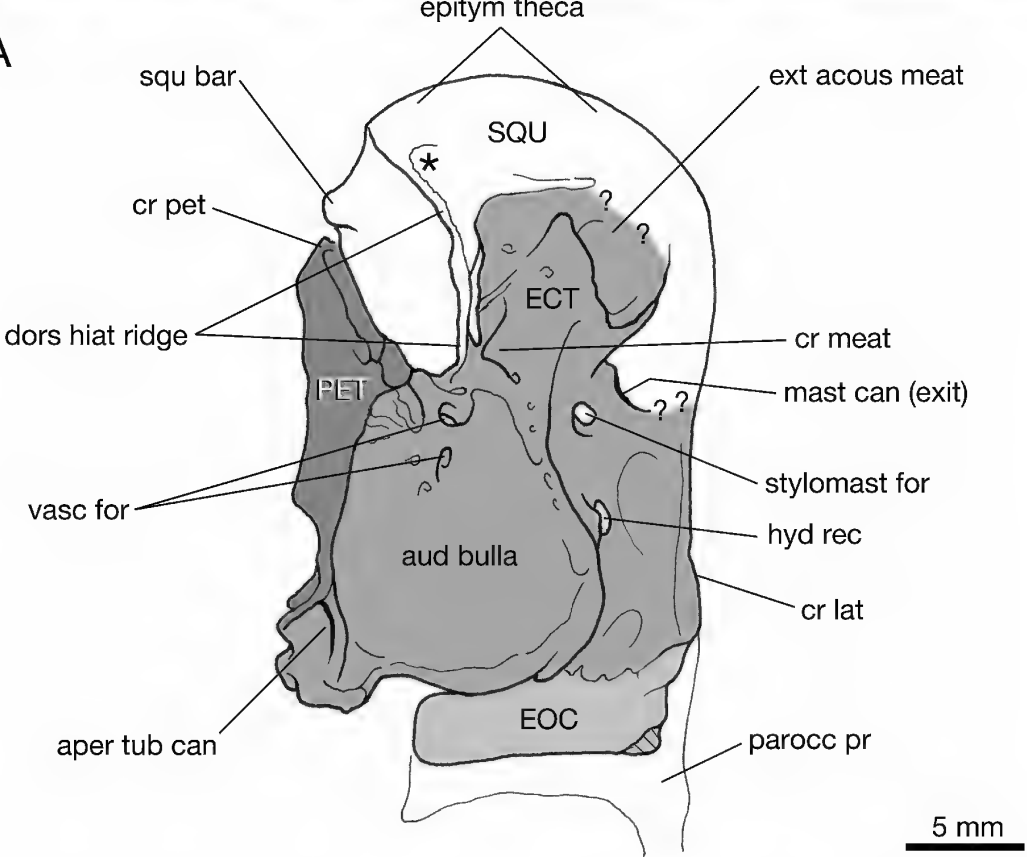

FIG. 9. Paedotherium MLP unnumbered2, stereopair views of isolated left auditory region (with keys) in lateral (A) and medial (B) aspects. Both to scale in A. Shading convention as in figure 8. Specimen not in life position (see fig. $8 \mathrm{~B}$ for proper orientation). This specimen, evidently adult, is relatively complete except for loss of thecal spine (single asterisk in A) and damage to exoccipital. Many features can be identified that are otherwise very difficult to see in intact skulls. Sutural divisions can be detected where expected in most areas; however, squamosal and ectotympanic are smoothly continuous (probable position of boundary indicated by question marks). Ectotympanic probably forms most or all of meatal roof; entotympanic participation has not 

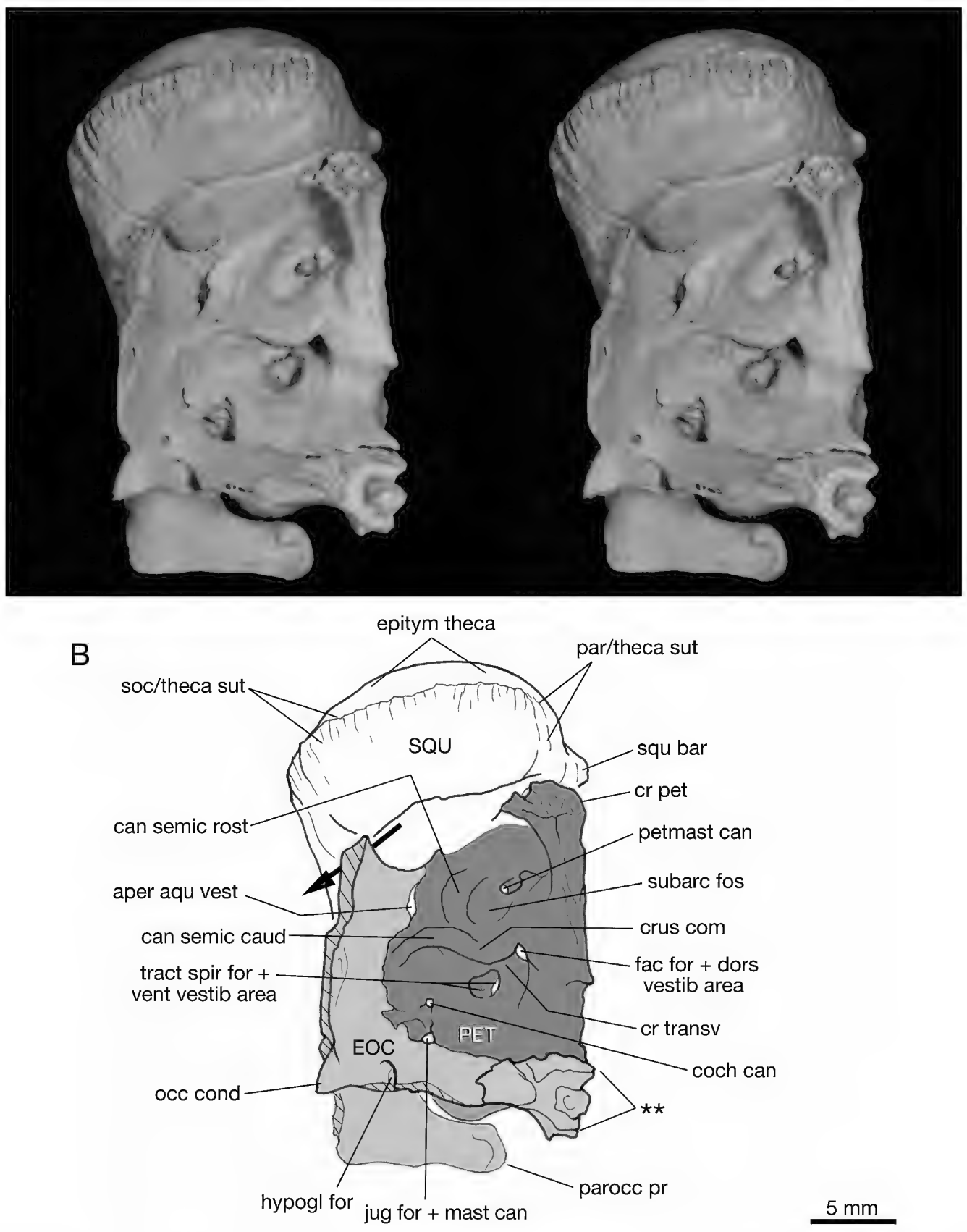

$5 \mathrm{~mm}$

been confirmed in pachyrukhine bullae and is thus omitted (see text). Paroccipital process is largely missing; reconstructed outline based on AMNH-VP 45914 (fig. 8B; note differences in position of petrotympanoexoccipital suture in these two specimens). The numerous vascular foramina punctuating dorsal part of auditory bulla are of uncertain homology. In B, double asterisks identify major vascular grooves. Note rugose sutural surfaces for supraoccipital and parietal on medial aspect of theca. Large black arrow is situated in transverse dehiscence between tentorium and medial thecal wall, connecting transverse sulcus with posttemporal canal (not preserved). Note large, pillarlike petrosal crest, which contributes to tentorium. 

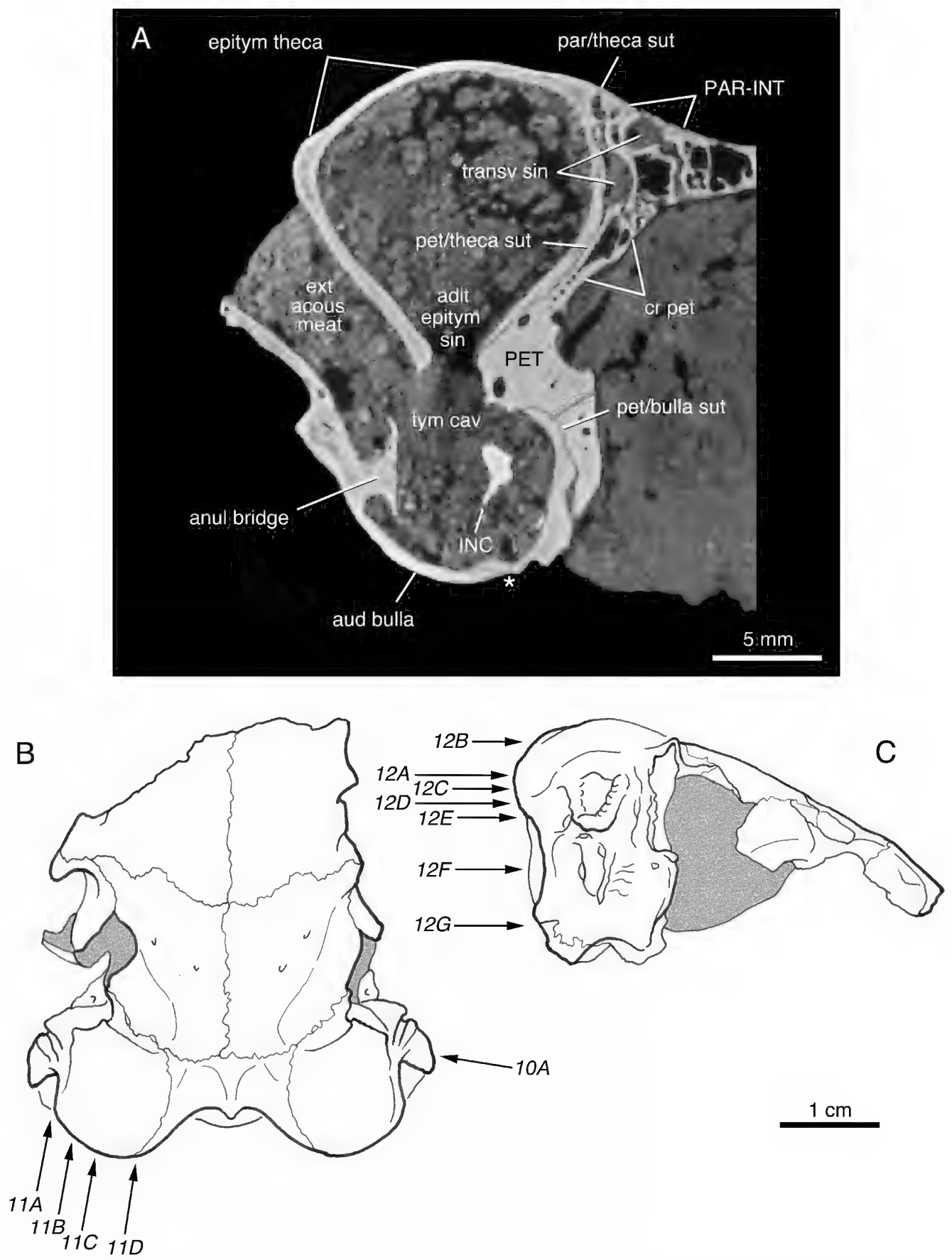

FIG. 10. Paedotherium sp. MLP 52-IX-28-29. A is virtual coronal section through external auditory canal, medial to right. $\mathbf{B}$ and $\mathbf{C}$ locate planes of sectioning for sections illustrated in figures 10-12 (exposed matrix colored gray). On skulls, ectotympanic material appears to contribute to dorsal wall of external acoustic meatus, although no suture between ectotympanic and squamosal theca can be identified in adult and actual situation therefore uncertain. Note incus (out of position) and prominent anular bridge. Asterisk $\left(^{*}\right)$ below bulla indicates fracture (not ectotympano-entotympanic suture). 
enough to their leporid counterparts to make comparison worthwhile (cf. figs. 8-9 and fig. 18). Sutures concerns us first. Immediately subjacent to the mandibular fossa the squamosal and alisphenoid form a delicate preotic flange of bone (not to be confused with the preotic crest, a quite different feature found in some placentals; MacPhee, 1981). In well-preserved Paedotherium fossils this flange touches, but is not fused to, the surface of the auditory bulla. (The flange in the specimen depicted in figure $8 \mathrm{~B}$ is somewhat damaged.) Although it barely qualifies as such, topologically the contact between flange and bulla can be described as comprising the glaserian fissure in this taxon. Termination of the preotic part of the squamosal at the glaserian fissure would normally mean that the squamosal does not contribute to structures lying directly caudal to this point, such as the epitympanic theca.

In pachyrukhines the epitympanic sinus is so large that it bulges caudally as well as dorsally, and this has several morphological consequences. Virtual sections and microscopic examination of specimens establish that no bones other than the squamosal and petrotympanic directly face onto the airspace within the theca. However, the sutural picture is made complex by the growth of wings or alae from various elements that slightly overlap the swollen thecal walls as well as nearby structures (figs. 12B-E). This is particularly evident in the case of alae developed from the petrosal (or petrotympanic), producing a far greater caudal exposure of this element than is typical for notoungulates (cf. Cochilius, fig. 13; Billet, 2011).

On the dorsal aspect of the skull (fig. 8C, D), the theca enters into sutural relationships with the other bones in the caudal cranium (supraoccipital, parietal, and interparietal). As all relevant sutures are patent in the available material, it is certain that these other bones are separate from, and therefore do not contribute to, the thecal walls. Sutural contacts continue onto the caudal surface of the cranium, between the rear of the auditory region and divisions of the occipital (including the interparietal, which is partly fused to the supraoccipital; see Interparietal Complex). Endocranially (fig. 9B), the exoccipital is in lengthy sutural contact with the petrotympanic, and the medial and lateral ends of the tentorial process of the supraoccipital articulate with the petrosal crest (figs. 11D, 12C). All of these elements are firmly locked together but only weakly joined to the rest of the skull along the caudal perimeter of the ICJ.

Returning to the midcranial region, it may be noted that bone-to-bone contacts are interrupted by two lengthy gaps, denoted here as the piriform fenestra and the dorsal midcranial hiatus (fig. 8A, B). The mammalian piriform fenestra as defined by MacPhee (1981) is present in adult stages of many groups, although it varies greatly in size and conformation (Wible, 2007). In Paedotherium the outlet for the mandibular nerve (foramen ovale) is not separable osteologically from the larger piriform fenestra; this joint aperture is sometimes identified as the sphenotympanic fissure (Gabbert, 2004), but here their theoretically separate identities will be maintained. The fenestra is typically positioned, i.e., on the basicranial floor, lateral to the central stem and sandwiched between the auditory region caudally and preotic portions of the alisphenoid and squamosal rostrally.

The dorsal midcranial hiatus is the much larger vacuity situated on the dorsolateral aspect of the skull between the preotic flange and the squamosal bar (fig. 8B, D). Roth (1903) did not describe the hiatus as such, although it can be clearly made out in his illustration of the skull of Pachyrukhos (fig. 3). Significantly, he showed the hiatus as bounded dorsomedially by his "sutura squamoso-mastoidea," the existence of which comprises his principal evidence for inferring that another, nonsquamosal element must cover the epitympanic theca. Although Roth doubtless had several pachyrukhines to examine, the one depicted in his plate is misleading: as may be seen by comparing figures 3 and $8 \mathrm{D}$, the indicated suture is actually the one between the parietal and the theca, the squamosal bar having been lost in his specimen. (This may or may not 


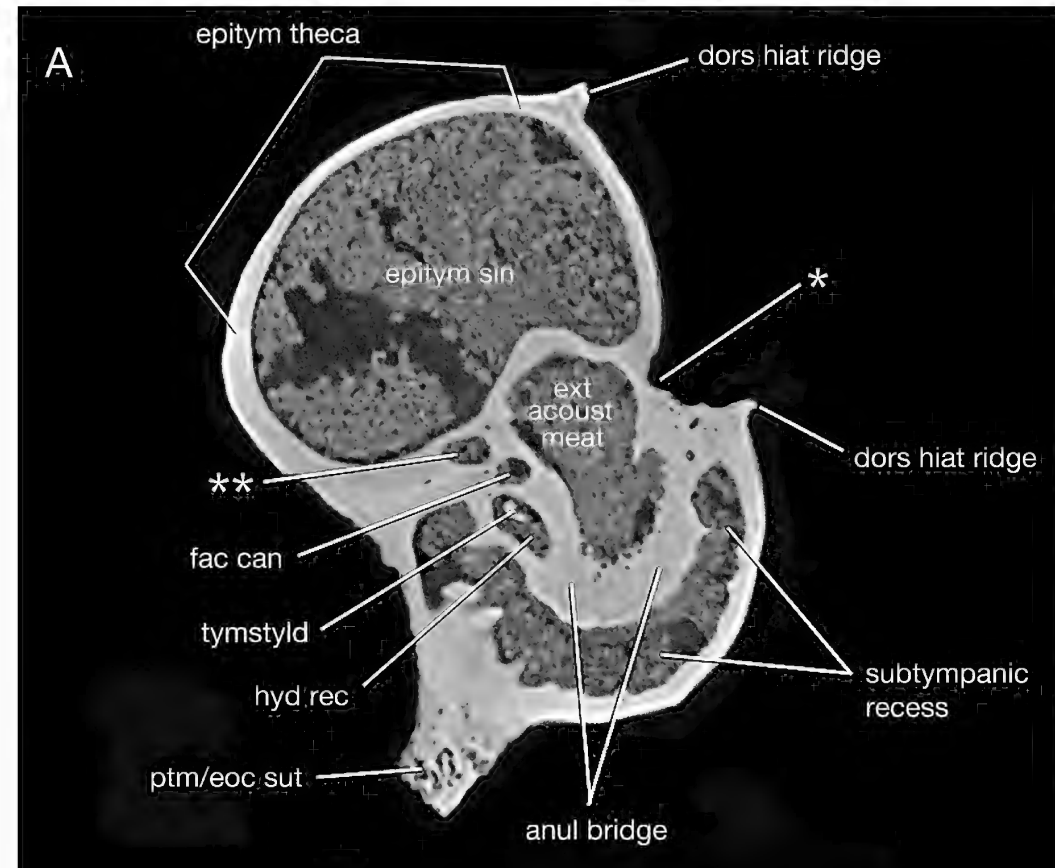

B epitym theca

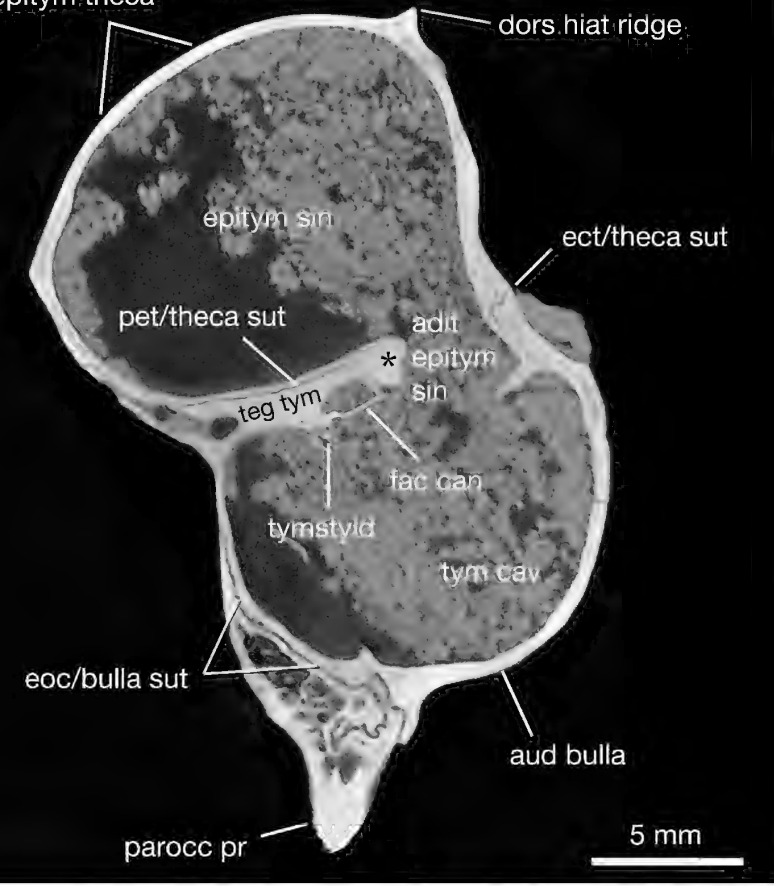

FIG. 11. Paedotherium sp. MLP 52-IX-28-29, four virtual parasagittal sections, left auditory region, rostral to right. All to scale in B. Sections are in lateromedial sequence, beginning with slice through external acoustic meatus and progressing through medialmost part of the tympanic cavity and bullar wall (see locator diagram, fig. 10B). In A, single white asterisk, sulcus for transverse sinus, grooving medial aspect of theca; double white asterisks, ?vascular conduit of uncertain homology, traveling within mastoid canaliculus. The dorsal hiatal 


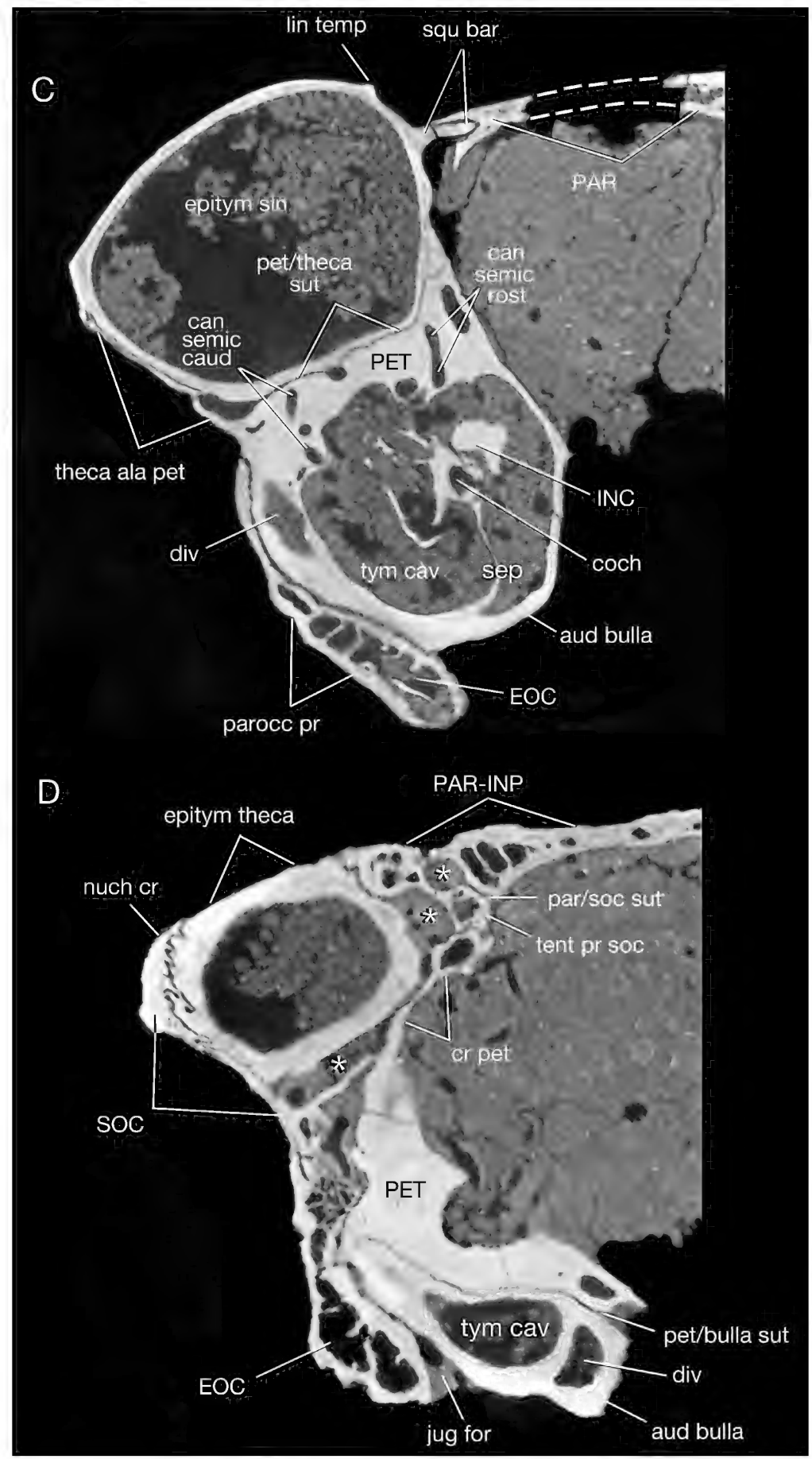

ridge appears twice in this section, curving across rostrolateral aspect of theca. In $\mathbf{B}$, single black asterisk identifies adital margin of tegmen tympani. Tympanostyloid has retained ontogenetic connection with tegmen tympani, despite sculpturing effects of massive middle ear pneumatization. In C, discontinuity seen in squamosal bar is a fracture, not a suture. Note small vertical septum running between tympanic floor and cochlear promontorium. In $\mathbf{D}$, white asterisks in transverse sinus and its tributaries. Note extensive fracturing of petrosal. 


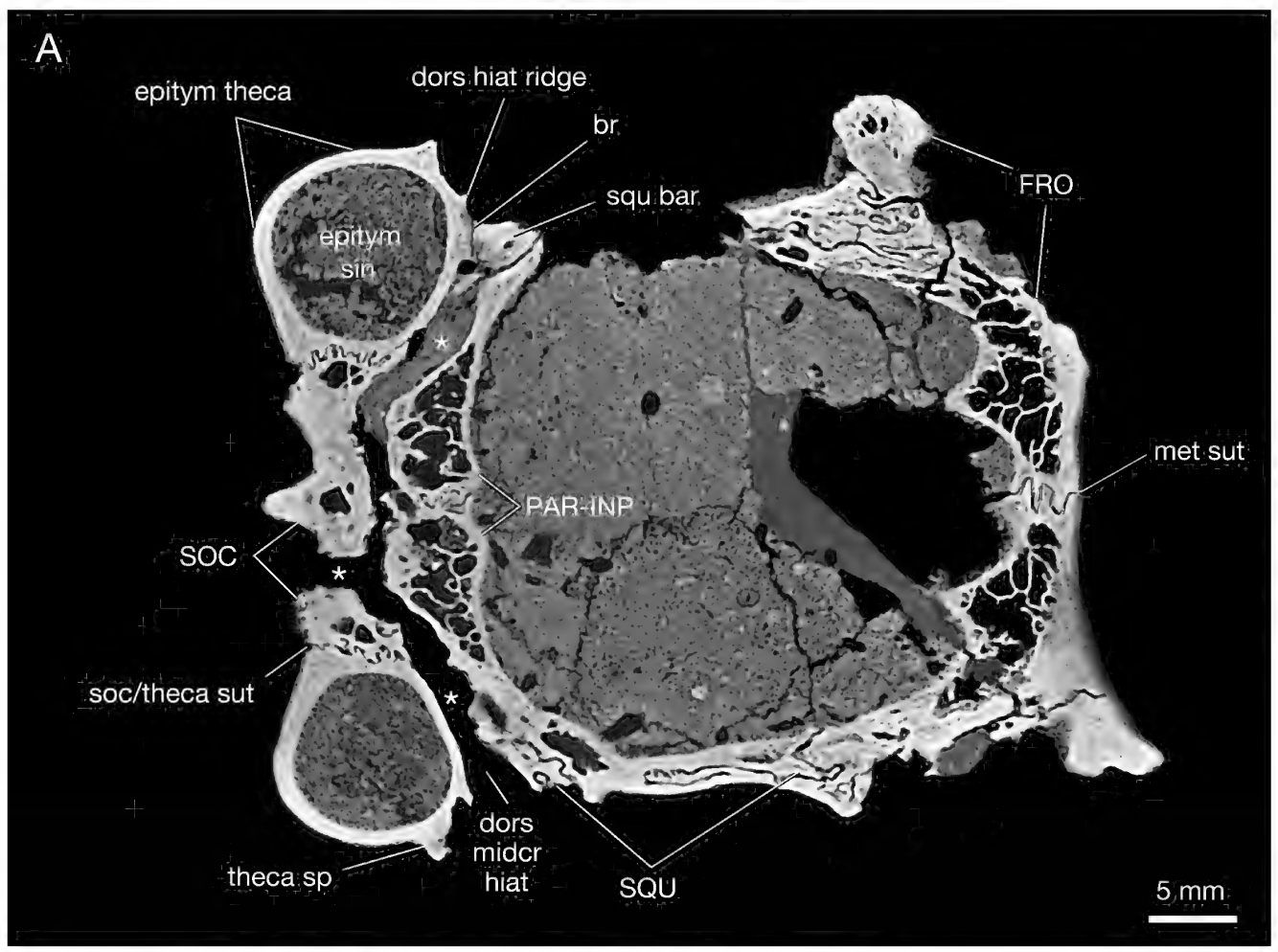

FIG. 12. Paedotherium sp. MLP 52-IX-28-29, seven virtual horizontal sections on this and subsequent pages, rostral to right. All to scale in A. For orientation, rostral portion of cranium is shown in A but cropped out in succeeding sections. In A, note continuity between transverse sulcus and posttemporal canal (white asterisks) and fracture (br, not a suture) passing through squamosal bar. Sections $\mathbf{B}-\mathbf{G}$ are in dorsoventral sequence, beginning with a plane passing slightly beneath cranial roof and progressing through occipital condyles. Contributions of major elements to tentorium osseum, thecal alae, and walls of the transverse sinus are easily distinguished. Note extensive caudolateral exposure of petrosal material, unusual in a notoungulate.

be the same specimen as the one figured by Lydekker [1893: pl. 1], who thought the squamosal bar was part of the parietal. Simpson (1936) probably could not have fathomed any of this from the accounts of these authors, and these misidentifications must have added to his overall frustration.)

Despite Roth's (1903) inadequate descriptions, it is important to consider whether the dorsal hiatus, given its very large size in pachyrukhines, might have held an element, or part of an element, during life. This possibility is nominally suggested by the presence of the low, rugose, dorsal hiatal ridge on the rostral surface of the thecal wall (figs. 8B, 9A). The ridge is denticulated like a typical cranial sutural margin, although less so than (for example) the suture formed between the theca and supraoccipital (figs. 9B, 11D). It runs in a tight, downturning arc from the position of (and in the same convex plane as) the squamosal bar and ends facing on (and in the same convex plane as) the preotic ends of the alisphenoid and squamosal. The fact that these features are oriented in such a specific way strongly implies that something stretched between them in life, thereby shutting off the dorsal hiatus. There are several possibilities:

1. Closure by bone originally present. There is no indication in any of the pachyrukhine skulls examined that an independent ossicle was ever 
B

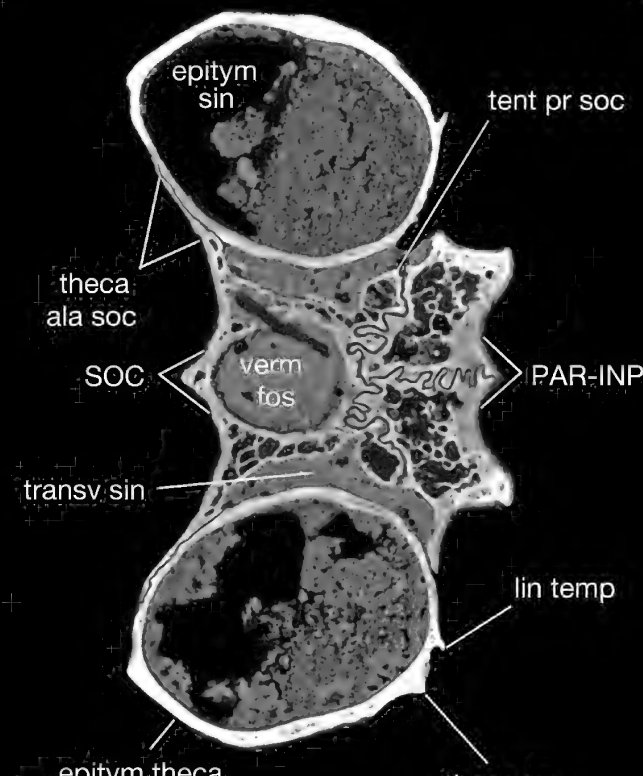

epitym theca

theca sp
C

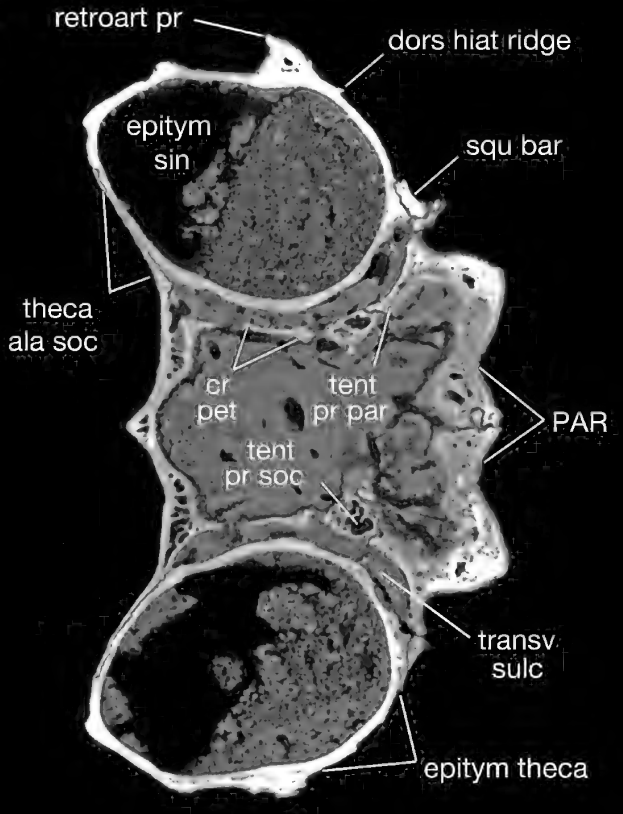

D

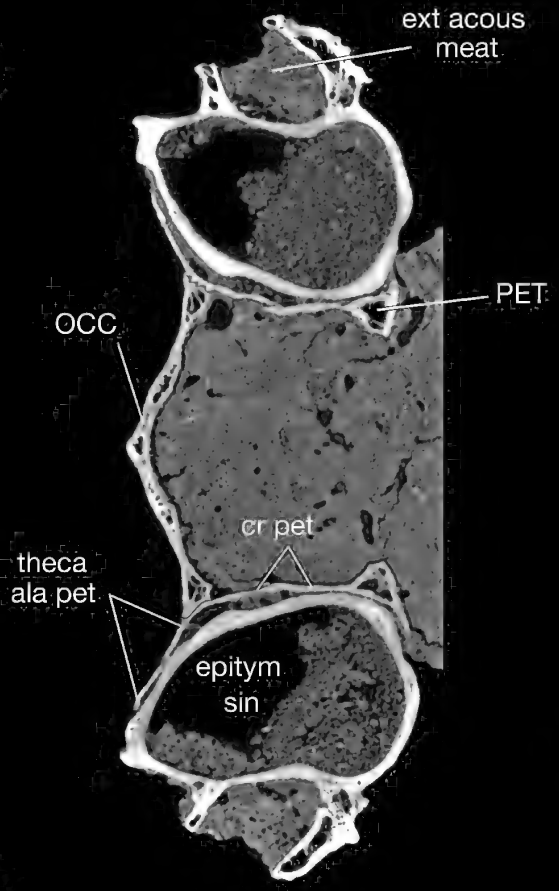

E

hyd rec + tymstyld

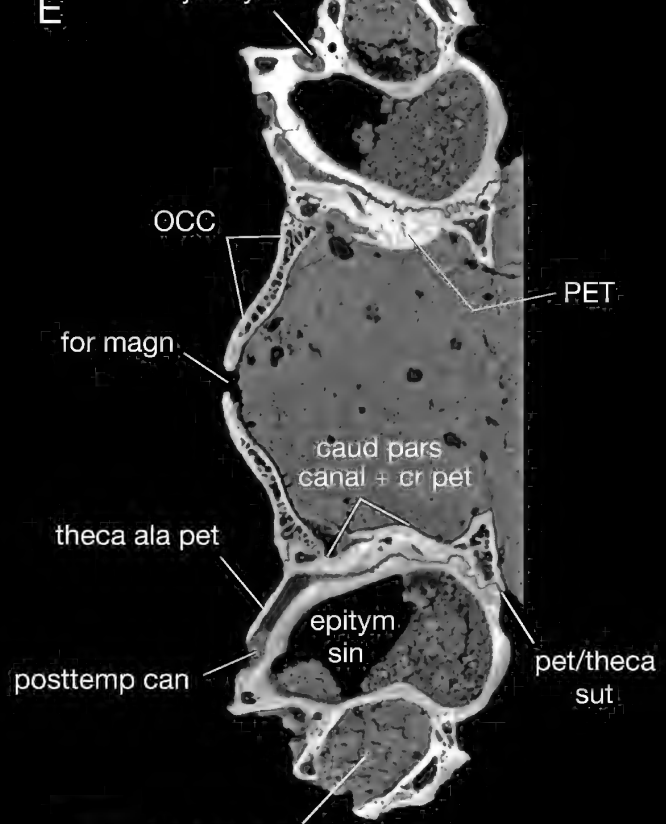

ext acous meat 


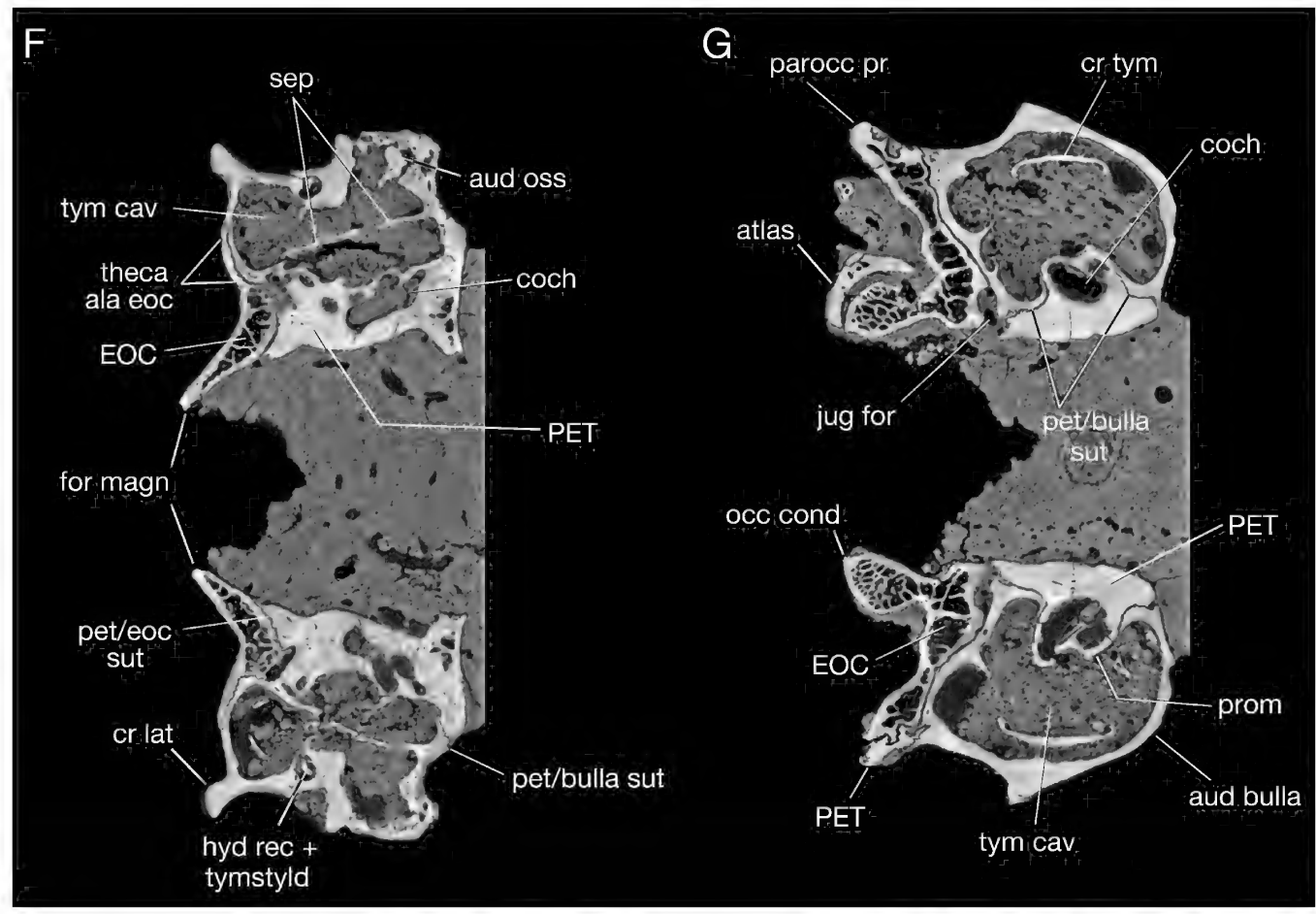

FIG. 12. (Continued.)

present in the space occupied by the midcranial hiatus, even though the caudal margin of the preotic flange is probably not entirely complete in any specimen examined. If during life the flange made contact with the ventral section of the hiatal ridge, the result would have been the closing off of a part, but certainly not all, of the hiatus.

In Lepus californicus the elongated caudoventral end of the interparietal projects under the squamosal bar and into the hiatus (fig. 18B), where it freely inserts between the squamosal and petrosal, effectively locking them together. Bramble (1989) called this projection the hiatal plate and interpreted it as another, albeit passive, component of the jackrabbit's ICJ: because it does not articulate suturally with the petrosal, it "does nothing to impede movement along the intracranial joint” (Bramble, 1989: 307). In wellpreserved pachyrukhine skulls the shelflike tentorial processes of the supraoccipital and parietal/ interparietal can be seen through the hiatal opening; they do not actually project into the latter, but do form a strong sutural bond with the petrosal crest in the tentorium osseum (figs. 11D, 12C). Rather than having anything to do with the hiatus as such, then, perhaps in both leporids and pachyrukhines the arrangement of these outgrowths acts to reinforce the bony framework of the caudal cranium. This interpretation does not, however, explain the presence or orientation of the organized array of bony edges and spicules that constitutes the dorsal hiatal ridge.

2. Undifferentiated dense connective tissue. Rather than by bone, the midcranial hiatus might have been closed by membrane, continuous with the primitive ectomeninx (cf. MacPhee, 1981). Such tissues cover the midcranial hiatus in leporids as well as the piriform fenestra in shrews and some other eulipotyphlans (Gasc, 1963; MacPhee, 1981; personal obs.). The appearance and radial disposition of the pachyrukhine dorsal hiatal 
ridge recalls the kind of marginal ectopic ossification that may occur at bony attachment points of dense connective tissues under significant, repeated stress. Muscle attachment to such tissues might produce sufficient stress to initiate the ossification of the latter; this is often a pathological process (Standring, 2009) but of course need not be (e.g., production of sagittal crest for temporalis $\mathrm{m}$.).

A feature of possible relevance in this regard is the stout projection (thecal spine) on the rostral thecal wall, situated in an exposed position just above the hiatal ridge (figs. $8 \mathrm{~B}-\mathrm{D}, 12 \mathrm{~A}$ ) and often damaged or broken in fossils (fig. 9A). The spine is in line with and appears to be functionally related to the linea temporalis for the origin of temporalis $\mathrm{m}$. Alternatively, it may have acted as an attachment for a well-developed pinnal extrinsic such as parietoauricularis $\mathrm{m}$. or its equivalent-an attractive argument if pachyrukhines possessed large, heavy external ears. The spine's prominence may have been due to the large number of muscle fibers arising from it, perhaps because there was insufficient area for a more rostral attachment. This might have been the case if the hiatus were exclusively covered by membrane.

3. Membranous port for blood vessels. In all notoungulates examined, the medial wall of the theca is deeply incised by the large sulcus for the transverse sinus (fig. 9B, 15B, 17C). This sinus and its various tributaries presumably drained to the jugular/occipital system of veins via several ports, including the posttemporal, jugular, and retroarticular foramina. In pachyrukhines, however, this last aperture is missing as such, because the preotic portion of the cranial wall is largely unossified. Apparently, the retroarticular sinus simply passed through the midcranial hiatus in order to join the jugular system, as suggested by the presence of truncated sulci that suddenly end on the immediately adjacent thecal wall. (Misinterpreting the relevant morphology, Sinclair [1909: 89] stated that he was unable to find a "postglenoid" foramen in Pachyrukhos, as all the skulls he examined displayed a "fracture" in the relevant area.) From one standpoint it could be said that pachyrukhines differed from other notoungulates in possessing a greatly enlarged, membranous retroarticular foramen (which may have carried an artery as well as a vein). However, hiatal width in pachyrukhines is surely much larger than any plausible diameter for transiting blood vessels, indicating that this cannot be the complete explanation for the gap's presence.

4. Rarefaction zone within the squamosal. Whatever the functional reasons for their appearance, the various fenestrations or rarefactions characteristic of leporid crania are not random in their disposition or patterning (Wible, 2007; Moss and Feliciano, 1977). This point applies not only to the specific elements affected, but also to features consistently lying within their territories (such as the large dorsal foramen consistently seen in the fenestrated nuchal area of Lepus californicus; fig. 18B). Fenestration in pachyrukhine cranial bones is more restrained, but it exists (see Sinclair, 1909: pl. X, fig. 1) and is likewise patterned. This raises the question whether the midcranial hiatus could be interpreted as a particularly large and continuous zone of orchestrated bone loss within the territory of the squamosal, without having to infer that its presence was due to the transmission of an outsized vessel. In this argument, absent the hiatus and with normal ossification patterns restored, the pachyrukhine cranial sidewall-including the epitympanic theca-would now be in seamless continuity with other squamosally derived material, just as in other notoungulates in which the hiatal opening is lacking. This explanation is attractive primarily because it solves the morphological paradox of inflating a large epitympanic sinus entirely from within the confines of a tiny bone territory (squamosal bar) situated far from the primordial location of the competent tissue apparently responsible for inducing middle ear expansion (epithelial lining of the developing cavum tympani; see Thompson and Tucker, 2013).

The first three interpretations of the morphological significance of the midcranial hiatus are 

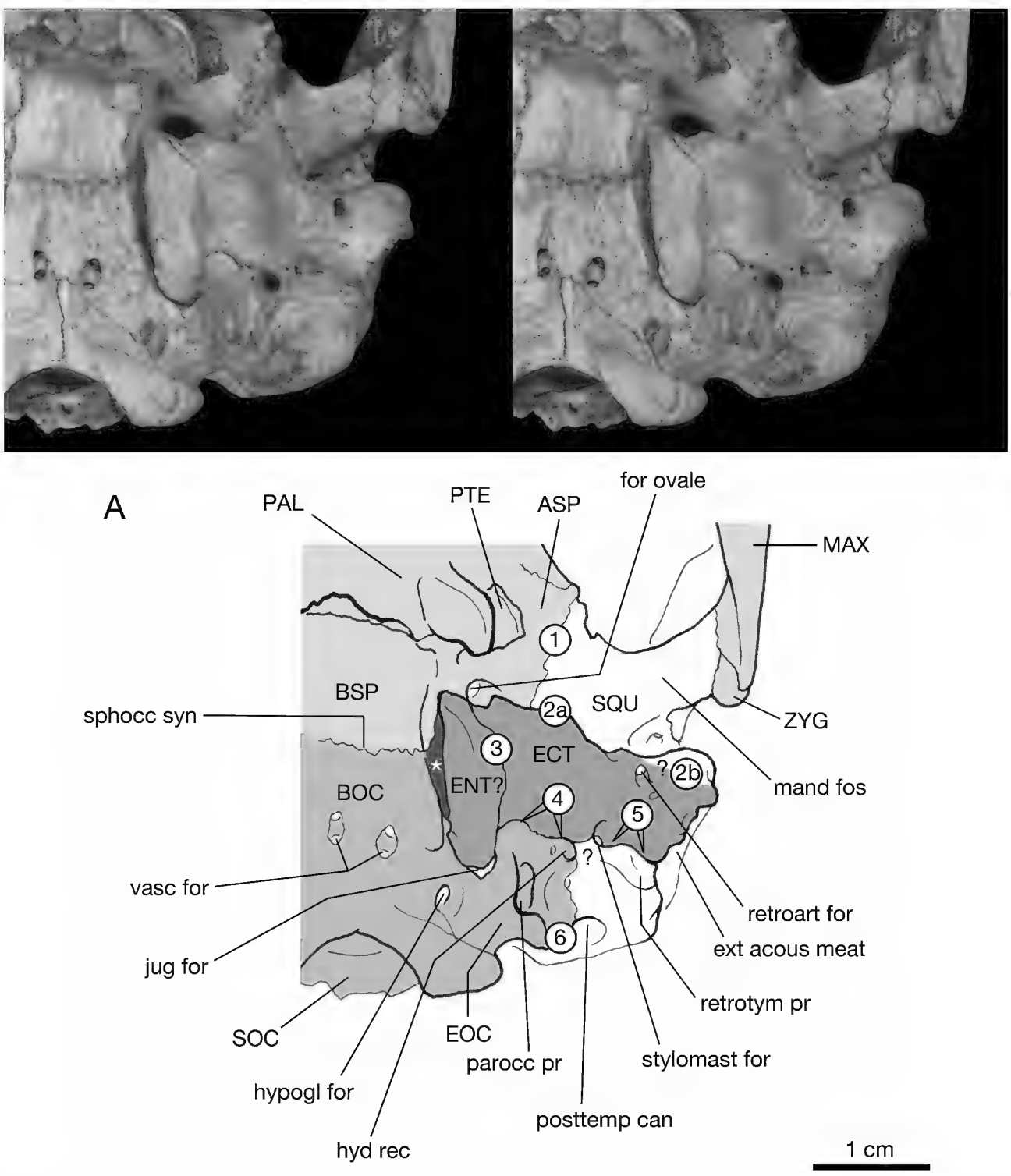

FIG. 13. Cochilius volens AMNH-VP 29651, stereopairs of left side of caudal cranium (with keys) in ventral (A), oblique ventrolateral (B), and dorsal (C) aspects, on this and subsequent pages. Shading convention as in fig. 8. Key to A and B: 1, squamoso-alisphenoid suture (preotic area); $\mathbf{2 a / 2} \mathbf{b}$, squamoso-ectotympanic suture (incl. glaserian fissure; question mark indicates boundary in meatal area uncertain); 3, putative ectotympano-entotympanic suture; $\mathbf{4}$, exoccipito-ectotympanic suture; 5 , petrotympano-squamosal suture (question mark indicates uncertain boundary); 6, squamoso-exoccipital suture (on paroccipital process). Key to C: 1, squamoso-parietal suture; 2 , inferred squamoso-interparietal suture; 3 , speculative reconstruction of parieto-interparietal suture (externally obliterated, actual confirmation unknown); 4, supraoccipito-(inter)parietal suture; 5, squamoso-zygomatic suture. In A, petrosal (asterisk) slightly exposed in basicapsular fissure due to 

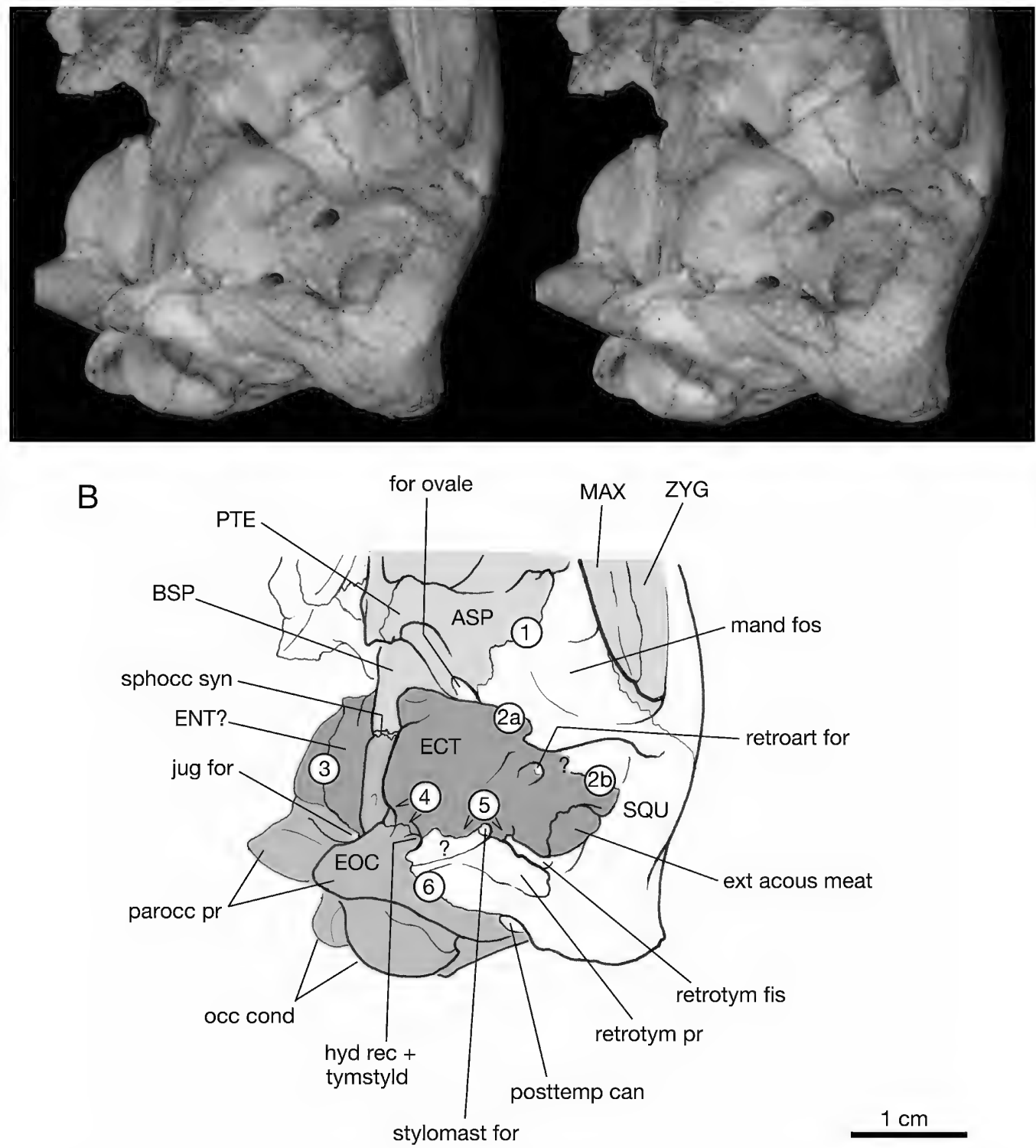

deformation. Pars canalicularis of the petrosal contributes to floor of posttemporal canal, but as it is not exposed externally to any significant extent (see fig. 15D) it is not colored as such in key diagrams. Although entotympanic (ENT?) participation in bulla is considered highly likely, decisive evidence would have to come from early stages (see text). This specimen is well preserved, but it nonetheless exhibits several fractures that superficially mimic sutures. In C, feature a is situated in a location similar to the "sutura squamoso-serrialis" in Roth's (1903) illustration of a young Toxodon (fig. 2). Another break, nearly the mirror image of this one, occurs in the same position on the right side (not shown). The explanation for their presence may be taphonomic: large vascular channels (transverse sinus and tributaries, situated just beneath the cranial roof in this area) may increase the likelihood of postmortem fracturing (e.g., fig. 14B). 

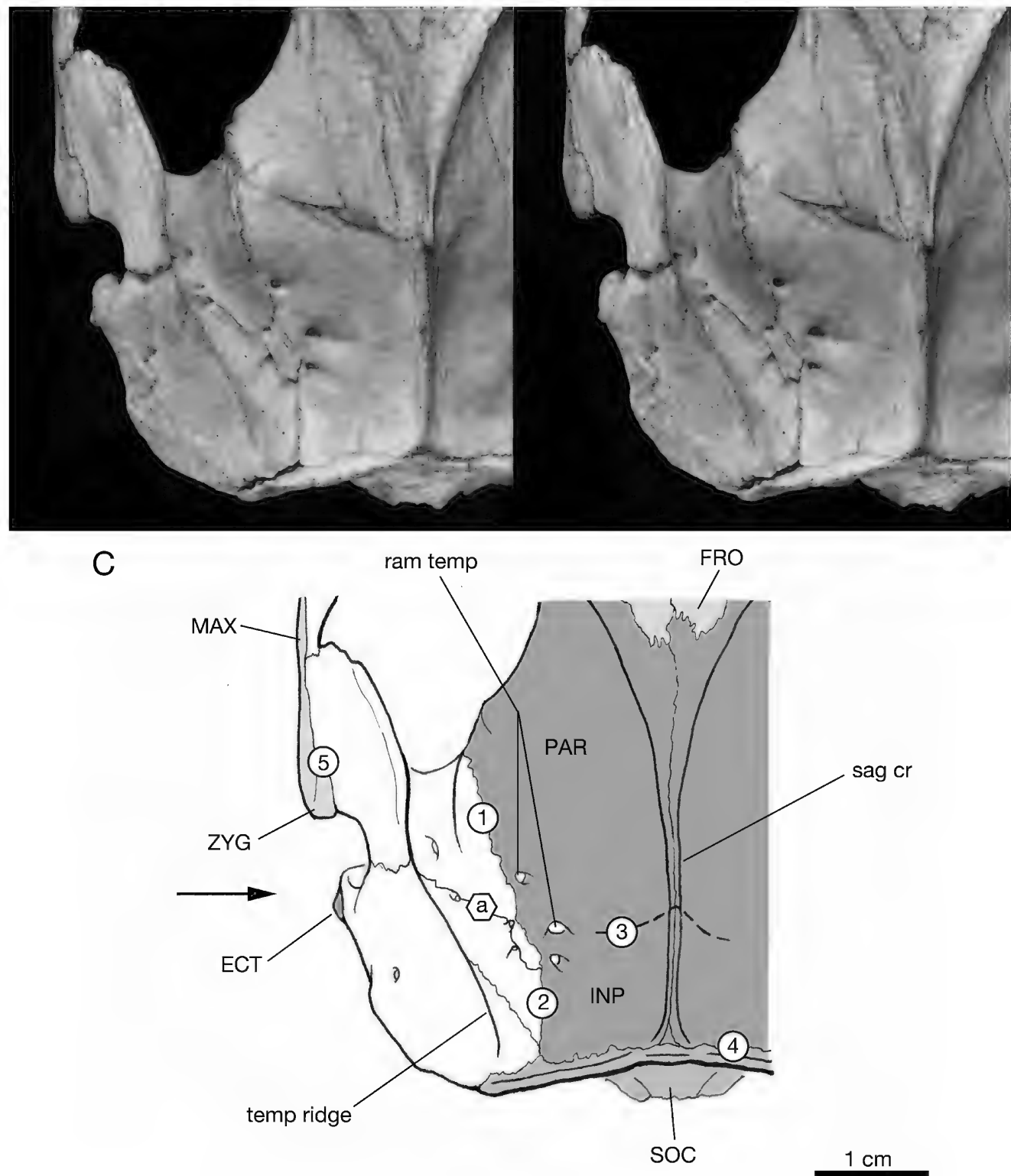

FIG. 13. (Continued.)

uncontroversial in the sense that they do not require any unusual developmental processes, whatever their likelihood may be on other grounds. However, they presuppose a very small squamosal component in the theca, perhaps no larger than the area circumscribed by the hiatal ridge (fig. 9B). By contrast, the fourth interpretation asserts that the squamosal was actually of normal size and relations in pachyrukhines, but for unknown reasons developed an extensive rarefaction zone within its caudal portion.

Another taxon that sheds light on the organization of the pachyrukhine caudal cranium is the kangaroo rat Dipodomys, which exhibits hypertrophied paratympanic spaces in combination with a highly reduced squamosal but lacks the 
morphological correlates of the ICJ. Thanks to Webster's (1975; see also Webster and Webster, 1975) exhaustive studies of ear region ontogeny in this heteromyid, there is no question about the individual contribution of bone territories to the formation of the epitympanicum (= epitympanic sinus/theca of this paper). In the kangaroo rat this volume is exclusively covered by the petrotympanic (both elements participating); the squamous squamosal is reduced to a bar (suprameatal spine of the squamosal; fig. 19A), which is applied against, but not fused to, the dorsal wall of the external acoustic meatus. The parietals, interparietals, and supraoccipital make no contribution to the walls of the epitympanicum (Beer, 1965).

The demonstrable separateness of the squamosal throughout ontogeny in Dipodomys is a key difference from Paedotherium, in which, as virtual sectioning shows (figs. 10-12), most of the theca is squamosally derived. This observation does not establish that the pachyrukhine hiatus is therefore due to rarefaction in the manner discussed above, but it does allow the presumption that this group differs from other notoungulates only in the degree of definitive squamosal development, and that in no regard is it necessary to invoke the existence of an independent serrialis to explain the origin of the thecal covering.

On this point comparison to heteromyids is again useful, for they likewise vary in the degree of squamosal participation in the cranial sidewall (Webster and Webster, 1975; Nikolai and Bramble, 1983). In heteromyines (e.g., Liomys), the squama of the squamosal is still small compared to that of most eutherians, but it is large enough to contribute to the cranial wall dorsal to the meatus. In dipodomyines and also in perognathines (Perognathus, Chaetodipus) this portion is always small, never amounting to much more than the tiny rod seen in Dipodomys. Interestingly, this difference is correlated with the scale of paratympanic pneumatization: in heteromyines inflation is relatively conservative, but in some dipodomyines, of which Dipodomys deserti is the outstanding example (Webster, 1975; Best et al., 1989), pneumatization is so extensive that the combined volume of the two middle ears exceeds that of the braincase.

\section{Cochilius}

Of the three interatherioid skulls submitted for CT scanning (Cochilius volvens AMNH-VP 29651, Progaleopithecus tournoueri AMNH-VP 29603, and Protypotherium sp. MLP 12-1280), only the first produced good results and therefore comments will be largely limited to this specimen.

Macroscopically, Cochilius volvens AMNH-VP 29651 (figs. 13-15) is solidly constructed and, like other interatherioids (fig. 16), lacks the large piriform fenestra and dorsal midcranial hiatus seen in pachyrukhine hegetotherioids. In volume the epitympanic sinuses are in fact quite large, but the outline of their thecae on the caudal cranium is subdued because of the extreme robustness of the temporal ridges (fig. 13C).

A number of cranial sutures in AMNH-VP 29651 are either open, or, if fused, still identifiable in section by indicia (fig. 14C). On the dorsal surface of the skull, the external suture between the squamous part of the squamosal and the parieto-interparietal is apparent and punctuated by large foramina for rami temporales (fig. 13C). Sutural relationships are as in notoungulates generally, in that there is no evidence of any atypical sutures or subdivisions of bone territories (but see Entotympanics and Septum Bullae). The squamosal and the rostral crus of the ectotympanic are fused, and the sutural line between the bulla and the petrosal has largely disappeared (although its trace is still identifiable; fig. 13A).

Virtual sectioning of the skull (figs. 14, 15) reveals that the thecal covering is separate from all other bone territories except the squamosal, which unequivocally forms most of the theca; and the petrotympanic, which is continuously fused with the thecal wall in a small zone around the aditus and along the medial wall of the notably inflated retrotympanic process (fig. 15B, C). Roth (1903) claimed that the "protuberancia 
A
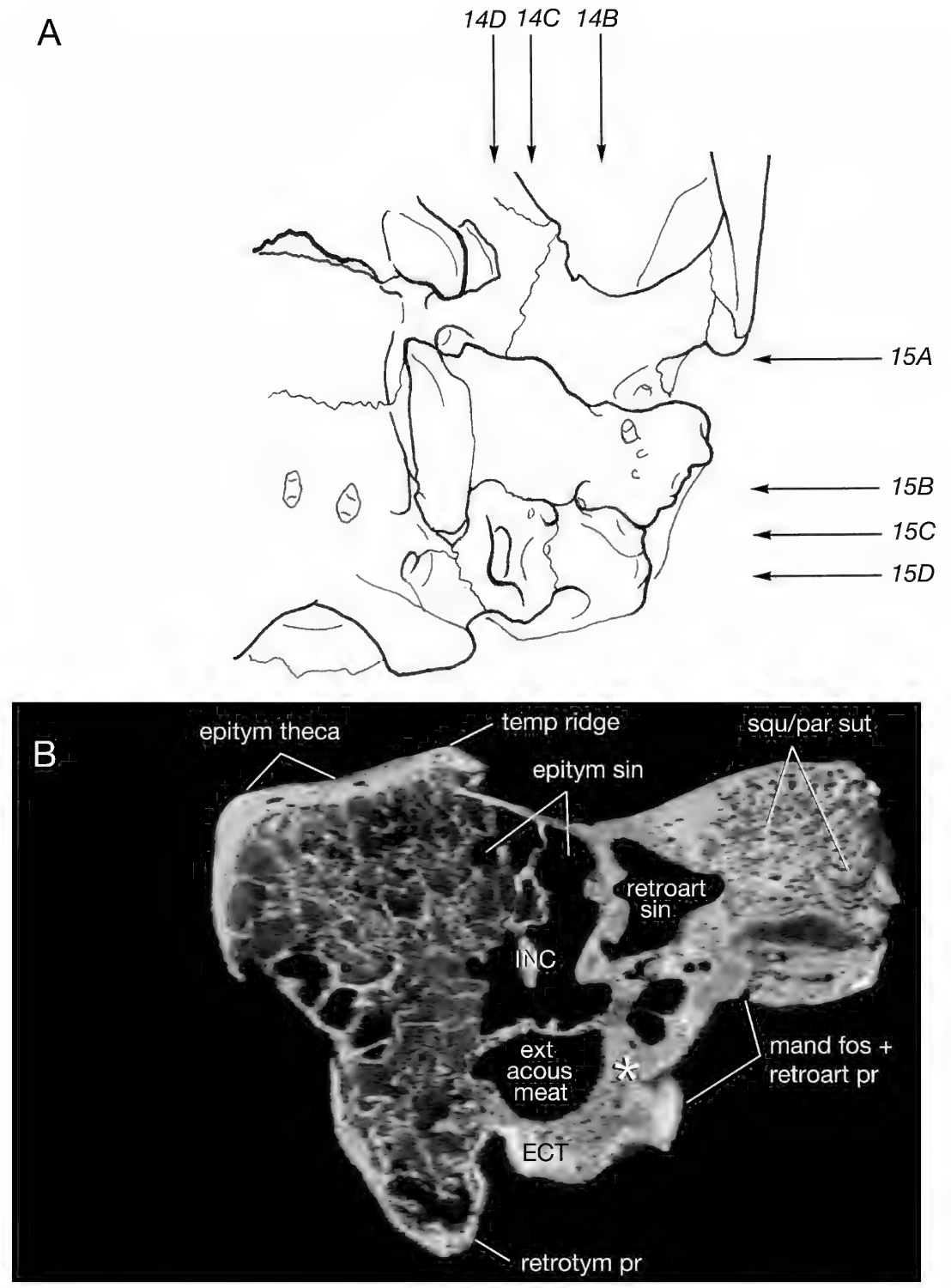

FIG. 14. Cochilius volens AMNH-VP 29651, three virtual parasagittal sections, left side, arranged in lateral to medial order on this and subsequent pages; rostral to right. All sections to scale in C. Diagram A indicates planes of sectioning in this figure and figure 15. B, section through external acoustic meatus; note incus in epitympanic sinus, out of position post mortem (also seen in fig. 15B). Although remodeling has erased most suture lines, still partly represented is suture between ectotympanic's rostral crus and preotic portion of squamosal (squamoso-ectotympanic suture, large white asterisk). Suture between caudal crus and retrotympanic process is no longer identifiable. Upper leader to mand fos (mandibular fossa) points to damage comparable to that seen in a similar place in Oldfieldthomasia AMNH-VP 28600 (feature 3 in fig. 1A); it is not evidence of a suture. C, section through towered tip of cochlear promontory. Simpson (1936) thought the small septum (small white asterisk) on rear wall of bulla conducted internal carotid in Oldfieldthomasia; in Cochilius this feature is better interpreted as conduit for tympanic nerve. D, section through medial aspect of middle ear; the part of the bulla articulating with petrosal is probably of entotympanic origin (see text). Rostralmost end of septum bullae in this section is confluent with bullar wall; more caudally it is distinct and connects with 


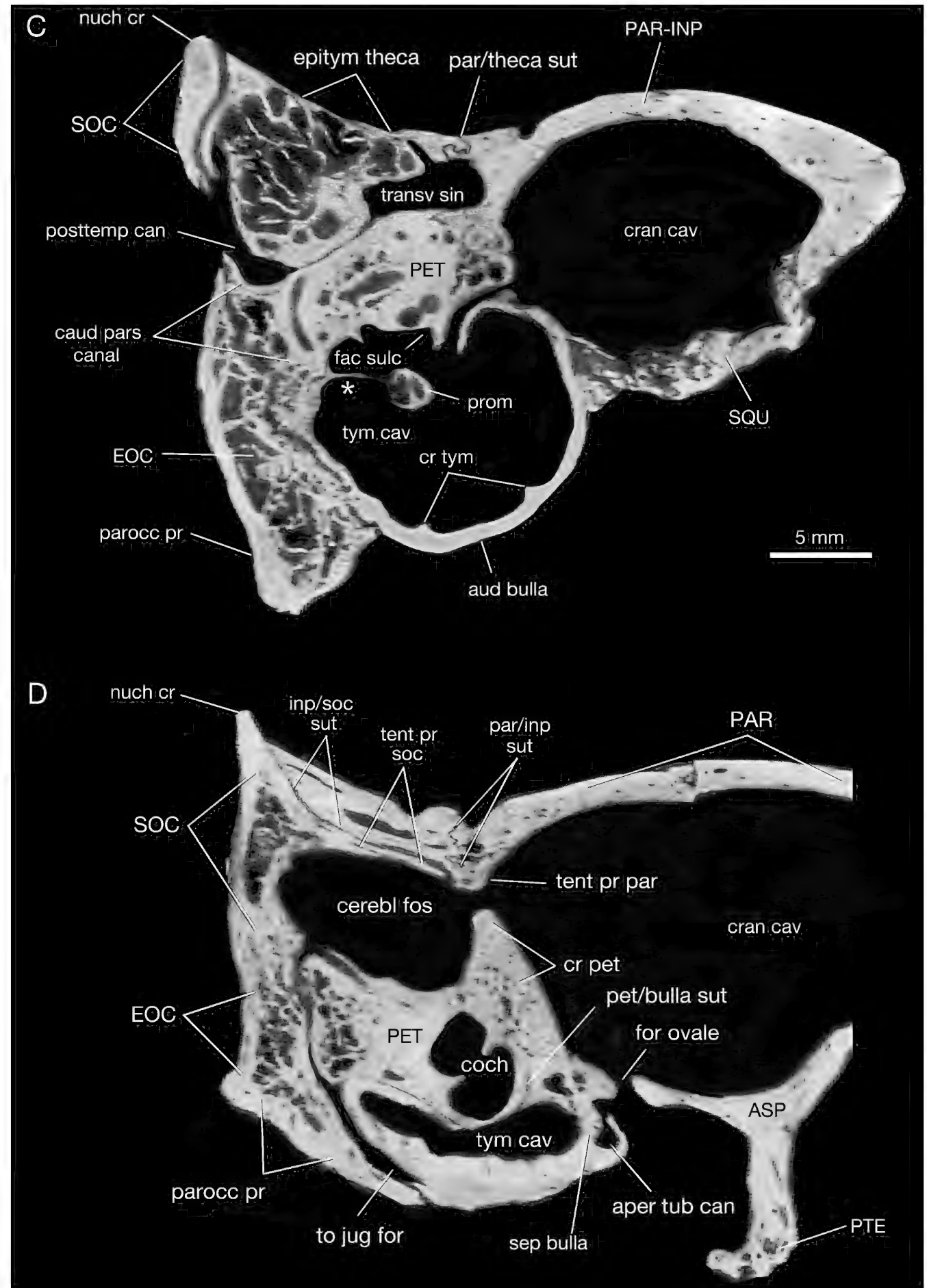

promontorium, as in other notoungulates in which this feature has been detected. Note long tongue of tentorial process of supraoccipital (tent pr soc) meeting tentorial process of parietal (tent pr par). Exoccipital and supraoccipital are completely fused, but the division between parietal and interparietal can still be identified. 


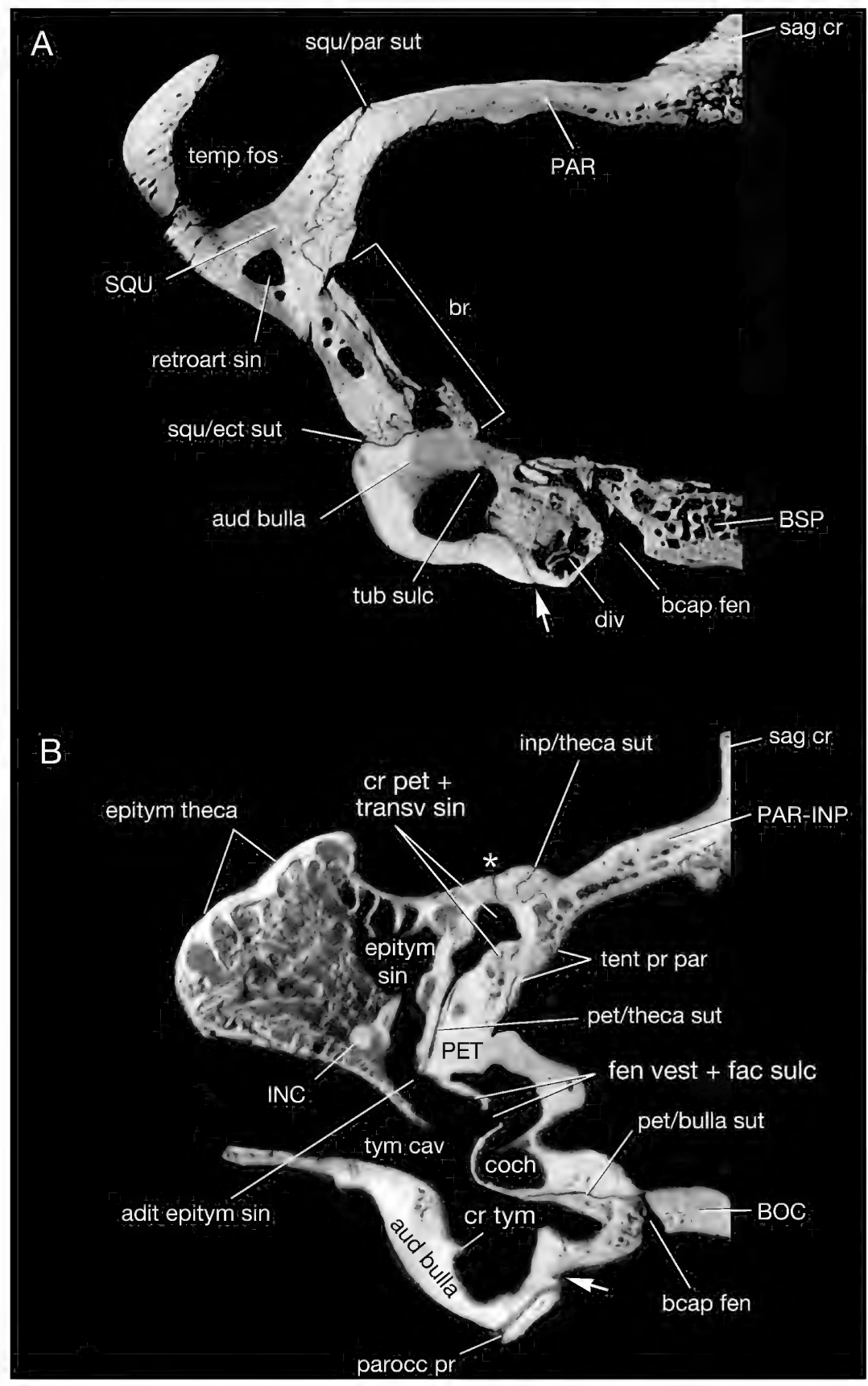

FIG. 15. Cochilius volens AMNH-VP 29651, four virtual coronal sections, left side (rev.), arranged in rostral to caudal order (for approximate locations of sectioning planes, see fig. 14A). All to scale in D. A, section through rostralmost end of bulla. Note fracturing (br) on medial surface of squamosal, which mimics a true suture. Arrow, discontinuity on rostral lip of bulla thought to represent nearly obliterated ectotympano-entotympanic suture. B passes through external acoustic meatus (note incus in epitympanic sinus, out of position post mortem). Arrow identifies caudal end of same groove seen in A. Except for petroso-bullar suture, other discontinuities are fractures. Asterisk identifies the large longitudinal fracture, seen on dorsal aspect of skull and positioned in roughly the same place as Roth's "sutura squamoso-serrialis" (see fig. 13C). Note that fracture intersects the 


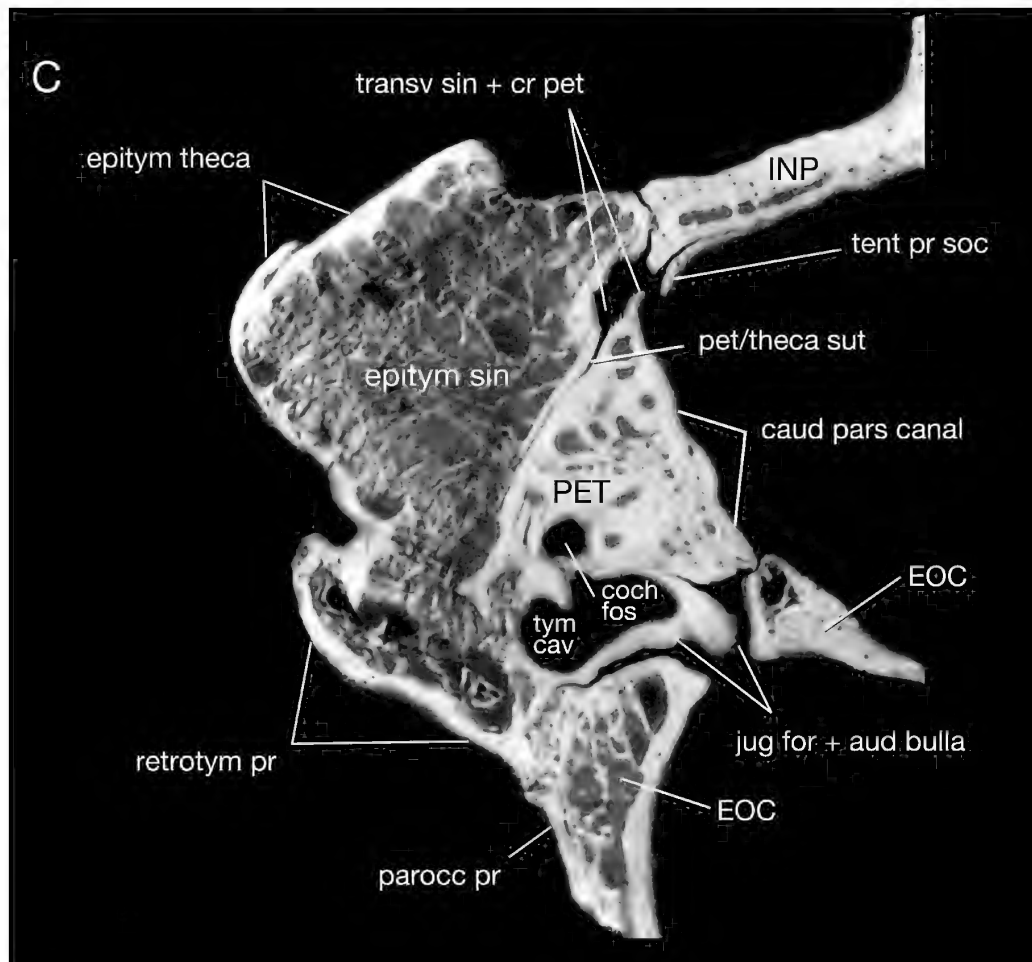

D

inp/theca sut

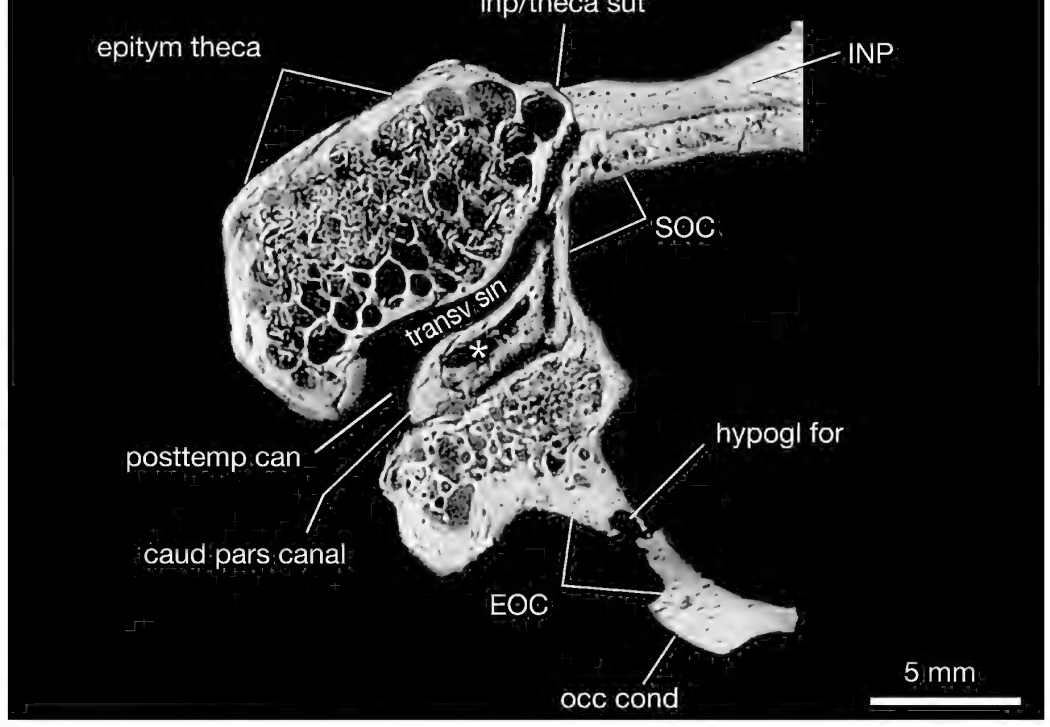

very large transverse sinus, also longitudinally positioned. In C (section through caudal portion of epitympanic sinus and retrotympanic process), it appears that rearmost part of petrosal was pneumatized in concert with retrotympanic process; thus, sidewall of epitympanic sinus in this region is probably both squamosal and petrosal in origin. This should be distinguished from conditions in $\mathrm{D}$ : here caudal portion of pars canalicularis helps to frame part of posttemporal canal, but trabeculated space (asterisk) seen internally within "mastoid" is a marrow cavity, unconnected to middle ear. Caudalmost part of epitympanic theca appears suspended in space, separated from more medial parts of skull by relatively enormous posttemporal canal and sulcus for transverse sinus. 


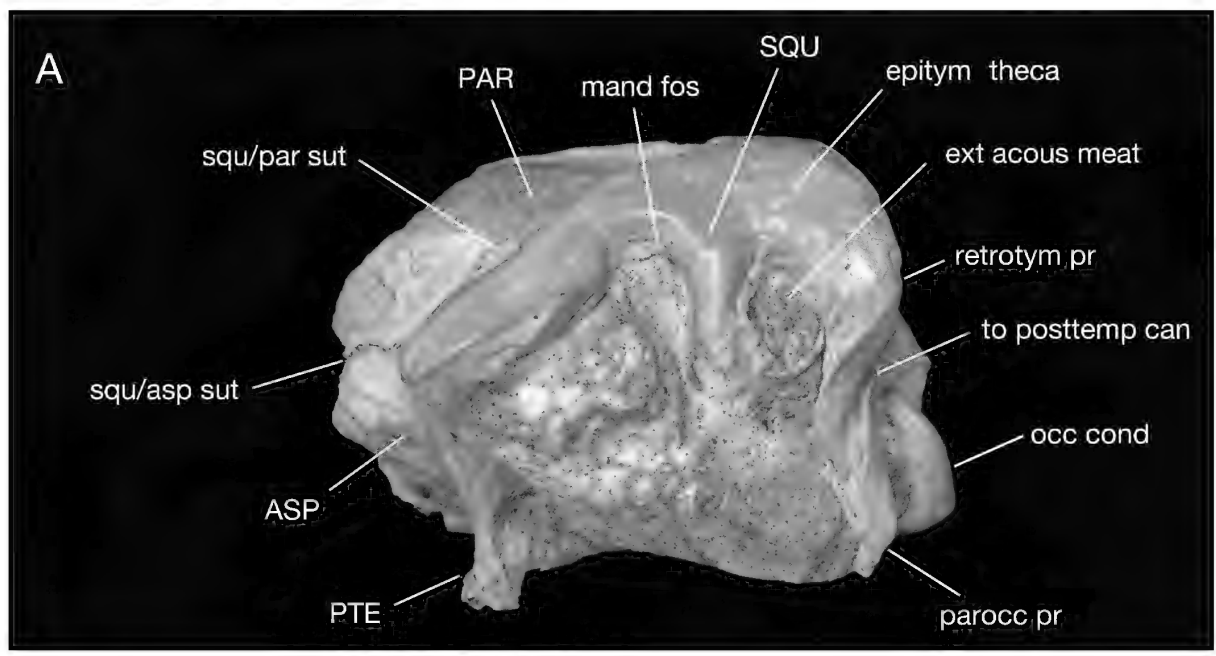

FIG. 16. Protypotherium sp. MLP 12-2780, caudal cranium in left lateral (A), dorsal (B), and caudal (C) aspects. All to scale in C. Caudal cranium of Protypotherium strongly resembles that of close relative Cochilius (fig. 13). Both of these interatherioids possessed large epitympanic sinuses, although thecal prominence is relatively less than in pachyrukhines. Few sutures can be identified on the caudal cranium of this particular specimen, but there is no reason to think that it differed from other notoungulates in sutural content or element composition. Note broken areas above posttemporal canal. Large size of foramina for rami temporales is noteworthy (size varies within taxon; cf. Sinclair, 1909, pl. III, fig. 2).

mastoidea" was pneumatized in notoungulates, but this is probably not correct judging from conditions in Cochilius. In this taxon (fig. 15D) the caudal end of pars canalicularis presents large, trabeculated spaces, possibly for hematopoeic tissue, but these lack a connection with either the tympanic cavity or the epitympanic sinus. Unlike Paedotherium (fig. 12), alae are not significant and the petrotympanic has only limited exposure on the caudal aspect of the skull, where it helps to frame the aperture of the posttemporal canal. Protypotherium sp. MLP $12-2780$ is apparently similar in these respects (fig. 17B, C).

In summary, the caudal cranium of adult $\mathrm{Co}$ chilius bears no evidence of a serrialis or unusual sutural relationships suggestive of additional elements. The epitympanic theca is largely formed by the squamosal, with small contributions from the compound petrotympanic. Because of crushing it is not clear whether the rostral crus of the ectotympanic contributes to the lateral part of the meatal roof. The caudal crus definitely does not, as there is a marked fissure (retrotympanic fissure; fig. 13B) between the two. As far as may be ascertained this last statement applies to other interatherioids as well.

\section{Oldfieldthomasia}

As already noted, Oldfieldthomasia AMNHVP 28600 was not a happy choice for Simpson's (1936) purpose, not only because of its general condition, but because it was not one of the taxa that Roth (1903) specifically noted as possessing the serrialis. Despite its greater geological age compared to that of most other notoungulates known to Simpson in the early 20th century, in its caudal cranial construction Oldfieldthomasia cannot be described as especially primitive (as compared, for example, to the definitely more primitive henricosborniid Simpsonotus [Late Paleocene; see Billet, 2011]).

Although Simpson (1936) maintained in his text that the thecal walls (his "pars epitympan- 


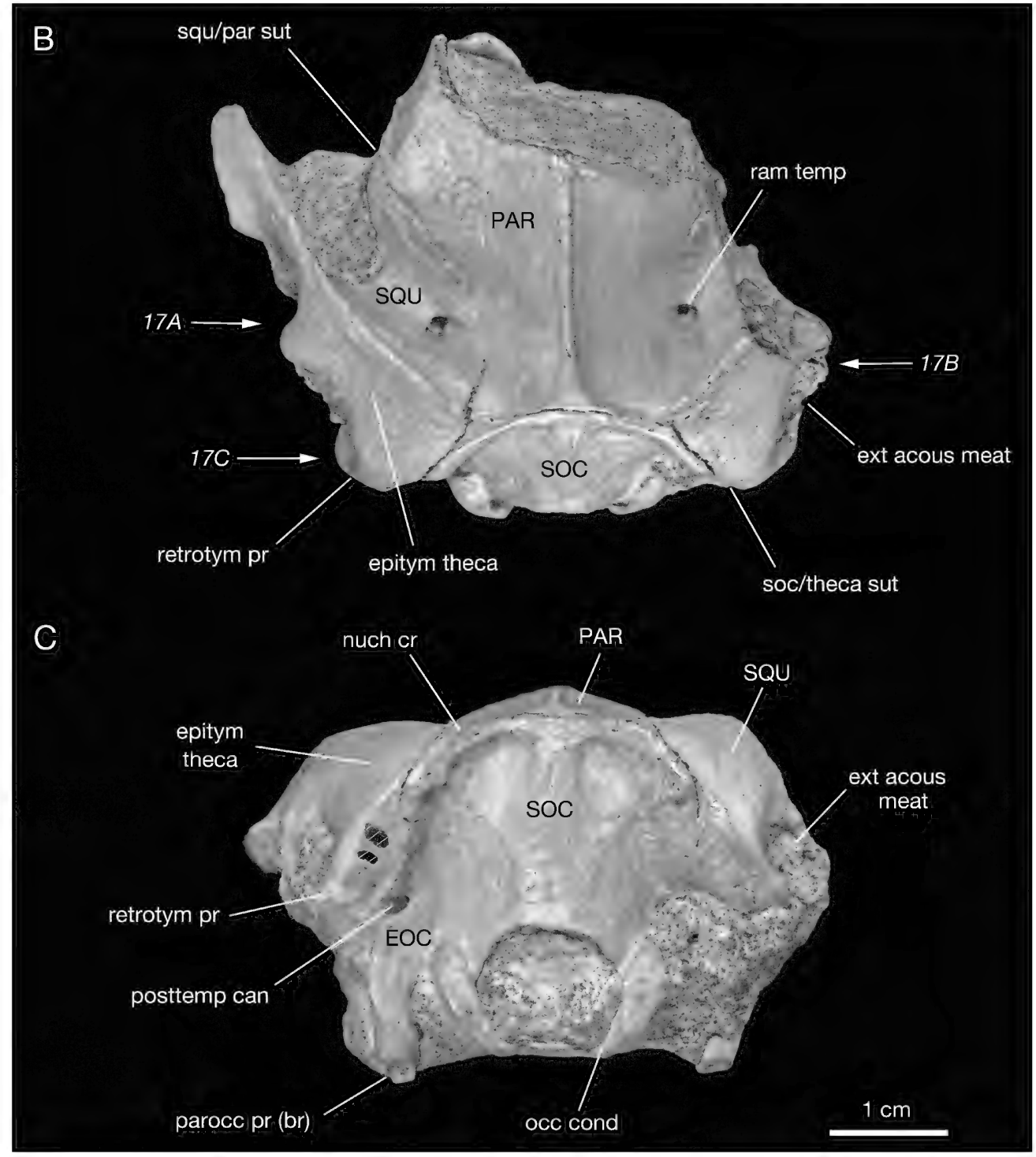

ica") of Oldfieldthomasia were squamosal, some section drawings show apparent continuity between thecal walls and bone that is surely ectotympanic in origin; others show a connection with his putative adventitious elements (see The $\mathrm{X}$ Elements). However, ignoring these, there is no reason to doubt that the squamosal contributed most of the thecal covering in Oldfieldthomasia, with the petrotympanic contributing modestly to the adital area where bulla, theca, and tegmen tympani anatomically meet and where intense remodeling probably first began during ontogeny. Evidence for a serrialis is accordingly completely lacking.

\section{INTERPARIETAL COMPLEX}

"The" interparietal bone (or, better, interparietal complex, as now understood; see Koyabu et al., 2012) has long been known as a participant 


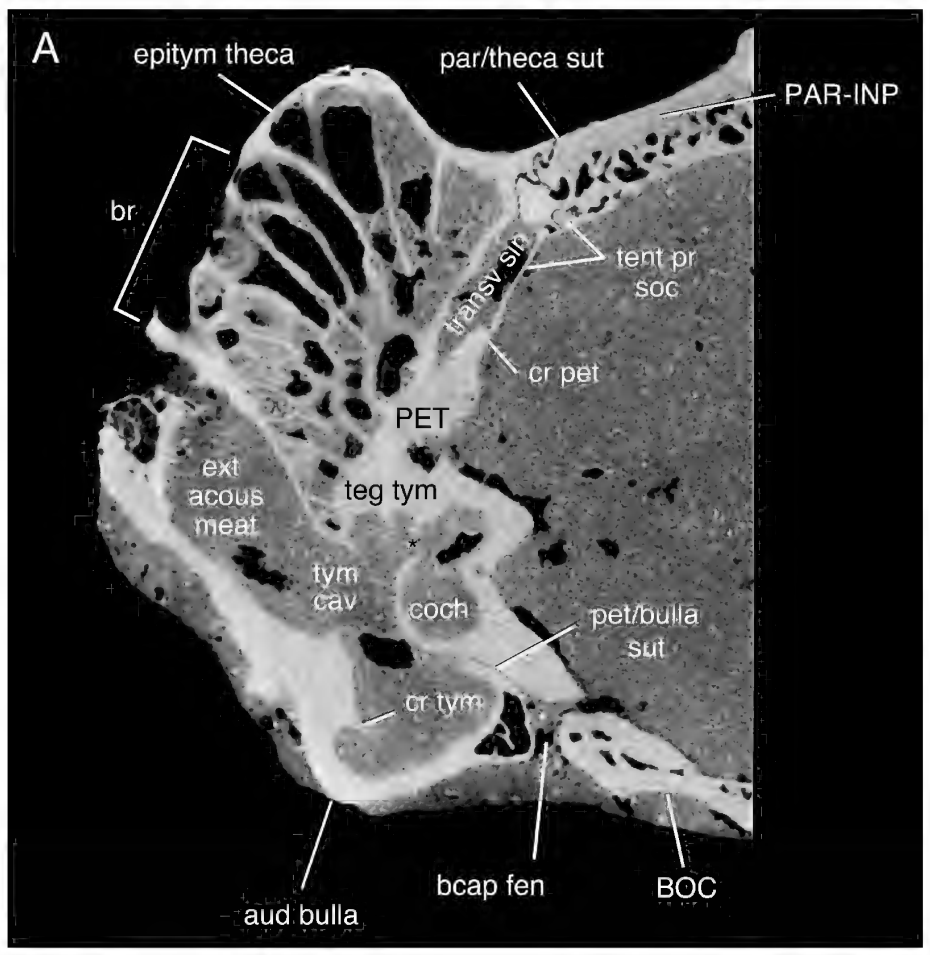

FIG. 17. Protypotherium sp. MLP 12-2780, virtual coronal sections through caudal cranium, apparent right side: rostral (A), middle (B), and caudal (C) portions of middle ear (A and $\mathrm{C}$ rev.). All to scale in C. For approximate locations of sectioning planes, see fig. 16B. Although this matrix-embedded specimen is in good condition overall except for damage to thecal walls, CT resolution is relatively poor and fine details cannot be discriminated. Note well developed medial paratympanic cavity in A and B. In B, arrow identifies approximate position of suture between squamosally derived theca and caudal crus of ectotympanic, not evident in this section but clearly present in others, confirming that squamosal contributes the most to epitympanic sinus enclosure. In C, caudal part of highly trabeculated epitympanic sinus extends deep into retrotympanic process (asterisk). Suture between supraoccipital and overplated interparietal is obvious.

in the mammalian caudal cranium, and in that sense its occurrence in South American ungulates is uncontroversial. However, it has relevance here because Koyabu et al. (2012) have substantially refined our understanding of the interparietal complex by providing a wealth of new observations, some of which bear on interpreting conditions in notoungulates. Utilizing combinations of paleontological, neontological, and experimental evidence, these authors persuasively argue not only that most, and quite possibly all, major mammalian clades possess "the" mammalian interparietal, but also that the structure as expressed in the adult stage is itself de- velopmentally compound, consisting of four subunits (two medial and two lateral interparietals, in their terminology) that usually fuse, pairwise, very early in cranial ontogeny. The complex may remain independent or, more often, fuse to surrounding bones, particularly the supraoccipital and parietal. This helps to make sense of what were often previously considered to be anomalous observations regarding unexpected sutures or evidence of subdivision in the more limited set of elements traditionally thought to make up the caudal part of the mammalian cranium (e.g., Broom, 1916; MacPhee and Novacek, 1993). 


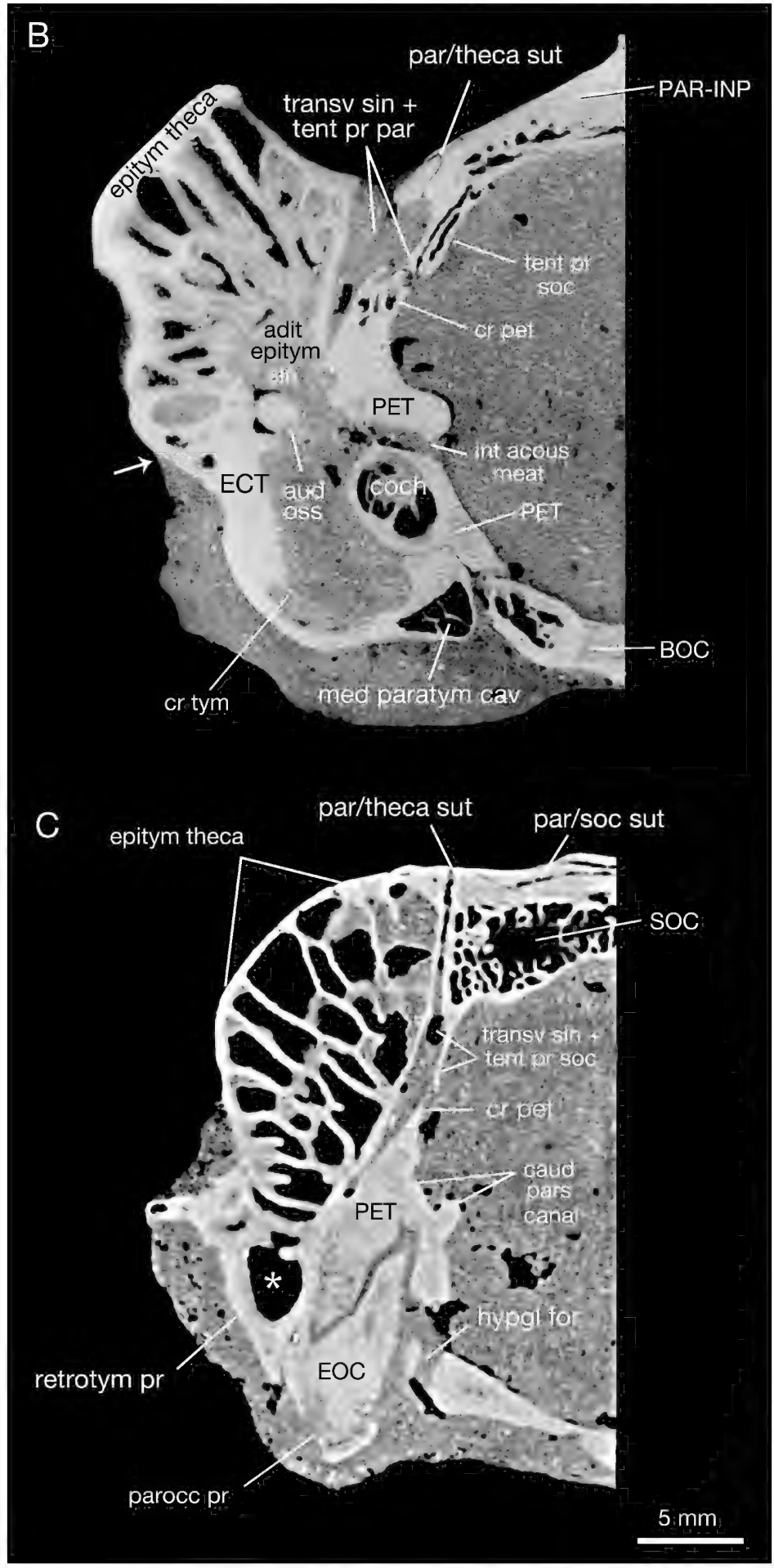



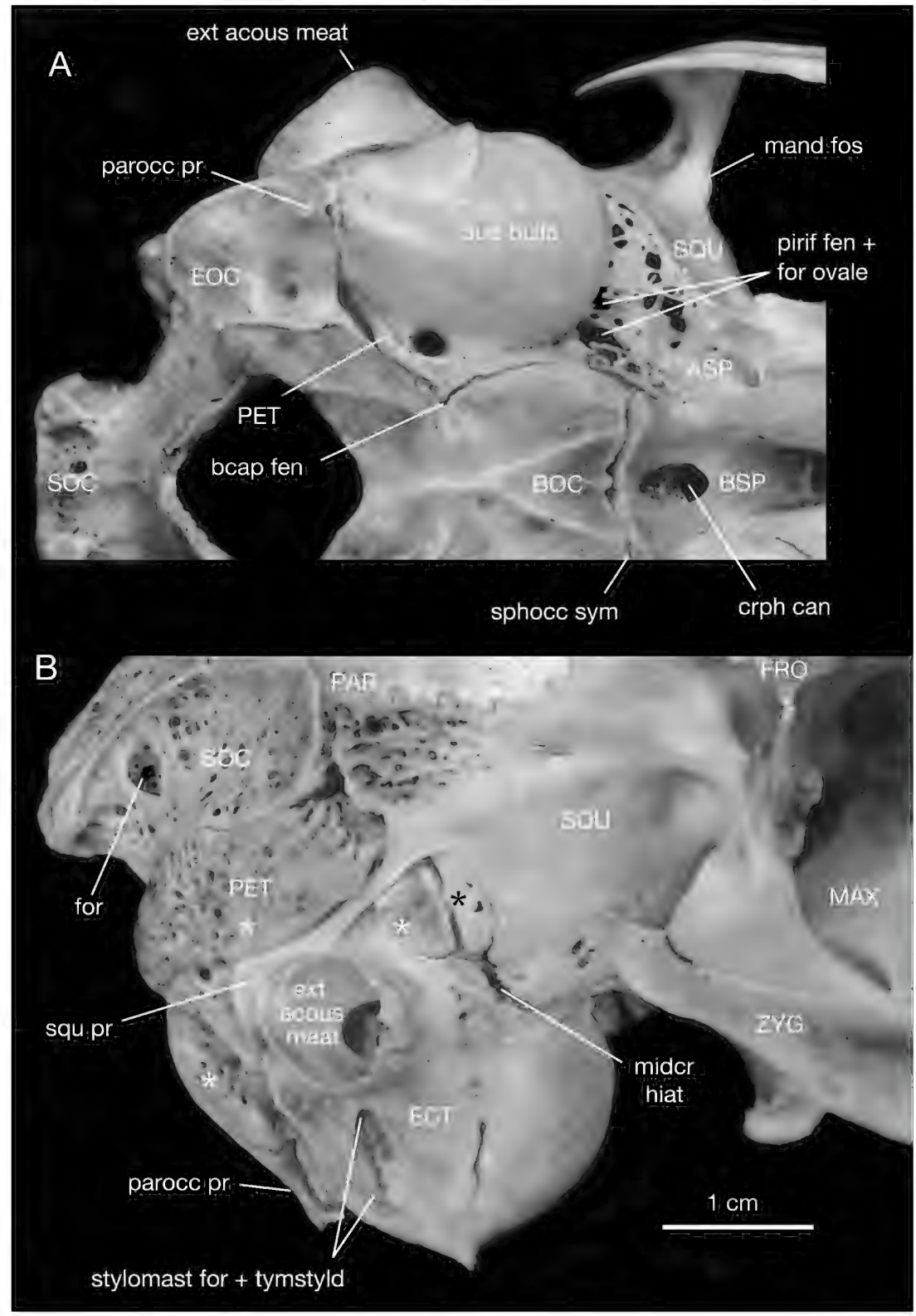

FIG. 18. Lepus californicus AMNH-M 177068, left side (rev.) of caudal cranium in ventral (A) and oblique rostrolateral (B) aspects, illustrating extent of rarefaction (fenestration) and several osteological features related to intracranial "joint" (ICJ) between rostral and caudal parts of cranium. Both to scale in B. Only features of direct relevance are labeled; for a detailed cranial osteology of lagomorphs, see Wible (2007). The leporid ICJ, conceived by Bramble (1989) as a linked series of narrow gaps (sphenooccipital synchondrosis/ foramen ovale/piriform fenestra/midcranial hiatus), divides the skull into rostral and caudal moieties. In life these gaps would be filled with dense connective tissues, including sutural soft tissues and, within sphenooccipital synchondrosis only, cartilage. Hiatal plate (black asterisk), filling dorsal part of midcranial hiatus in $\mathrm{B}$, is a process of the interparietal; it projects under processus squamosus (squ pr), perhaps acting as a strengthening member in absence of a caudally extensive squamous squamosal. Among cranial elements 
With regard to notoungulates, Koyabu et al. (2012) reported on the basis of a literature search that medial and lateral interparietals were present in several taxa (Toxodon, Mesotherium [= Typotherium], Nesodon, Pachyrukhos) but gave no other details. A few additional features revealed by CT scanning are presented here as they have a bearing on the interpretation of the caudal cranium in this group. One observation of interest is the fact that, in Paedotherium, Cochilius, Protypotherium, Progaleopithecus, Oldfieldthomasia, and Notopithecus (this study) and thus very probably typotheres in general, the bones comprising the caudalmost part of the cranial roof exhibit a relationship similar to that described for certain soricids (specifically Sorex araneus and S. unguiculatus) by Koyabu et al. (2012: 14076, captions to supplemental fig. S11-S12). In these shrews, the caudalmost part of the roof is double tiered, an arrangement in which the interparietal complex largely covers the dorsal exposure of the supraoccipital-effectively the reverse of the expected in terms of traditional identifications, in which any suture-delimited element on the caudalmost margin of the cranial dorsum is usually regarded as supraoccipital in origin. How frequent the double-tiered arrangement is in mammals is not known. Figures $14 \mathrm{C}$ and 15C-D illustrate arrangements in Cochilius, which are much like those seen in the other taxa investigated. In Cochilius the (true) supraoccipital makes up much of the caudal aspect of the cranium, including the nuchal ridge. This element also makes the expected unions with the lower part of the occipital squama and exoccipital. The interparietal complex lies relatively more rostrally, where it is completely fused to the parietals (through not obvious externally in AMNH-VP 29651, the remnant of the suture line can be seen in sections; e.g., figs. 14C, 15C). Interparietal material covers the endocranial tentorial process of the supraoccipital, which projects forward beneath the former (fig. 14C).

As Koyabu et al. (2012) also show, in certain caviomorphs (e.g., Dolichotis) the lateral interparietals develop in close proximity to the auditory capsule. In this position they could be invaded by the expanding middle ear, although whether that actually happens in any caviomorph is presently undocumented. The positioning of sutural indicia in Cochilius AMNH-VP 29651 indicates that the interparietal does not participate in the ear region in this taxon, but there is another feature that requires explanation in this regard. On both sides of the dorsal surface of this skull there is a noticeable discontinuity that intersects the line of the definite suture bordering the parietal/ interparietal (fig. 13C, feature a). It is situated in essentially the same relative position as the distal part of the Roth's (1903) "sutura squamososerrialis" (fig. 2), and at one point in the present investigation it seemed plausible that it might mark a sutural boundary between the squamosal and lateral interparietal, i.e., that the lateral parietal was integrated into the epitympanic theca. CT imagery indicates, however, that the apparent suture is a fracture. As may be seen in figure 15B, the (true) suture between the squamosal theca and the parieto-interparietal possesses strongly interdigitating margins, as is typical of vault sutures, while the discontinuity in question (double asterisks) is straight edged and thus a break. These images also make clear that the angle of the break coincides with the trend of the trans-

showing significant rarefaction in jackrabbit are alisphenoid, supraoccipital, and noncapsular parts of petrosal (white asterisks). Although small-scale features within rarefactions seem to be random in size and distribution, some apertures are constant (e.g., for, innominate foramen in supraoccipital). With regard to pachyrukhine convergences, the most important difference from a constructional point of view is complete exclusion of squamosal from middle ear in Lepus, whereas it forms almost all of epitympanic theca in investigated notoungulates (fig. 8). Pachyrukhines exhibit limited areas of rarefaction in maxillae, but none in caudal cranium unless the dorsal midcranial hiatus is considered an example (see text). 


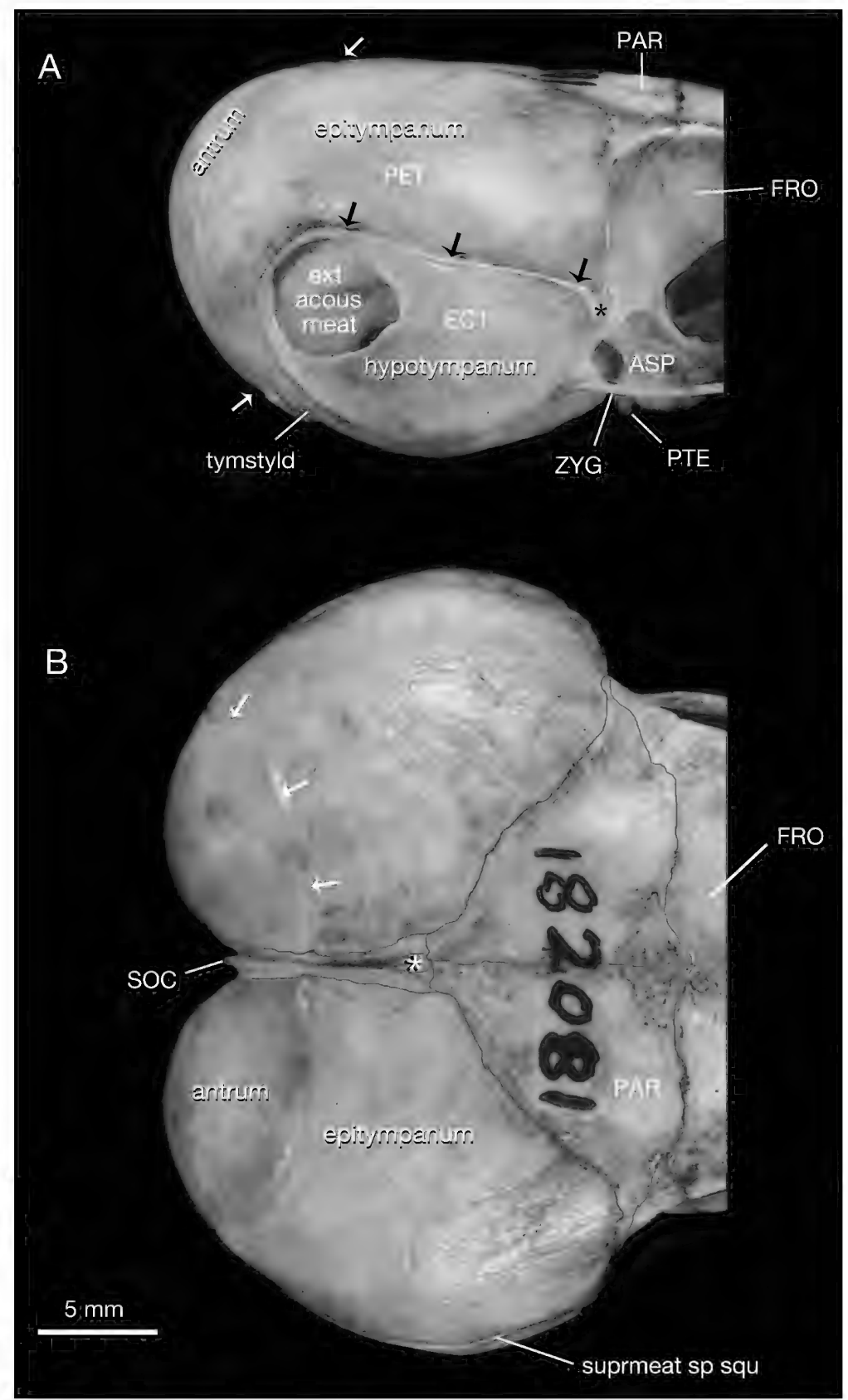

FIG. 19. Dipodomys merriami AMNH-M 182081, caudal cranium in left lateral (rev.) (A) and dorsal (B) aspects; certain sutures emphasized to improve visibility. Names for middle-ear spaces and sutural bounds after Webster (1975). Insignificant rod (small black arrows in A, suprmeat sp squ in B) running across surface of multipartite middle ear (hypotympanum, epitympanum, antrum) is all there is of squamous portion of squamosal in this heteromyid. Rod ends freely over external acoustic meatus, and is nowhere fused to cranial sidewall. In A, black asterisk lies on equally insignificant "body" of squamosal. Apparent suture (large white arrows) crossing caudal bulge of immense middle ear in A and B marks track of an internal "mastoid" septum, seen through translucent walls. Roof of external acoustic meatus is formed by ectotympanic, whose 
verse sinus, which as a large vacuity in the dry skull might have suffered structural failure along its walls as a result of postdepositional sediment pressure. Whether this interpretation also applies to cases such as Roth's Toxodon specimen (fig. 2) or Campanorco inauguralis MLP 79-IV-16-1 (personal obs.) is uncertain, but considering that the transverse sinus is very large in all taxa investigated it seems distinctly plausible.

A final point of interest is an unusual feature of Paedotherium AMNH-VP 45914: in this specimen, what superficially appears to be a small, independent structure is bilaterally exposed in the region in which the supraoccipital, (inter) parietal, and squamosal theca form a three-way junction (asterisk, fig. 8D). Close inspection of virtual sections of this clearly adult specimen indicates that the structures in question are continuous with the supraoccipital, without any indication of sutural division or pneumatization. If they are not simply rostrolateral parts of the supraoccipital, it might be argued on the basis of their position that they represent lateral interparietals, fused not with the rest of the interparietal complex but instead with the supraoccipital. Similar structures were not identifiable in other pachyrukhine specimens available for study, so their significance is currently uncertain.

\section{The X Elements}

The history of Simpson's (1936) elements Xa and $\mathrm{Xp}$ is short: he described these putatively independent ossifications only once, and, as he explained in a footnote, he chose not to give the $\mathrm{X}$ elements formal names because he did not want to have to commit himself to any specific theory of their homologies. In his later summary monograph on meridiungulate systematics (Simpson, 1967), he simply quoted his earlier paper without adding any updates or new insights. Perhaps because of the tentative way in which the X elements were thus characterized, later investigators have largely ignored them. This is unsurprising; if Simpson's difficulties in interpreting fine-scale features in Oldfieldthomasia are any guide, assembling evidence for the occurrence of such minuscule elements in other notoungulate taxa would likely be just as discouraging.

Simpson's (1936) descriptions of the X elements in Oldfieldthomasia AMNH-VP 28600 were reasonably detailed, but as already noted his supporting visual documentation was limited to uninformative views of the damaged left side and a few section drawings in which the elements were said to appear (figs. 1, 5). The case for element Xp concerns us first. Simpson (1936) labeled this feature in the diagrams of sections 20 and 23 as "Xp(ppt)" and "Xp," respectively. In both drawings the element is represented as a thin-walled, irregular piece of bone, in very close contact or actually continuous with the ectotympanic on the one hand, and close to or part of the retrotympanic (= posttympanic) process on the other. Simpson (1936: 10) allowed that Xp "shows

crura inscribe a complete ring on lateral cranial wall. Externally visible parts of comparatively tiny interparietals (white asterisk) are enclosed by rostral arms of supraoccipital (Beer, 1965; Koyabu et al., 2012), which intervenes between the two thecae but does not contribute to their walls. Relatively well-developed tympanostyloid (tymstyld) externally overlaps caudalmost part of ectotympanic bulla and thus contributes to wall of the caudal cranium (Webster, 1975). Nondipodomyine heteromyids display similar, but relatively smaller, paratympanic spaces; those with the smallest middle ears (Liomys) also exhibit larger squamosals, suggesting an inverse correlation. Notoungulates resembled Dipodomys in possessing massively expanded epitympanic sinuses, but they expanded the true tympanic cavity only moderately and lacked altogether the antrum as a separately identifiable space. Although epitympanic sinus expansion can be plausibly related to enhancement of low-frequency audition in notoungulates, this has never been properly demonstrated (but see Macrini et al., 2010). 
A

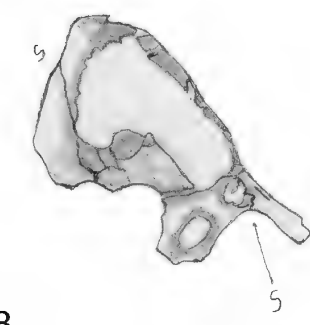

8

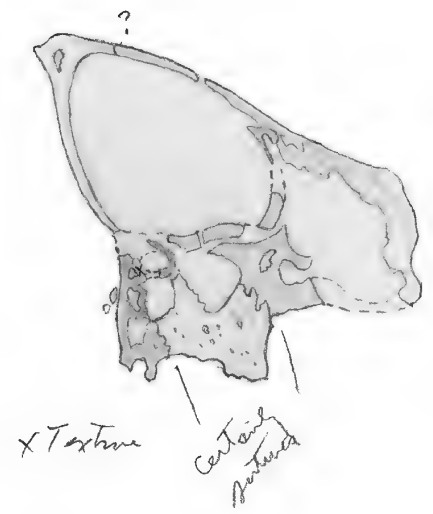

17
13

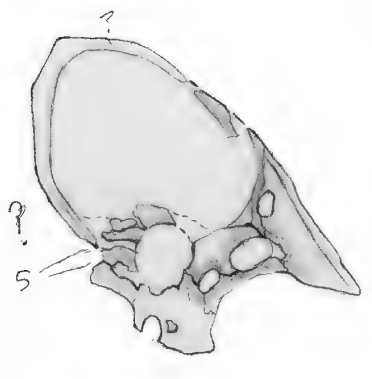

$x$ Protitine

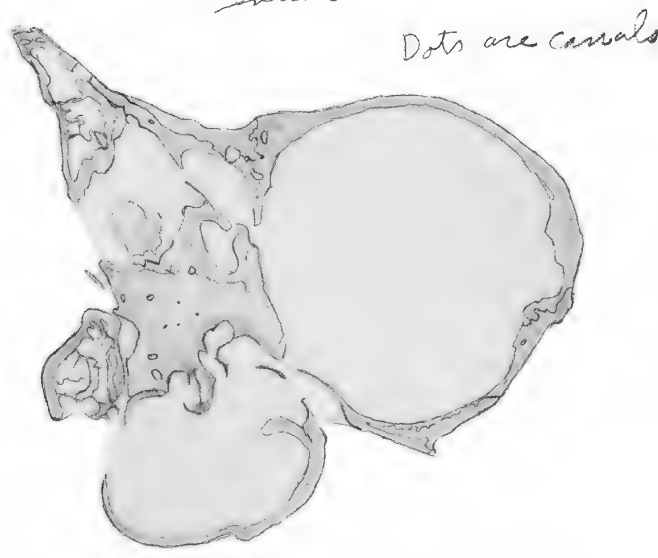

32

FIG. 20. Selection of section drawings of Oldfieldthomasia cf. debilitata AMNH-VP 28600, from AMNH-VP archives; right side (ss. 8, 13, 17, 32, and ss. 19-22; approximately twice natural size). Drawings are presented with original pencil shading, but gray tone has been added to each section to improve overall legibility. Annotations are by G. G. Simpson; most are concerned with his efforts to locate possible or probable sutures (" $\mathrm{s}$ ") bounding adventitious elements $\mathrm{Xa}$ and $\mathrm{Xp}$. (Annotations have been repositioned to facilitate reading.) As Simpson himself concluded, most candidate "sutures" turned out to better interpreted as breaks. Asterisk

some apparent tendency to fuse with the ectotympanic in this skull, and in others studied seems to be completely so fused ... [but] there is in several sections (e.g., [s.] 17) a clear suture which cannot possibly be a crack." Simpson did not identify the "others studied" for evidence of $\mathrm{Xp} / \mathrm{ectotympanic} \mathrm{fusion;} \mathrm{the} \mathrm{very} \mathrm{poorly} \mathrm{pre-}$ served specimen of the primitive toxodontian Pleurostylodon (AMNH-VP 28878), discussed in a sort of postscript to his 1936 paper, cannot have been among them as it lacks almost all of its auditory region.

In the section drawings of AMNH-VP 28600 the platelike feature disappears caudal to s. 24 , 


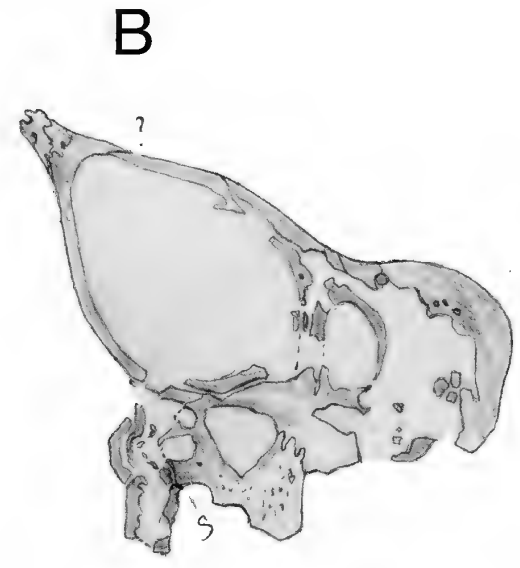

19

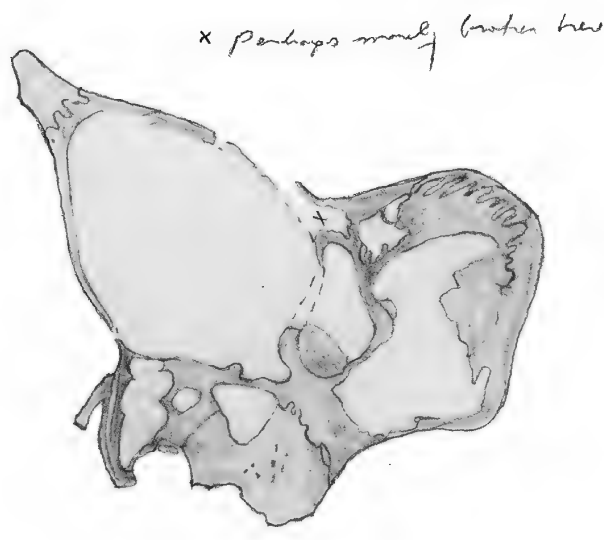

21

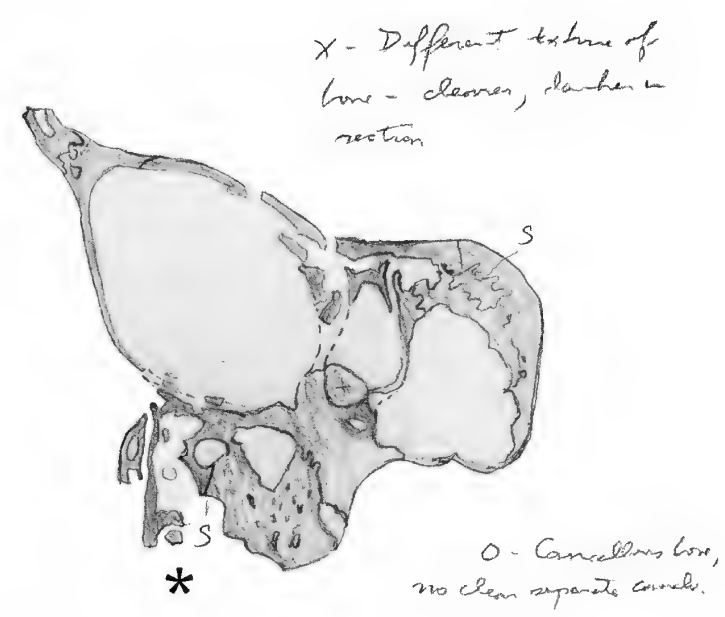

20

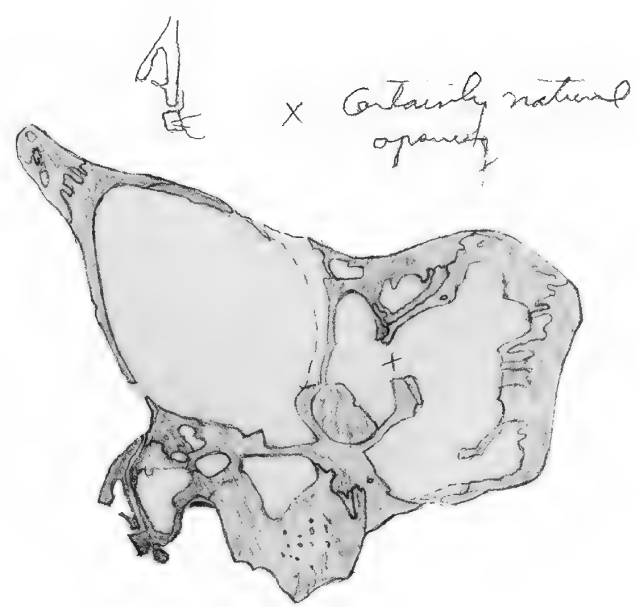

22

added to s. 20 lies just beneath the darkly shaded structure that, in the published version of this section, Simpson (1936; see also fig. 5) labeled as "Xp(p.pt.)"-that is, element Xp, including posttympanic (= retrotympanic) process. Separate structure immediately lateral to this feature is the rostralmost portion of paroccipital process. Dense shading also occurs in some other sections reproduced here (including s. 17), but the area of Simpson's Xp does not appear to have been otherwise distinctive.

and its relative position is thereafter occupied, as Simpson correctly noted, by pars canalicularis of the petrosal (region of crista parotica) and the paroccipital process of the exoccipital. Simpson's only other pictorial reference to Xp occurs on one of the illustrations of the unsectioned left half of the skull (fig. 1C). However, this drawing lacks any indication of the sutures that supposedly set this element off from its surroundings (nor can any be seen today).

With regard to Simpson's identification of putative sutures in this region, the drawing of s. 17 (fig. 20), previously unpublished, shows rostral and caudal sutures bounding definite ectotympanic 
material; they are marked, in Simpson's hand, as "certainly sutural." The more rostral of the two is simply the squamoso-ectotympanic suture. The caudal suture is also certainly real, as it can be continuously traced as far as s. 24 in the archived drawings. Virtual imaging (fig. 6C) establishes that this latter suture is the interface between the caudal crus of the ectotympanic and the tegmen tympani, i.e., the portion of the petrosal that supports the facial sulcus and articulates with the tympanostyloid via the crista parotica.

This last is an important, constant relationship in mammals (Howes, 1896; Starck, 1967; MacPhee, 1981), and raises the question whether the tympanostyloid itself could be element Xp. Simpson (1936) did not discuss the hyoid apparatus as such, but it seems doubtful that he would have mistaken it for an adventitious element if it were still housed in its recess. The specimen's left side is so badly damaged in the relevant area that it is essentially uninterpretable (fig. 1B). In Paedotherium the tympanostyloid is never more than a simple, relatively unexpanded rod situated deep within the hyoid recess (e.g., fig. 12E, F). In mammals the more distal hyoid elements are almost always lost postmortem because they are usually separated from the tympanostyloid by tracts of unossified cartilage (cf. MacPhee, 1981). Notoungulates appear to be no different in this regard.

The only other author to recognize the $\mathrm{Xp}$ as an adventitious ossification was Patterson (1936: fig. 52), who portrayed it as a vaguely defined area on the lip of the stylomastoid foramen of the toxodontian Homalodotherium cunninghami. Unfortunately, other than denoting it as the "posterior adventitious bone" in his table of abbreviations, his text is completely silent on this element.

My interpretation is that $\mathrm{Xp}$ is simply the dorsal part of the (true) retrotympanic process and thus an extension of the squamosal, or the squamosal plus a small contribution from the petrotympanic. Because of damage, unbroken continuity of Simpson's "Xp (p.pt.)" and the squamosal cannot be directly demonstrated on the left side of AMNH-VP 28600 (fig. 1C), but there is nothing in his section drawings that conflicts with the interpretation favored here. Simpson noted on the drawing of s. 20 (fig. 20B) that the bone composing Xp appeared "cancellous," which I take to mean that it was slightly pneumatized, presumably from the epitympanic sinus, as occurs (often to a much greater extent) in some other notoungulates (e.g., figs. 15C, 17C).

Element $\mathrm{Xa}$ is more problematic to characterize. Simpson (1936: 10) represented this element as a small, vaguely prismatic ossicle "in the postglenoid [= retroarticular] process" and thus actually forming part or even most of the latter. It was distinct from the ectotympanic as well as "pars epitympanica and the periotic, both of which are in contact with it but without even a sutural union." In the next sentence he stated, confusingly, that "separation [of Xa] from the inferolateral portion of the squamosal is not clearly shown, because of cracks in this region and, doubtfully, partial fusion, but laterally it has a distinct suture against the pars glenoidea of the squamosal." In virtual sections of the left side of AMNH-VP 28600, the squamoso-ectotympanic suture is indeed present, as it is universally in mammals (as either the suture per se or as the glaserian fissure). All other discontinuities in this region are fractures (fig. 6A, B).

Simpson (1936: 11) maintained that his squamoso-Xa suture was "clearly visible on the other, unsectioned, half of the skull running transversely across the glenoid surface to the squamoso-tympanic suture anterior to the fissura glaseri, exactly corresponding with its course as shown in the sections." This suture was not called out in Simpson's illustrations of the left half of the skull, although there is a discontinuity crossing the mandibular fossa that is quite clearly a fracture line (feature 3, fig. 1A), as virtual sections confirm (fig. 6A, B). AMNH-VP 28896, another example of $O$. debilitata and not illustrated here, exhibits a pattern of cracks on the left mandibular fossa different from that seen on AMNH-VP 26800. None corresponds to Simpson's putative squamoso-Xa suture. 
A final complication is that Simpson (1936) also thought that elements $\mathrm{Xa}$ and $\mathrm{Xp}$ were primordially independent of every other cranial ossification except, interestingly, each other. They were seemingly united, he maintained, by a continuous bony surface that crossed the meatal roof; this raised the possibility in his mind that they might be part of a single, morphologically complex ossification consisting of rostral and caudal sections. Nothing corresponding to Simpson's conjoint $\mathrm{Xa} / \mathrm{Xp}$ is known in other mammals. In the drawings of sections 19-22 (fig. 20) the meatal roof is shown as continuous with the feature he designated as element $\mathrm{Xa}$. At the end of this series the aditus to the epitympanic sinus appears, and thereafter only the petrosal is found on the tympanic roof. The drawings, however, are ambiguous because the meatal roof is itself continuous with a complicated series of septa and laminae that connect with (or at least are not distinguishable from) the theca and even the parietal (cf. fig. 6A, B).

Given all of these uncertainties it is not possible to argue convincingly for the presence of independent elements in the auditory region of Oldfieldthomasia, whether fused or separate, and Simpson's inferences to the contrary are therefore rejected. From a broader comparative perspective, it may be briefly noted that accessory elements related to the external acoustic meatus have been described for elephant shrews, the armadillo Dasypus, and various rodents, according to van der Klaauw (1931; see also MacPhee, 2011). Such features appear to be due, for the most part, to calcification or ossification of portions of the cartilaginous ring around the porus meatus. In any case they have no relation to the middle ear as such and would not serve to explain either Roth's or Simpson's observations concerning adventitious elements.

\section{Entotympanics and Septum Bullae}

The independent bullar elements known as entotympanics confirmably occur in a number of extant and extinct placental groups (e.g., van der
Klaauw, 1922, 1929; 1930; 1931; Spatz, 1966; MacPhee, 1979; Hunt, 1974, 1989; Wible, 2009; Gaudin and Wible, 1999; Maier et al., 2012; Maier, 2013), and may even be primitive for Eutheria (MacPhee and Novacek, 1993). Although much progress in understanding their comparative morphology and development has been made during the past century, there is no consensus on entotympanic homologies, if any, with structures in nonmammals (Moore, 1981; Presley, 1993; Maier, 2013). It is reasonably clear that the rostral entotympanic is frequently and perhaps always associated in a developmental sense with the cartilage of the auditory tube (a constant element in therian mammals, so far as is known, that also lacks an obvious homolog in nonmammals). The caudal entotympanic, when it can be meaningfully distinguished as such from the rostral, shows in some cases a developmental association with Reichert's cartilage, but whether this means it is in fact a second arch derivative is likewise uncertain. Pharyngeal arch mesoderm thus remains a possible, but still undemonstrated, source for entotympanic primordia.

The fundamental problem with identifying entotympanics in any given taxon is that they typically appear late in fetal life and very rapidly fuse with their surroundings. Thus, the best evidence for entotympanic presence is always developmental, whether that emerges from an ontogenetic series or a juvenile in which a patent bullar suture can be given no other plausible explanation. However, for fossil taxa such evidence is usually unavailable; chiefly for this reason, other means for hypothesizing entotympanic presence are often utilized. Morphological correlations constitute one such approach, as exemplified by the feature known as the septum bullae.

Strictly speaking, identification of the septum bullae should be restricted to cases in which the articulating margins of the entotympanic and some other bullar element (almost always the ectotympanic) are known to form a stable interface during ontogeny. If there is significant middleear pneumatization, the contact may become markedly lamelliform as a result of coordinated 
osteoblastic/osteoclastic activity operating on opposing surfaces of the interface, metaphorically carving the septum out of the inflating tympanic floor (MacPhee, 1981; MacPhee and Cartmill, 1986). In some groups (e.g., carnivores; Hunt, 1974, 1989) the correlation between septum presence and entotympanic occurrence is high. However, as van der Klauuw (1931: 209) warned, in other groups " $t$ ]his septum resembles very much the other septa which may occur in the auditory bulla," and one therefore has to be careful not to misapply the name.

Following on from his identification of a septum bullae in several notoungulates (Hegetotherium, Pachyrukhos, Archaeohyrax, Homalodotherium), Patterson (1936) argued for the existence of a compound bulla-and therefore of an entotympanic-in these taxa. Although he later retreated from this assertion, he continued to make reference to the "likelihood" of entotympanic presence in at least some meridiungulate taxa, claiming in particular that the "hegetotheriid septa and the very distinct hypotympanic sinus of the Toxodonta [sic] nevertheless incline me to believe that the bulla is compound" (Patterson, 1936: 223; see also Patterson, 1977). As the next section illustrates, Patterson's inference, although more hopeful than empirical, nevertheless requires that we take a new look at the evidence.

\section{Entotympanic Presence in Cochilius volvens AMNH-VP 29651}

I looked for signs of entotympanic participation in the best-preserved notoungulate skulls in the AMNH, MLP, and MACN paleontological collections but found only one specimen-Cochilius volvens AMNH-VP 29651-for which a reasonably compelling argument can be made (figs. $13 \mathrm{~A}, \mathrm{~B})$. Interestingly, this specimen was apparently fully mature at death according to Simpson (1932b), who compared it to another specimen (AMNH-VP 29657) of the same species in which milk teeth were present.
In Cochilius AMNH-VP 29651 the tympanic floor in ventral aspect consists of three morphological portions: a rather flattened medial section, a swollen central part, and, completing the lateral region, the canal of the external acoustic meatus. Emphasizing the division between the two firstnamed portions is a shallow groove, running more or less parasagittally (feature 3 in fig. 13A, B). Externally, the groove extends from the rim of the aperture for the auditory tube to the intersection of the bulla with the paroccipital process, where it disappears from view. Grooves on the right and left sides are symmetrically disposed, unlike most of the small thrust fractures or hairline breaks seen elsewhere on the skull. Bullar surface textures on either side of the groove differ slightly, and serve to divide the larger, rather smooth-walled and well-inflated central portion from the slightly rugose, less-inflated medial section. Although the groove and surface texture differences can scarcely be described as conspicuous, they were evidently obvious enough to Simpson's artist, who suggested them with contour lines on the ventral surface of the skull (cf. Simpson, 1932b: fig. 2). Simpson (1932b: 6) himself, however, noted only that "in this apparently fully adult specimen all sutures are still open and the bullae not fused with surrounding elements."

In coronal section (fig. 15B) the difference in inflation between the medial and central portions is quite noticeable, the changeover being marked by a distinct "knee" or inflection on the internal (tympanic) surface of the bulla. Here the external groove, which follows the trend of the inflection, is barely identifiable as a slight dimple on the bullar wall except in relation to the paroccipital process, near which it becomes more prominent (arrow in fig. 15B). However, there is only one place-the margin of the aperture for the auditory tube-where a discontinuity interpretable as an unfused sutural remnant can be convincingly identified (fig. 15A). Small disjunctions in the caudal bullar wall also exist, but all seem better interpreted as artificial breaks. The only other suture related to the tympanic 
floor lies as expected between the bullar floor and the otic capsule (figs. 15B, C). It is still patent and can be continuously traced in virtual sections along the entire contact zone between these bone territories.

A final point of interest is that Cochilius AMNH-VP 29651 possessed a septum (fig. 14C) that corresponds in location to the "vertical" septum bullae identified in hegetotherioids by Patterson (1936; see also Billet, 2011). The septum runs from the rostral pole of the promontory to the bullar wall, creating thereby a small rostromedial diverticulum adjacent to the bony channel for the auditory tube. There is another, smaller septum (fig. 14B) in the position of the one that Simpson (1936) thought conducted the internal carotid into the tympanic cavity in Oldfieldthomasia, but in both taxa the structure in question and its associated foramen (fig. 14C) probably carried the tympanic nerve, not the internal carotid (cf. inferences similar to Simpson's by García López [2011] and Billet and de Muizon [2013]).

\section{Entotympanic Presence in Other Notoungulates}

Conditions in other well-preserved specimens available for study were equivocal. The tympanic floors of another specimen of Cochilius (MLP 2339, ex coll. Lillo) displayed slight textural differences, similar to that seen in AMNH 29651, but clear evidence of the groove was lacking. Interatherium (= Icochilius) extensus MACN 9738-39 and Interatherium rodens MACN 9857-58 exhibited bullae conformationally much like that of Cochilius volvens, but no suture line or textural difference was observable. In Progaleopithecus AMNH-VP 29603 there is no evidence, in the tubal region or elsewhere, of an entotympanic. Scans of Notopithecus adapinus AMNH-VP 28949 , despite the very poor preservation of cranial architecture in this specimen, show a small rostral septum like that of Cochilius but no unequivocal evidence of a suture.
On relatively intact skulls of Mesotherium pachygnathum (AMNH-VP 14509) and Hegetotherium andinum (MLP 12-2194a) there was again a tiny fold on the rim of the tubal aperture, suggestive of a suture, but the fold did not extend caudally as a groove. Skulls of Pachyrukhos (e.g., MACN A1251-52) sometimes displayed surface differences on their bullar walls, similar to those observed in Cochilius AMNH-VP 29651, but once again distinct grooves were not present. Although in very good material sites of suspected sutural fusion may be detected by reference to histological features of the bone matrix (MacPhee and Cartmill, 1986), as already mentioned the resolution of conventional micro-CT instruments is generally inadequate for such a purpose.

With regard to the septum bullae, Patterson (1936) stipulated that this structure was absent in two interatherioids he studied (Interatherium and Protypotherium), although "vestiges" might remain. Although often discriminated in character analyses, I suspect that such "vestiges" are probably universal within notoungulates, but scored only when well developed. Protypotherium MLP 12-2780 exhibits a double medial bullar wall (fig. 17B), but this is not evidence of an entotympanic as such. Instead, this appearance is due to the expansion of a paratympanic space (medial paratympanic cavity) that inflated the entire medial bullar wall up to the point where the bulla meets the paroccipital process (which the cavity did not invade). Its aditus is a small aperture on the medial wall of the bony channel for the auditory tube (not shown). Extension of the middle ear cavity into the substance of the bulla in this manner is not rare in mammals generally (MacPhee, 1981), although this appears to be the first example to be reported in a meridiungulate.

Finally, as Billet (2011) has noted, the saliency of the crista tympanica within the tympanic cavity varies, projecting medially in some notoungulates taxa as a wide, curved shelf (e.g., Paedotherium, fig. 10A). The presence of this 
shelf (anular bridge) has nothing to do with the occurrence of an entotympanic, nor does it represent yet another novel element (a separately ossified "anulus membrane"). Its form and width are simply a function of the amount of remodeling activity occurring in the subtympanic recess, as has been documented for various primates and rodents in which a similar feature occurs (MacPhee and Cartmill, 1986; MacPhee, 2011).

In summary, the symmetrical, parasagittal grooves on the bullar floors of Cochilius volvens AMNH-VP 29651 can be plausibly interpreted as marking the position of an ectotympano-entotympanic suture in this taxon. In other specimens such grooving is absent, possibly because it was normally obliterated during ontogenetic remodeling of the bullar wall. Symmetrical presence of grooves is not an absolute guarantee that postmortem crushing can be excluded as an explanation (cf. "symmetrical" cracks in dorsum of caudal cranium of same specimen, fig. 13C), but it seems unlikely in this case because virtual sectioning shows that the grooves are just that, rather than breaks passing entirely through the bullar bone. Although AMNH-VP 29651 is but a single example, it offers about as clear a case of ectotympanic/entotympanic fusion in an adult fossil eutherian as I have seen, and permits the reasonable conclusion that Cochilius possessed a compound bulla made up of both elements. In this interpretation, the central and lateral portions of the tympanic floor are certainly ectotympanic because they include the crista tympanica; the striplike medial part of the bulla must be derived from entotympanic material-practically by definition, as all other basicranial constituents can be accounted for.

\section{DISCUSSION AND CONCLUSIONS}

(1) Roth's (1903) thesis that the notoungulate caudal cranium exhibited extra elements, particularly the "elementum serriale," was predicated on what now seems a rather uncritical treatment of the evidence available to him. While Simp- son's (1936) rejection of Roth's observations was certainly warranted, his own study of Oldfieldthomasia AMNH-VP 28600 was actually inconclusive. To settle the issue a more decisive example is needed, and is supplied by conditions in pachyrukhines. Roth (1903) believed that in these hegetotherioids the reduced squamosal could be conclusively eliminated as the source of the bony covering (theca) of the epitympanic sinus. Although some aspects of pachyrukhine thecal development remain obscure (e.g., relationship of dorsal midcranial hiatus to ICJ development), the only conclusions supported by the available facts are that the theca is almost entirely squamosal in origin, and that there is no evidence at all for the participation of a novel element. In all other taxa examined the thecal covering is just as unquestionably derived from the squamosal, with petrotympanic involvement generally limited to the immediate area of the aditus to the epitympanic sinus. Roth's observations relating to "extra" sutures in one or another notoungulate taxon seem to relate either to incorrectly interpreted fractures or to unrecognized self-sutures within bones forming thecal alae. Whether the pachyrukhine ICJ functioned as part of a shock-absorption apparatus in ballistic leaping is an interesting question requiring additional investigation.

(2) A full suite of lateral and medial interparietals are probably present in Notoungulata, as Koyabu et al. (2012) contended, although only "the" (fused) interparietal can ordinarily be detected on adult skulls, if at all. It is possible that interparietal units which failed to fuse completely with surrounding bones may have been the basis for some of Roth's sutural misidentifications, but in the specimens examined there is no evidence for their participation in the thecal covering or other portions of the auditory region. Apart from these issues, it is of interest that at least some notoungulates possess the doubletiered arrangement of the interparietal complex and supraoccipital, heretofore described for only a few placental taxa but probably much more widespread within that group. 
(3) Simpson's (1936) elements Xa and Xp, identified by him on the hemisectioned skull of Oldfieldthomasia AMNH-VP 26800, have not been reported in recent years in this or any other notoungulate. As far as may be gauged from Simpson's original drawings and the CT imagery examined in this paper, element $\mathrm{Xp}$ is either the same thing as, or is a pneumatized outgrowth from, the retrotympanic process-which in notoungulates is squamosal (or squamosal + petrotympanic) in origin and inflated more or less extensively by the epitympanic sinus. The possibility that $\mathrm{Xp}$ is, or is derived from, the cranial end of the hyoid apparatus can also be rejected; in CT scans of well-preserved material the cranial end of the hyoid can easily be recognized as a narrow bar lodged within the hyoid recess, and therefore in no position to contribute extensively to the lateral wall of the auditory region and the meatal roof. Element Xa could not be identified as a structure separate from the retroarticular area of the squamosal in any specimen, and Simpson's identification of it in Oldfieldthomasia appears to be the result of misinterpretation of fractures.

(4) A partially obliterated apparent suture on the external bullar wall of a well-preserved example of the interatheriid Cochilius strongly implies that this taxon possessed a compound bulla composed of the ectotympanic and at least one entotympanic. Conditions in other notoungulates examined are inconclusive; the presence of a septum within the middle ear of certain taxa is not regarded as sufficient to assert that their bullae are compound as well. Recent authors studying other meridiungulates have also failed to find any positive indications of an entotympanic (e.g., Billet, 2010). On the other hand, given the fact that entotympanic elements seem to occur in most of the extant major groups of placentals according to recent investigations (MacPhee and Novacek, 1993; Maier et al., 2012; Maier, 2013), their presence would not be unexpected in notoungulates in particular or meridiungulates in general.

(5) Although it cannot be argued that otic characters have a privileged status when it comes to defining monophyletic groups, experience with various mammalian clades teaches that, more often than not, they can be very helpful in this regard (MacPhee, 2011). Thus, Billet and de Muizon (2013) have recently shown that a suite of apparently derived features of Notoungulata (bean-shaped promontorium, a laterally located tensor tympani fossa, and merged stapedial fossa and postpromontorial tympanic sinus) can be used to conclusively attribute isolated petrosals whose affinities were previously uncertain. This is important, because it shows, as does the present study, that there is still much to be learned about the morphology of the caudal cranium in South American ungulates.

\section{ACKNOWLEDGMENTS}

For assistance in accessing collections in their care I thank Marcelo Reguero (MLP/CONICET), Alejandro Kramarz (MACN/CONICET), Stella Alvarez (MACN), and Laura Cruz (CONICET). I also want to acknowledge a very enjoyable hour discussing notoungulate morphology with Mariano Bond (MLP/CONICET), who inspired the research for the present paper. Guillaume Billet (Universität Bonn) and an anonymous reviewer read the manuscript and made many useful suggestions. I am especially indebted to Dr. Billet for identifying several significant errors of morphological interpretation. For CT scanning and software assistance, I am grateful to Pat O'Connor and Waymon Holloway (Heritage College of Osteopathic Medicine, Ohio University), and James Thostenson and Morgan Hill (Microscopy and Imaging Facility, AMNH). My colleagues Meng Jin and John Flynn granted access to the rich collections of notoungulate material in the AMNH-VP, and Ruth O'Leary and Alana Gishlick arranged archival access and loans. As always, I am grateful to Lorraine Meeker (AMNH-VP) for her excellent work on illustrations, and to Mary Knight (managing editor, AMNH scientific publications) and Clare Flemming for their careful editing and attention to detail. Partly funded by NSF OPP ANT 1142052. 


\section{REFERENCES}

Agnolin, F., and N.R. Chimento. 2011. Afrotherian affinities for endemic South American "ungulates." Mammalian Biology 76: 101-108.

Beer, J.R. 1965. The interparietal in kangaroo rats. Southwest Naturalist 10: 145-150.

Best, T.L., N.J. Hildreth, and C. Jones. 1989. Dipodomys deserti. Mammalian Species 339: 1-8.

Billet, G. 2010. New observations on the skull of Pyrotherium (Pyrotheria, Mammalia) and new phylogenetic hypotheses on South American ungulates. Journal of Mammalian Evolution 17: 21-59.

Billet, G. 2011. Phylogeny of the Notoungulata (Mammalia) based on cranial and dental characters. Journal of Systematic Palaeontology 9: 481-497.

Billet, G., and T. Martin. 2011. No evidence for an afrotherian-like delayed dental eruption in South American notoungulates. Naturwissenschaften 98: 509-517.

Billet, G., and C. de Muizon. 2013. External and internal anatomy of a petrosal from the Late Paleocene of Itaboraí, Brazil, referred to Notoungulata (Placentalia). Journal of Vertebrate Paleontology 33: 455-469.

Billet, G., B. Patterson, and C. de Muizon. 2009. Craniodental anatomy of late Oligocene archaeohyracids (Notoungulata, Mammalia) from Bolivia and Argentina and new phylogenetic hypotheses. Zoological Journal of the Linnaean Society 155: 458509.

Broom, R. 1916. On the structure of the skull in Chrysochloris. Proceedings of the Zoological Society of London 32: 449-659.

Bond, M., et al. 2011. Critical analysis of the alleged characters used to link afrotherian mammals and South American native ungulates. Program and abstracts, XXIV Jornadas Argentinas de Mastozoologia, 8-11 November, 2011: 33.

Bramble, D.M. 1989. Cranial specializations and locomotor habit in the Lagomorpha. American Zoologist 29: 303-317.

Bronner, G., E. Jones, and D.J. Coetzer. 1990. Hyoiddentary articulations in golden moles (Mammalia: Insectivora: Chrysochloridae). Zeitschrift für Säugetierkunde 55: 11-15.

Cassini, G.H., M. Mendoza, S.F. Vizcaíno, and M.S. Bargo. 2010. Inferring habitat and feeding behavior of early Miocene notoungulates from Patagonia. Lethaia 44: 153-165.

Cerdeño, E., and M. Bond. 1998. Taxonomic revision and phylogeny of Paedotherium and Tremacyllus
(Pachyrukhinae, Hegetotheriidae, Notoungulata) from the late Miocene to Pleistocene of Argentina. Journal of Vertebrate Paleontology 18: 799-811.

Cifelli, R.L. 1985. South American ungulate evolution and extinction. In F.G. Stehli and S.D. Webb (editors), The great American biotic interchange: 249266. New York: Plenum Press.

Cifelli, R.L. 1993. The phylogeny of the native South American ungulates. In F.S. Szalay, M.J. Novacek, and M.C. McKenna (editors), Mammal phylogeny 2: 195-216. New York: Springer-Verlag.

De Beer, G.R. 1937. The development of the vertebrate skull. Oxford: Clarendon.

Dozo, M.T. 1996. Endocranial casts of Hegetotheriidae notoungulates: a case of neuromorphological convergence between extinct South American ungulates and living rodents. Fifty-Sixth Annual Meeting of the Society of Vertebrate Paleontology, Abstracts of Papers: 31A.

Dozo, M.T. 1997. Paleoneurología de Dolicavia minuscula (Rodentia, Caviidae) y Paedotherium insigne (Notoungulata, Hegetotheriidae) del Plioceno de Buenos Aires, Argentina. Ameghiniana 34: 42-435.

Evans, H.E., and A. de Lahunta. 2012. Miller's anatomy of the dog., 4th ed. New York: Elsevier.

Fawcett, D.W. 1997. Bloom and Fawcett, a textbook of histology, 12th ed. Boca Raton FL: CRC Press.

Fleischer, G. 1973. Studien am Skelett des Gehörorgans der Säugetiere, einschliesslich des Menschen. Säugetierkunde Mitteilungen 21: 131-239.

Fleischer, G. 1978. Evolutionary principles of the mammalian middle ear. Advances in Anatomy, Embryology and Cell Biology 55: 1-69.

Flower, W.H. 1876. An introduction to the osteology of the Mammalia, 2nd ed. London: Macmillan.

Gabbert, S.L. 2004. The basicranial and posterior cranial anatomy of the families of Toxodontia. In G.C. Gould and S.K. Bell (editors), Tributes to Malcolm C. McKenna, chapter 14. Bulletin of the American Museum of Natural History 285: 177-190.

Gacek, R.R. 1975. The ear. In G. Cooper and A.L. Schiller (editors), Anatomy of the guinea pig: 363-368. Cambridge MA: Harvard University Press.

García López, D.A. 2011. Basicranial osteology of Colbertia lumbrerense Bond, 1981 (Mammalia: Notoungulata). Ameghiniana 48: 3-12.

Gasc, J.-P. 1963. Sur une fenestration de la base du crâne chez les espèces de petite taille du genre Suncus Ehrenburg. Mammalia 27: 81-91.

Gaudin, T.J. 2011. On the osteology of the auditory region and orbital wall in the extinct West Indian 
sloth genus Neocnus Arredondo, 1961 (Placentalia, Xenarthra, Megalonychidae). Annals of Carnegie Museum 80 (1): 5-28.

Gaudin, T.J., and J.R. Wible. 1999. The entotympanic of pangolins and the phylogeny of the Pholidota (Mammalia). Journal of Mammalian Evolution 6: 39-65.

Goodrich, E.S. 1931. Studies on the structure and development of vertebrates. New York: Dover.

Gregory, W.K. 1910. The orders of mammals. Bulletin of the American Museum of Natural History 27: 3-524.

Hitz, R., J.J. Flynn, and A.R. Wyss. 2006. New basal Interatheriidae (Typotheria, Notoungulata, Mammalia) from the Paleogene of central Chile. American Museum Novitates 3520: 1-32.

Howell, A.B. 1932. The saltorial rodent Dipodomys: the functional comparative anatomy of its muscular and osseous systems. Proceedings of the American Academy of Arts and Sciences 67: 337-536.

Howes, G.B. 1896. On the mammalian hyoid, with especial reference to that of Lepus, Hyrax, and Choloepus. Journal of Anatomy and Physiology 30: 513-526.

Hunt, R.M., Jr. 1974. The auditory bulla in Carnivora: an anatomical basis for reappraisal of carnivore evolution. Journal of Morphology 143: 21-76.

Hunt, R.M., Jr. 1989. Evolution of the aeluroid Carnivora: significance of the ventral promontorial process of the petrosal, and the origin of basicranial patterns in the living families. American Museum Novitates 2930: 1-32.

Kampen, P.N. van. 1905. Die Tympanalgegend des Säugetierschädels. Gegenbaurs Morphologisches Jahrbuch 34: 321-722.

Klaauw, C.J. van der. 1922. Über der Entwickelung des Entotympanicums. Tijdschrift der Nederlandsche Dierkundige Vereeniging 18: 135-174.

Klaauw, C.J. van der. 1929. On the development of the tympanic region of the skull in the Macroscelididae. Proceedings of the Zoological Society of London 1929: 491-560.

Klaauw, C. J. van der. 1930. On mammalian auditory bullae showing an indistinctly complex structure in the adult. Journal of Mammalogy 11: 55-60.

Klaauw, C.J. van der. 1931. The auditory bulla in some fossil mammals, with a general introduction to this region of the skull. Bulletin of the American $\mathrm{Mu}-$ seum of Natural History 62 (1): 1-352.

Koyabu, D., W. Maier, and M.R. Sánchez-Villagra. 2012. Paleontological and developmental evidence resolve the homology and dual embryonic origin of a mam- malian skull bone, the interparietal. Proceedings of the National Academy of Sciences of the United States of America 109: 14075-14080.

Kraglievich, L. 1936. Sobre el conducto humeral en las vizcachas y paquirucos chapadmalenses con descripción de Paedotherium imperforatum. Anales del Museo de Historia Natural Bernardino Rivadavia 34: 45-88.

Lydekker, R. 1893. A study of the extinct ungulates of Argentina. Anales del Museo de La Plata, Palaeontología Argentina 2 (3): 1-91.

MacPhee, R.D.E. 1979. Entotympanics, ontogeny and primates. Folia primatologica 31: 23-47.

MacPhee, R.D.E. 1981. Auditory regions of primates and eutherian insectivores: morphology, ontogeny, and character analysis. Contributions to Primatology 18: 1-282.

MacPhee, R.D.E. 2011. Basicranial morphology and relationships of Antillean Heptaxodontidae (Rodentia, Ctenohystrica, Caviomorpha). Bulletin of the American Museum of Natural History 363: 1-70.

MacPhee, R.D.E., and M. Cartmill. 1986. Basicranial structures and primate systematics. In D.R. Swindler (editor), Comparative primate biology, vol. 1, Systematics, evolution and anatomy: 219-275. New York: Liss.

MacPhee, R.D.E., and M.J. Novacek. 1993. Definition and relationships of Lipotyphla. In F.S. Szalay, M.J. Novacek, and M.C. McKenna (editors), Mammal phylogeny 2: 13-31. New York: Springer-Verlag.

Macrini, T.E., J.J. Flynn, D.A. Croft, and A.R. Wyss. 2010. Inner ear of a notoungulate placental mammal: anatomical description and examination of potentially phylogenetically informative characters. Journal of Anatomy 216: 600-610.

Maier, W., A. Tröscher, and I. Ruf. 2012. The entotympanic of Equus caballus (Perissodactyla, Mammalia). Mammalian Biology-Zeitschrift für Säugetierkunde 78: 231-234.

Maier, W. 2013. The entotympanic in late fetal Artiodactyla (Mammalia). Journal of Morphology 274: http://onlinelibrary.wiley.com/doi/10.1002/ jmor.20149.

McKenna, M.C., and S.K. Bell. 1997. Classification of mammals above the species level. New York: Columbia University Press.

Mead, J.G., and R.E. Fordyce. 2009. The therian skull: a lexicon with emphasis on the odontocetes. Smithsonian Contributions to Zoology 627: 1-249.

Metscher, B.D. 2009. MicroCT for developmental biology: a versatile tool for high-contrast $3 \mathrm{D}$ imaging at 
histological resolutions. Developmental Dynamics 238: 632-640.

Moriss-Kay, G.M. 2001. Derivation of the mammalian skull vault. Journal of Anatomy 199: 143-151.

Moore, W.J. 1981. The mammalian skull. Cambridge: Cambridge University Press.

Moss, M.L., and W.C. Feliciano. 1977. A functional analysis of the fenestrated maxillary bone of the rabbit (Oryctolagus cuniculus). Anatomia, Histologia, Embryologia 6: 167-187.

Nickolai, J.C., and D.M. Bramble. 1983. Morphological structure and function in desert heteromyid rodents. Great Basin Naturalist Memoirs 7: 4-63.

Nomina Anatomica Veterinaria (5th ed.). 2012. Online resource (http://www.wava-amav.org/nav_nev.htm).

Novacek, M.J. 1977. Aspects of the problem of variation, origin, and evolution of the eutherian auditory bulla. Mammalian Reviews 7: 131-149.

Novacek M.J. 1993. Patterns of diversity in the mammalian skull. In J. Hanken and B.K. Hall (editors), The skull 2: 438-545. University of Chicago Press.

O'Leary, M., and 23 others. 2013. The placental mammal ancestor and the post-K-Pg radiation of placentals. Nature 339: 662-667.

Parker, W.K. 1885. On the structure and development of the skull in Mammalia. Philosophical Transactions of the Royal Society of London B176: 121-275.

Patterson, B. 1932. The auditory region of the Toxodontia. Field Museum of Natural History, Geological Series 6: 1-27.

Patterson, B. 1936. The internal structure of the ear in some notoungulates. Field Museum of Natural History, Geological Series 7: 199-227.

Patterson, B. 1977. A primitive pyrothere (Mammalia, Notoungulata) from the early Tertiary of northwestern Venezuela. Fieldiana: Geology 33: 397-422.

Presley, R. 1993. Preconception of adult structural pattern in the analysis of the developing skull. In J. Hanken and B.K. Hall (editors), The skull 1: 347377. Chicago: University of Chicago.

Prothero, D.R. 1993. Ungulate phylogeny: molecular vs. morphological evidence. In F.S. Szalay, M.J. Novacek, and M.C. McKenna (editors), Mammal phylogeny 2: 173-181. New York: Springer-Verlag.

Reguero, M.A., M.T. Dozo, and E. Cerdeño. 2007. A poorly known rodentlike mammal (Pachyrukhinae, Hegetotheriidae, Notoungulata) from the Deseadan (Late Oligocene) of Argentina. Paleoecology, biogeography, and radiation of the rodentlike ungulates in South America. Journal of Palaeontology 81: 130-1307.
Reguero, M.A., and F.J. Prevosti. 2010. Rodent-like notoungulates (Typotheria) from Gran Barranca, Chubut Province, Argentina: phylogeny and systematics. In R.H. Madden, A.A. Carlini, M.G. Vucetich, and R.F. Kay (editors), The paleontology of Gran Barranca: evolution and environmental change through the middle Cenozoic of Patagonia: 152 169. New York: Cambridge University Press.

Riggs, E.S., and B. Patterson. 1935. Description of some notoungulates from the Casamayor (Notostylops) beds of Patagonia. Proceedings of the American Philosophical Society 75: 163-215.

Romer, A.S., and T.S. Parsons. 1977. The vertebrate body, 5th ed. Philadelphia: Saunders.

Roth, S. 1903. Los ungulados sudamericanos. Anales de Museo de La Plata. Sección Paleontología 5: 1-36.

Schindelin, J., et al. 2012. Fiji: an open-source platform for biological-image analysis. Nature Methods 9: 676-682.

Scott, W.B. 1912a. Mammalia of the Santa Cruz Beds. Part 2. Toxodonta of the Santa Cruz Beds. Reports of the Princeton University Expeditions to Patagonia 6 (2): 111-238.

Scott, W.B. 1912b. Mammalia of the Santa Cruz Beds. Part 3. Entelonychia of the Santa Cruz Beds. Reports of the Princeton University Expeditions to Patagonia 6 (3): 239-300.

Scott, W.B. 1937. A history of land mammals in the Western Hemisphere, 2nd ed. New York: Macmillan.

Shockey, B.J., and J.J. Flynn. 2007. Morphological diversity in the postcranial skeleton of Casamayoran (?Middle to Late Eocene) Notoungulata and foot posture in notoungulates. American Museum Novitates 3601: 1-26.

Simpson, G.G. 1932a. Skulls and brains of some mammals from the Notostylops Beds of Pagonia. American Museum Novitates 578: 1-11.

Simpson, G.G. 1932b. Cochilius volvens from the Colpodon Beds of Patagonia. American Museum Novitates 577: 1-13.

Simpson, G.G. 1933a. A simplified serial sectioning technique for the study of fossils. American Museum Novitates 634: 1-6.

Simpson, G.G. 1933b. Structure and affinities of Trigonostylops. American Museum Novitates 608: 1-28.

Simpson, G.G. 1936. Structure of a primitive notoungulate cranium. American Museum Novitates 824: $1-31$.

Simpson, G.G. 1967. The beginning of the age of mammals in South America. Part 2. Bulletin of the American Museum of Natural History 137: 1-260. 
Sinclair, W. 1909. Mammalia of the Santa Cruz Beds. Part 1. Typotheria. Reports of the Princeton University Expeditions to Patagonia 6 (1): 1-110.

Sisson, S. 1911. A text-book of veterinary anatomy. Philadelphia: Saunders.

Spatz, W.B. 1966. Zur Ontogenese der Bulla tympanica von Tupaia glis Diard 1820. Folia primatologica 4: 26-50.

Standring, S. 2009. Gray's anatomy, the anatomical basis of clinical practice, 40th ed. New York: Churchill Livingstone.

Starck, D. 1967. Le crâne des mammifères. In P.-P. Grassé (editor), Traité de zoologie 16/1: 405-549, 1095-1102. Paris: Masson.

Steele, D.G., and C.A. Bramblett. 1988. The anatomy and biology of the human skeleton. College Station, TX: Texas A\&M Press.

Stott, P., N. Jennings, and S. Harris 2010. Is the large size of the pinna of the ear of the European hare (Lepus europaeus) due to its role in thermoregulation or in anterior capital shock absorption? Journal of Morphology 271: 674-681.

Thompson, H., and A.S. Tucker. 2013. Dual origin of the epithelium of the mammalian middle ear. Science 339: 1453-1456.

Vizcaíno, S.F., G.H. Cassini, N. Toledo, and M.S. Bargo. 2012. On the evolution of large size in mammalian herbivores of Cenozoic faunas of southern South America. In B.D. Patterson and L.P. Costa (editors), Bones, clones and biomes: the history and geography of Recent Neotropical mammals: 76-101. University of Chicago.

Webster, D.B. 1975. Auditory systems of Heteromyidae: postnatal development of the ear in Dipodo- mys merriami. Journal of Morphology 146: $377-$ 394.

Webster, D.B., and M. Webster. 1975. Auditory systems of Heteromyidae: functional morphology and evolution of the middle ear. Journal of Morphology 146: 343-376.

Weber, M.W.C. 1927. Die Säugetiere. Einführung in die Anatomie und Systematik der recenten und fossilen Mammalia, vol. 1, anatomischer Teil, 2nd ed. Jena: Fischer.

Wible, J.R. 1984. The ontogeny and phylogeny of the mammalian cranial arterial pattern. Ph.D. dissertation, Duke University, Durham, NC.

Wible, J.R. 2007. On the cranial osteology of the Lagomorpha. Bulletin of the Carnegie Museum of Natural History 39: 213-234.

Wible, J.R. 2009. The ear region of the pen-tailed treeshrew, Ptilocercus lowii Gray, 1848 (Placentalia, Scandentia, Ptilocercidae). Journal of Mammalian Evolution 16: 199-234.

Wible, J.R. 2010. Petrosal anatomy of the nine-banded armadillo, Dasypus novemcinctus Linnaeus, 1758 (Mammalia, Xenarthra, Dasypodidae). Annals of Carnegie Museum 79 (1): 1-28.

Wible, J.R., D. Miao, and J.A. Hopson. 2008. The septomaxilla of fossil and recent synapsids and the problem of the septomaxilla of monotremes and armadillos. Zoological Journal of the Linnaean Society 98: 203-228.

Zeller, U. 1989. Die Entwicklung und Morphologie des Schädels von Ornithorhynchus anatinus (Mammalia: Prototheria: Monotremata). Abhandlungen der Senckenbergischen Naturforschenden Gesellschaft 545: 1-188. 


\section{APPENDIX 1}

\section{The Section Drawings of AMNH-VP 26800 OLDFIELDTHOMASIA CF. DEBILITATA (Simpson, 1936)}

The AMNH-VP archives contain several unaccessioned sets of drawings of the sectioned half of AMNH-VP 26800, drawn by artist Mildred Clemans and variously annotated by Simpson. Notes on this archive are presented here for their historical interest. The archive consists of a cover page and three sets of drawings:

Cover Page. "Sections of Oldfieldthomasia skull, Amer. Mus. No. 28600, Parasagittal sections of right side of cranium. Interval $-0.4 \mathrm{~mm}$. Sections-1-55 [55 not drawn;] \#55 is ca. $30 \mathrm{~mm}$ from the midline. Distance-21/6 mm (\#1-\#55)." This information is followed by a table of measurements listing all 54 sections seriatim, with column headings "Sec. No.," "From \#1," and "From Mid."

Set \#1, Originals, Whole Block. This is a set of 54 drawings made with pencil on light cardboard or bristol board, $14 \times 14 \mathrm{~cm}$. Camera lucida equipment or perhaps an Edinger apparatus must have been used to make these originals, which are about $2 \times$ life size and exquisitely detailed. The accuracy of depiction appears to be very high, in the sense that the illustrator was careful to include small cellules and vacuities in bones as well as their major outlines. These drawings were obviously the basis for the later ink versions (not found) that appeared in the published paper. Each drawing has orientation marks so that sections could be realigned for reconstruction purposes. The marks seem to be the result of scoring or drilling the top and bottom of the gypsum block in which the specimen was embedded.

On some drawings, short dashed lines appear to indicate the location of small pieces of bone that were lost during grinding, or were lost earlier (during fossilization). Their outlines presumably remained as divots on the block's surface, allowing their general contours to be included in the diagrams.
In this set of drawings there are a few annotations, in Simpson's hand, regarding possible sutures or character of the bone matrix. There are no identifying morphological labels.

Set \#2, Tracings, Petrosal. In the published paper Simpson (1936: figs. 8-9) included a suite of sections presenting outlines of the petrosal bone only. These are based on pencil tracings made on pieces of onion skin, roughly the same size as the bristol board squares used for the originals, with the same orientation marks. The set begins with s. 20 , which carries the label "Legends for periotic structures," and runs to s. 44. No tracing was found of s. 41.

In this set there are identifying labels for structures: nomina were written out in full in ordinary pencil, then were overwritten in red pencil with the abbreviations Simpson adopted for his paper.

Set \#3, Tracings, Whole Block. This is a set of 14 tracings of the original drawings, on full pages of onionskin, $21.5 \times 27.5 \mathrm{~cm}$. $\left(8.5 \times 11^{\prime \prime}\right)$, corresponding to sections illustrated in Simpson's (1936) figures 5-7. First section, s. 5, is entitled "Legends for whole sections." As with set \#2 tracings, structures are identified by their names (complete or abbreviated) in ordinary pencil, with final abbreviations superimposed or placed nearby in red pencil. Outlines of certain structures, such as the semicircular canals, were colored with red, orange, or blue pencil on the sections in which they appeared, evidently as a means of quickly identifying complex features.

Discussion. In his paper Simpson expresses uncertainty about the identity of several possible sutures he encountered. These are marked as "s" or "s?" on section drawings; in the end he seems to have usually decided that he either couldn't tell for certain, or that the breaks were definitely cracks and not sutures. Thus, on the tracing of the original of section 10 there is a penciled note, "Doubtful suture-prob. not??" with a leader going to a wedge of bone (as seen in section) defining both the dorsal rim of the external acoustic meatus and the floor of the epitympanic sinus. The rostral side of the wedge is bounded 
by a double line, which elsewhere signifies a definite suture; the caudal side, which bears the leader, is defined by only a single line. However, in this case I believe Simpson's original instinct was correct-what he saw was suture-delimited ectotympanic material. In the final paper, neither suture is indicated as such, but the ectotympanic appears immediately thereafter in sections (Simpson, 1936, fig. 5, s. 15). Whether Simpson used a hand lens to examine each ground surface is not stated but certainly likely.

Handwritten terms or explanations occur on a number of the pages in set \#3, most of them illegible, as well as some notes evidently made to serve as memory aids. These will not be reproduced here, but reference to a couple of examples imparts some idea of his efforts to achieve accuracy. Thus on the drawing for s. 31 Simpson recorded for one such structure that it was "probably ductus endolymphaticus"; underneath it there is a second line, obviously written later, to the effect that "no, open into fissure below epitympanic sinus." On s. 30 occurs the line "foramen caroticum anterius or foramen spinosum," with the latter having been crossed out at some later point. Here he was wrestling with whether there was any evidence for the passage of the internal carotid, a matter that he never satisfactorily settled. His alternative-that the aperture was foramen spinosum, or the aperture for the homolog of the middle meningeal in human anatomy, was actually an inspired guess, and is much more likely to be correct than anterior carotid foramen.
Here follows annotations on individual sections, with my comments in parentheses (vertical divider line | indicates beginning or end of individual lines in original):

ss. 8 and 13: | "s", "?s" (fractures, not sutures, in the squamosal theca; see also fig. 6A) |

s. 17: | "certainly sutural" (definite sutures; leaders point to sutures between ectotympanic's rostral and caudal crura and squamosal and petrosal, respectively) | "x Texture" | "?" (this possible suture is in fact a fracture extending through most of roof of epitympanic theca; also noted in ss. 13, 17, 19) |

s. 32: | $x$ Prob not suture" (major fracture line in petrosal) | "Dots are canals" (small vascular channels in petrosal) |

s. 19: | "s" (definite suture between posterior crus of ectotympanic and retrotympanic process, probably exclusively squamosal) |

s. 20: | lefthand "s" (as in s. 19) | righthand "s" (squamoso-parietal suture) |" $\mathrm{x}$-Different texture of bone-clearer, darker in section" (reference to tip of petrosal apex, characteristically darkstaining because of its density) | "o-Cancellous bone, no clear separate canals" (probably an indication that the noted feature-in fact the retrotympanic process-was pneumatized) |

s. 21: " $x$ Perhaps merely broken here" (refers to loss of bone composing cranial roof) |

s. 22: | "x Certainly natural opening" (refers to limit of tentorium osseum or endocranial sulcus of major venous sinus seen in section; adjacent small drawing, presumably Simpson's, may refer to same feature) | 
